\title{
Sistemática, filogenia e distribuição geográfica das espécies sul-americanas de Centris (Paracentris) Cameron, 1903 e de Centris (Penthemisia) Moure, 1950, incluindo uma análise filogenética do "grupo Centris" sensu Ayala, 1998 (Hymenoptera, Apoidea, Centridini) ${ }^{1}$
}

Fernando César Vieira Zanella

\begin{abstract}
Systematics, phylogeny and geographical distribution of the South American species of Centris (Paracentris) Cameron, 1903, and Centris (Penthemisia) Moure, 1950, including a phylogenetic analysis of the "Centris group" sensu Ayala, 1998 (Hymenoptera, Apoidea, Centridini). A cladistic analysis with the objective of testing the hypothesis of monophily of Centris (Paracentris) Cameron, 1903, and of studying its phylogenetic relationships with the other subgenera that belong to the Centris group, sensu Ayala, 1998, and the relationships among the species that occur in South America, is presented. Centris (Paracentris) is a group of New World bees of amphitropical distribution, especially diversified in the Andes and in the xeric areas of South and North America. Thirty-one species were included in the analysis, four considered as outgroup, and 49 characters, all from external morphology and genitalia of adult specimens. Parsimony analyses with equal weights for the characters and successive weighting were performed with the programs NONA and PAUP, and analyses of implied weighting with the program PeeWee. The strict consensus among the trees obtained in all the analyses indicates that $C$. (Paracentris), as previously recognized, is a paraphyletic group. In order to eliminate that condition, the subgenera C. (Acritocentris), C. (Exallocentris) and C. (Xerocentris), all described by SNelling (1974) are synonymized under C. (Paracentris). The subgenus C. (Penthemisia) Moure, 1950, previously considered a synonym of C. (Paracentris), is reinstated, but in a more restricted sense than originally proposed and with the following species: Centris brethesi Schrottky, 1902; C. buchholzi Herbst, 1918; C. chilensis (Spinola, 1851), C. mixta mixta Friese, 1904, and C. mixta tamarugalis Toro \& Chiappa, 1989. Centris mixta, previously recognized as the only South American species of the subgenus C. (Xerocentris), a group supposedly amphitropical, came out as the sister-species of $C$. buchholzi. The following South American species were recognized under Centris (Paracentris): Centris burgdorfi Friese, 1901; C. caelebs Friese, 1900; C. cordillerana RoigAlsina, 2000; C. euphenax Cockerell, 1913; C. flavohirta Friese, 1900; C. garleppi (Schrottky, 1913); C. klugii Friese, 1900; C. lyngbyei Jensen-Haarup, 1908; C. mourei Roig-Alsina, 2000; C. neffi Moure, 2000; C. nigerrima (Spinola, 1851); C. toroi sp. nov.; C. tricolor Friese, 1900; C. unifasciata (Schrottky, 1913), and C. vogeli Roig-Alsina, 2000. The relationships among the subgenera of the "Centris group" were: (Xanthemisia (Penthemisia (Centris s. str. - Paracentris))). Centris xanthomelaena Moure \& Castro 2001, an endemic species of the Caatinga and previously considered a C. (Paracentris), came out as the sister group of $C$. (Centris) s. str. A new species of $C$. (Paracentris) from Chile is described: Centris toroi sp. nov. Lectotypus designations and redescriptions are presented for Centris burgdorfi, C. caelebs, C. lyngbyei, C. tricolor, C. autrani Vachal, 1904 and C. smithii Friese, 1900. New synonyms proposed: C. buchholzi Herbst, $1918=$ Centris wilmattae Cockerell, 1926 syn. nov.; C. caelebs Friese, 1900 = Paracentris fulvohirta Cameron, 1903. The female of C. vogeli RoigAlsina, 2000 and the male of C. xanthomelaena are described.
\end{abstract}

KEYwords. Amphitropical distribution; Apidae; biogeography; dry regions; Neotropical Region

\section{INTRODUÇÃO}

As abelhas do gênero Centris Fabricius, 1804 são solitárias, apresentam porte de médio a grande e nidificam no solo, em termiteiros ou em cavidades pré-existentes. São restritas ao Novo Mundo, ocorrendo desde regiões muito áridas, como o
Deserto do Atacama ou da Califórnia, até florestas úmidas equatoriais.

As espécies descritas até o final do século passado foram revisadas por FrIESE (1901), o qual também descreveu várias espécies novas. Posteriormente, SNelling (1956, 1966, 1974, 1984) revisou as espécies que ocorrem na América do Norte.

1. Parte da Tese de Doutorado do autor na Pós-Graduação em Entomologia da Faculdade de Filosofia, Ciências e Letras de Ribeirão Preto / Universidade de São Paulo.

2. Departamento de Engenharia Florestal, Universidade Federal da Paraíba. Caixa Postal 64, 58700-970 Patos-PB, Brasil.

Endereço eletrônico: fzanella@cstr.ufpb.br 
Em uma recente análise das relações filogenéticas entre os subgêneros de Centris, realizada sob uma ótica cladística, Ayala (1998) reconhece a existência de três grupos: o "grupo Centris", que inclui $C$. (Paracentris), mais os subgêneros $C$. (Centris) Fabricius, 1804; C. (Acritocentris) Snelling, 1974; $C$. (Exallocentris) Snelling, 1974; C. (Xerocentris) Snelling, 1974 e C. (Xanthemisia) Moure, 1945; o "grupo Trachina”, com os subgêneros C. (Heterocentris) Cockerell, 1899 e C. (Trachina) Klug, 1807 e o "grupo Melacentris", formado pelos subgêneros C. (Melacentris) Moure, 1995; C. (Ptilotopus) Klug, 1910; C. (Wagencknechtia) Moure 1950 e C. (Ptilocentris) Snelling, 1984, mais espécies próximas que, segundo Ayala (op. cit.), devem pertencer a dois subgêneros ainda não descritos.

O presente trabalho teve como objetivo inicial o estudo da distribuição geográfica e das relações filogenéticas entre as espécies sul-americanas de C. (Paracentris), um subgênero de distribuição anfitropical, associada a regiões xéricas, sendo parte de um projeto mais amplo de investigação das relações históricas entre as regiões xéricas da América do Sul, em particular da Caatinga (ZANELla 2000a, b, c). Entretanto, como não havia confiança quanto à monofilia de $C$. (Paracentris), e também do grupo de espécies sul-americanas, foi empreendida uma análise filogenética mais ampla, com o intuito de testar a hipótese de sua monofilia.

No estudo realizado por AyAla (1998) não foi testada a monofilia dos subgêneros de Centris, pois ele utilizou como unidade de análise os subgêneros citados na literatura, codificando os caracteres por subgênero e não pelas espécies analisadas. Esse procedimento pode ter comprometido alguns dos seus resultados pois, enquanto para alguns subgêneros, como C. (Xanthemisia), são conhecidas várias autapomorfias evidentes, para outros, como C. (Paracentris), não há nenhuma autapomorfia potencial mencionada na literatura. Entre os caracteres utilizados por AyAla (op. cit.: 18) há um único, referente à cor do clípeo, que apresenta um estado exclusivo de $C$. (Paracentris). Entretanto, esse estado - "color . . . variable entre el negro, rojizo y amarillo (... algunas especies tienen manchas negras en el margen superior)" - está definido de forma muito ampla e variável, não podendo ser considerado, em meu entender, como uma sinapomorfia para as espécies de C. (Paracentris).

$\mathrm{Na}$ análise aqui realizada, o "grupo Centris", cuja monofilia está bem suportada pelos resultados de Ayala (op. cit.), foi considerado como grupo interno e, além das espécies sulamericanas de $C$. (Paracentris), foram incluídos representantes das espécies da América do Norte e dos outros subgêneros que pertencem ao grupo Centris.

Dentre as modificações na sistemática do gênero, como resultado da análise realizada, é proposta a revalidação do subgênero C. (Penthemisia) Moure, 1950, antes considerado sinônimo júnior de $C$. (Paracentris).

Este trabalho apresenta, ainda, uma revisão das espécies Centris (Penthemisia) e das espécies sul-americanas de $C$. (Paracentris).
As espécies Sul-AMERICANas de CENTRIS (PARACENTRIS)

Paracentris foi proposto como gênero monotípico por Cameron (1903), tendo como espécie-tipo, Paracentris fulvohirta Cameron, 1903.

Moure (1950), ao criar Penthemisia como subgênero de Centris, designou como espécie-tipo, Centris chilensis (Spinola, 1851), e relacionou as seguintes espécies: C. autrani Vachal, 1904; C. buchholzi Herbst, 1918; C. garleppi (Schrottky, 1913); C. nigerrima (Spinola, 1851) e C. mixta Friese, 1904.

Michener (1951), considerando Penthemisia como subgênero de Hemisia Klug, 1807, incluiu C. klugii Friese, 1900 e $C$. tricolor Friese, 1900, além de outras espécies exclusivas da América do Norte.

Em 1956, Snelling propôs o subgênero Centris (Trichocentris), tendo como espécie-tipo Centris rhodoleuca Cockerell, 1923; espécie da América do Norte, antes incluída entre os Centris (Penthemisia).

SNelling (1966) reconheceu a sinonímia entre Centris (Penthemisia) Moure, 1950 e Centris (Paracentris) Cameron, 1903. Em 1974, SNELling coloca Centris (Trichocentris) Snelling, 1956 como sinônimo júnior de Centris (Paracentris) e propõe três novos subgêneros, incluindo espécies antes consideradas como Centris (Paracentris): Centris (Xerocentris), com Centris californica Timberlake, 1940 como espécie-tipo, mais outras espécies da América do Norte e Centris mixta Friese, 1904, espécie da América do Sul; Centris (Exallocentris), somente com a espécie-tipo, Centris anomala Snelling, 1966, restrita à América do Norte; e Centris (Acritocentris), com Centris ruthannae Timberlake, 1940 como espécie-tipo, e outras espécies também retritas à América do Norte.

O subgênero Xerocentris, formado por abelhas que teriam perdido o hábito de coletar óleo nas flores, teria como uma de suas características distintivas, a ausência, nos basitarsos anteriores e médios, de cerdas modificadas para a sua coleta. Entretanto, na interpretação de NEFF \& SIMPSON (1981), haveria duas linhas evolutivas independentes e associadas a $C$. (Paracentris), que resultaram na perda desse hábito e das estruturas correspondentes: uma, representada pelas espécies da América do Norte e outra, por C. mixta, nos desertos costeiros do Chile. Ainda segundo esses autores, C. mixta estaria mais relacionada a $C$. buchholzi ou a $C$. brethesi Schrottky, 1902.

Algumas outras espécies sul-americanas têm sido citadas na literatura como pertencendo a C. (Paracentris): Centris burgdorfi Friese, 1901 (RoIG-Alsina 2000), C. lyngbyei JensenHaarup, 1908 (Michelette \& CAMARGO, 2000; Roig-Alsina 2000), C. hyptidis Ducke, 1908 e C. xanthomelaena Moure \& Castro, 2001 (Vogel \& MACHADO 1991).

Em sua recente análise do gênero Centris, Ayala (1998) apresenta uma lista de espécies relacionando-as por subgênero. As grandes diferenças, em relação ao acima relatado, são: Centris mixta está citada como pertencendo ao subgênero Xerocentris, seguindo a posição de Snelling (1974), e $C$. hyptidis é citada, pela primeira vez, como pertencendo ao 
subgênero Ptilocentris. Roig-Alsina (2000) sugere que $C$. hyptidis esteja relacionado ao subgênero Wagenknechtia. A ausência de cerdas grossas no gonocoxito, próximo ao gonóstilo, em $C$. hyptidis, torna evidente que não se trata de uma espécie pertencente ao "grupo Centris" sensu Ayala, 1998, grupo ao qual pertence o subgênero Paracentris. Assim, a questão do relacionamento de $C$. hyptidis foge ao escopo do presente trabalho, e essa espécie foi excluída da análise das relações internas de Paracentris.

Recentemente, Moure (2000) descreveu três novas espécies: Centris neffi, C. urens e C. willineri, e incluiu $C$. flavohirta Friese, 1900 no subgênero, e Roig-Alsina (2000), ao revisar as espécies da Argentina, descreveu como novas: Centris cordillerana, C. mourei e $C$. vogeli.

No presente trabalho, quatro espécies, todas exclusivas da América do Sul, são consideradas em Centris (Penthemisia), subgênero revalidado. 19 espécies sul-americanas, incluindo uma uma nova espécie, e 26 espécies da América do Norte, são consideradas em Centris (Paracentris). Dois novos sinônimos são propostos.

\section{MATERIAL E MÉTODOS}

\section{Material EXAMinado E Distribuição GEOGRÁFICA}

As siglas mencionadas no texto, e relacionadas abaixo, correspondem aos acrônimos de instituições, ou abreviações dos nomes de pesquisadores, que permitiram o estudo do material depositado em suas coleções. Após o nome das instituições está citado o nome dos curadores de suas coleções de Hymenoptera: AMNH (American Museum of Natural History, New York, NY, USA), Dr. Jerome Rozen; BNHM ( The Natural History Museum, London, England), Dr. David Notton e Christine Taylor; CAS (California Academy of Sciences, San Francisco, CA, USA), Dr. Wojciech Pulawski e Robert Zuparko; CCRD (Coleção particular, Claus Rasmussen, University of Aarhus, Dinamarca); CFZ (Coleção particular, Fernando Zanella, Patos, PB, Brasil); CGM (Coleção particular, Dr. Gabriel Melo, Ribeirão Preto, SP, Brasil); CTMI (Central Texas Mellitological Institut, Austin, TX, USA), Dr. John Neff; CUIC (Cornell University Insect Collection, Ithaca, NY, USA), Dr. E. Richard Hoebeke; DSEC (Coleção Entomológica do Departamento de Sistemática e Ecologia, Univ. Federal da Paraíba, João Pessoa, Brasil), Dr. Celso F. Martins; EME (Essig Museum of Entomology, University of California, Berkeley, CA, USA), Dra. Cheryl Barr; IDEA (Colección Entomológica del Instituto de Agronomia, Universidad de Tarapacá, Arica, I Região, Chile), Dr. Hector Vargas C.; IMLA (Intituto Miguel Lillo, San Miguel de Tucumán, Argentina), Dr. Abraham Willink e Dr. Gustavo Scrocchi; INHS (Illinois Natural History Survey, Champaign, IL, USA), Dra. Kathleen Zeiders; LPB (Laboratório de Pesquisas Biológicas, PUC-RS, Porto Alegre, RS, Brasil), Dra. Betina Blochtein; MCNZ (Museu de Ciências Naturais, Fundação Zoobotânica do Rio Grande do Sul, Porto Alegre, RS, Brasil), Dra. Ma. Helena Galileo; MCSN (Museo Cívico di Storia Naturale "Giacomo Doria”, Genova, Italia), Dr. Valter
Raineri; MELP(Museo Entomológico Luis Peña, Universidad de Chile, Santiago, Chile), Dr. Gerardo Barria; MLUH (MartinLuther Universität, Halle-Wittenberg, Germany), Dra. Karla Schneider; MNHN (Museum National D'Histoire Naturelle, Paris, France), Dra. Janine Casevitz-Weulersse; MNHU (Museum für Naturkunde der Humbolt Universität, Berlin, Germany), Dr. Frank Koch e Annette Kleine-Möllhoff; MZSP (Museu de Zoologia, USP, São Paulo, SP, Brasil), Dr. Carlos R. Brandão; NHMB (Natural History Museum Bern, Bern, Switzerland), Dr. Charles Huber; NHMW (Naturhistorisches Museum Wien, Wien, Austria), Dr. Stefan Schoedl; RPSP (Faculdade de Filosofia, Ciências e Letras de Ribeirão Preto, Coleção Camargo, USP, SP, Brasil), Dr. João M. F. Camargo; SEMK (Snow Entomological Museum, University of Kansas, Lawrence, KS, USA), Dr. Robert Brooks; SMNH (Swedish Museum of Natural History, Stockholm, Swedeen), Dr. Lars-Ake Janzon; UCCC (Museo de Zoología, Universidad de Concepción, Concepción, Chile), Dra. Viviane Jerez; UCVC (Universidad Católica de Valparaíso, Valparaíso, Chile), Dr. Haroldo Toro; UFMG (Universidade Federal de Minas Gerais, Coleção Fernando Silveira, Belo Horizonte, MG, Brasil), Dr. Fernando Silveira; UFVB (Museu Entomológico, Universidade Federal de Viçosa, Viçosa, MG, Brasil), Dra. Georgina Faria-Mucci; ZMUC (Universitetz Zoologiskes Museum, Copenhagen, Denmark), Dr. Lars Vilhelmsen e Dr. Rudolf Meier; ZSMC (Zoologische Staatssammlung, München, Germany), Dr. Johannes Schuberth.

As informações presentes nas etiquetas dos espécimens examinados, incluindo os tipos, foram transcritas ipsis litteris entre aspas. Se a etiqueta for manuscrita, isto é informado junto com a transcrição dos dados. Quando não há nenhuma informação a esse respeito, a etiqueta é impressa.

No item material examinado, a ordenação de países e de suas subdivisões segue o proposto em ZANELLA et al. (2000). As abreviações "s. l.", "s. d." e "s. c.", indicam a ausência de informação sobre o local, data de coleta e coletor, respectivamente.

As coordenadas geográficas das localidades de coleta foram obtidas, quando não informadas nas etiquetas, consultandose as seguintes fontes: Atlas Barsa (1980). Encyclopaedia Britannica Editora Ltda. Rio de Janeiro, Brasil; CIVI/IBGE (1995). Cadastro de cidades e vilas do Brasil. Instituto Brasileiro de Geografia; Carta do Brasil ao Milionésimo - IBGE (Instituto Brasileiro de Geografia e Estatística); Grande Atlas Mundial de Seleções do Reader's Digest (1967). Editora Ypiranga S. A., Rio de Janeiro, Brasil; National Imagery and Mapping Agency / USA (http://164.214.2.59/gns/html/index.html); Mapas dos países (várias fontes) e informações pessoais do Dr. Abraham Willink (IMLA), Dr. Haroldo Toro (Universidad Catolica de Valparaiso, Chile) e Dr. John Neff(CTMI).

\section{DESCRIÇÕES E DIAGNOSES}

A terminologia das estruturas morfológicas segue basicamente a apresentada em URBAN (1967), com exceção das estruturas da mandíbula, que está de acordo com MichenER \& 
FRASER (1978).

Nas descrições, as características importantes para a diagnose da espécie estão ressaltadas em negrito; as medidas relativas aos tipos encontram-se sem parênteses e as variações encontradas em outros espécimens estão citadas entre parênteses. Todas as medidas são dadas em milímetros. Os tergos metassomáticos estão citados como T1, T2, T3 ..., e os esternos como $\mathrm{S} 1, \mathrm{~S} 2, \mathrm{~S} 3$...

Todas as características relativas à pontuação e pilosidade do clípeo, labro e tergos metassomáticos referem-se, quando não indicado de modo diferente, à área central, lateral à faixa mediana longitudinal e, quando relativas ao mesoscuto, à área entre a linha mesoscutal e o sulco parapsidal. O tamanho e a dispersão dos pontos do tegumento foram descritos de acordo com o sistema de SNELling (1984), como segue: diminuta diâmetro entre 0,010 e $0,019 \mathrm{~mm}$; fina - entre 0,020 e 0,035 mm; moderada - entre 0,036 e $0,055 \mathrm{~mm}$; grossa: entre 0,056 e 0,070 $\mathrm{mm}$; muito grossa - maior que $0,070 \mathrm{~mm}$; contígua - pontos tão próximos que alguns são deformados, paredes estreitas agudas; subcontígua - espaço plano entre os pontos até 0,30 vezes o diâmetro deles; cerrada - entre 0,31 e 0,70 vezes o diâmetro dos pontos; densa - entre 0,71 e 1,50 vezes o diâmetro dos pontos; esparsa - entre 1,51 e 3,00 vezes o diâmetro dos pontos; dispersa - maior que 3,00 vezes o diâmetro dos pontos.

As distâncias interoculares superior e inferior estão indicadas com as siglas DIOS e DIOI, respectivamente. As medidas foram tomadas da seguinte forma: Comprimento da cabeça - em vista frontal, do bordo apical do clípeo ao vértice; comprimento da área malar - do bordo inferior do olho composto ao seu limite inferior, entre o côndilo inferior e o acetábulo da base da mandíbula; largura da mandíbula - em vista lateral, na sua base; comprimento da mandíbula - do acetábulo, na parte basal do bordo superior, à base do dente apical, indicada pelo início do espaço entre o dente apical e o subapical. Optou-se por esta medida, ao invés de medir até o ápice do dente apical, porque freqüentemente as mandíbulas estão desgastadas, especialmente na parte apical dos dentes.

\section{ANÁLISE FILOGENÉTICA}

Seleção e codificação de caracteres

Foram utilizados somente caracteres da morfologia externa de indivíduos adultos e da cápsula genital dos machos. Conjuntamente com a procura de caracteres, fez-se uma análise dos caracteres utilizados por AyALA (1998), para decidir sobre a sua reutilização e, se necessário, redefinição.

Caracteres considerados dependentes em relação ao estado de outros caracteres foram excluídos, como por exemplo, o caráter 37 de AyALA (op. cit.). Esse caráter refere-se à presença de elaiospata, estrutura formada por uma fileira de cerdas modificadas nos basitarsos médios das fêmeas e que, ao meu ver, nos Centris, está claramente relacionada à presença de elaiospata nos basitarsos anteriores (caráter 36 de AyAla). Como essas estruturas são utilizadas para a mesma função, a coleta de óleo nas flores, a sua redução ou ausência deve estar relacionada à perda do hábito de coleta de óleo.
Caracteres quantitativos que apresentam uma variação contínua não foram, em geral, utilizados. No caráter 9 , uma das espécies, Centris xanthomelaena, apresenta uma condição intermediária entre os dois estados, o que configura uma variação contínua no conjunto dos táxons analisados. Existem técnicas para estabelecer matematicamente estados discretos em caracteres com variação contínua (QUicke 1993), mas esse tipo de análise demandaria maior número de espécimens de várias das espécies analisadas, o que não seria possível. Assim, para permitir a utilização desse caráter, essa espécie foi codificada com um interrogante.

Nos casos de uma estrutura presente em alguns taxa, mas com diferentes estados, foram codificados dois caracteres: um, considerando a sua presença ou ausência, e outro, considerando os diferentes estados e colocando um interrogante nos táxons onde a estrutura é ausente. Esse procedimento pode fazer com que a resolução de uma região do cladograma influencie a de outra região, levando à seleção de árvores menos parcimoniosas. Isso acontece, quando o caráter é aplicável para duas regiões do cladograma que estão separadas por uma região onde o caráter não é aplicável (MAdDison 1993). Como essa configuração não foi observada nos resultados obtidos, a codificação em caracteres separados foi mantida, tendo em vista que permite manter o valor informativo da presença da estrutura.

Não foram utilizados caracteres relacionados ao padrão geral de coloração dos indivíduos, como a cor da pilosidade do mesossoma ou do tegumento no metassoma, por considerar que esses são caracteres de valor adaptativo, possivelmente relacionados ao reconhecimento por predadores. Isso é sugerido, entre os grupos analisados, pela ocorrência de um provável complexo de mimetismo mülleriano, formado por seis espécies de Centris, uma espécie não identificada de Monoeca e Thygater rubricata (Smith, 1879). Dentre as espécies de Centris, cinco, C. tricolor, C. brethesi, C. mourei, C. neffi e C. lyngbyei, pertencem ao grupo Centris e $C$. nigripes, pertence ao subgênero Heterocentris, grupo Trachina. Essas espécies ocorrem nas áreas áridas do noroeste e centroeste da Argentina e apresentam um padrão típico de coloração, que difere dos padrões observados em espécies que não ocorrem nessa região: cabeça e pernas pretas a castanho-escuras, pilosidade do tórax amarelo-palha-clara e tegumento do metassoma avermelhado.

Método de análise

Cladogramas mais parcimoniosos foram obtidos com o auxílio de programas de computador. Para as análises considerando pesos iguais para os caracteres selecionados foram utilizados os programas NONA, versão 1.5 (GoLOBOFF 1996) e PAUP, versão 3.1 (SwOFFord 1993). Para estabelecer pesos diferenciados para os caracteres, considerando os níveis de homoplasia, foram utilizados dois métodos: o de pesagem sucessiva - PS, por meio do PAUP, e o de pesagem implícita PI, por meio do programa PeeWee, versão 2.6 (Goloboff 1997).

Nas análises realizadas com o NONA e o PeeWee, foi utilizado o algoritmo que implementa a permuta de ramos por corte e reconexão ("tree bissection-reconnection swapping"), 
com 100 replicações. Para tornar a procura mais exaustiva, as árvores obtidas foram submetidas a novas análises com permutação de ramos por meio dos comandos: $\max ^{*}$, sswap $^{*} \mathrm{e}$ mswap ${ }^{*} 2$.

Com o PAUP, foram realizadas análises heurísticas com permuta de ramos por corte e reconexão, seqüência de adição de táxons ao acaso e 100 replicações.

Os grupos interno e externo foram analisados conjuntamente, sem proposição, a priori, de polarizações para os caracteres. Esta metodologia, proposta por FARRIS (1972) e revisada por NiXON \& CARPENTER (1993), tem a vantagem de testar a hipótese de monofilia do grupo interno e também de permitir uma polarização dos caracteres de forma mais objetiva, tendo em vista que a definição do estado plesiomórfico de um caráter, em relação ao nó ancestral do grupo interno, é, com exceção dos usualmente poucos casos em que não há variação no grupo externo, dependente das relações entre os táxons do grupo externo. Para enraizar as árvores obtidas na análise do grupo Centris, foi utilizado o ramo que opõe Anthophora californica Cresson, 1869 (Anthophorini) aos outros táxons estudados, que fazem parte da tribo Centridini.

Todos os caracteres foram considerados não-ordenados. Este procedimento, implementado pela chamada parcimônia de Fitch, não impõe nenhuma restrição à evolução do caráter e admite pesos iguais para todas as possíveis transformações de um estado para outro (HAUSER \& PRESCH 1991; MADDISON \& MADDISON 1992: 79).

Táxons e caracteres analisados

O grupo Centris foi considerado como grupo interno nas análises realizadas. Segundo Ayala (1998), o grupo Centris compreende os subgêneros Acritocentris, Centris, Exallocentris, Paracentris, Xanthemisia e Xerocentris. Na hipótese de filogenia por ele apresentada, a monofilia do grupo
Centris é consistentemente suportada por quatro autapomorfias: a presença de uma projeção média longa no oitavo esterno metassomático; de cerdas longas e grossas na área dorsodistal do gonocoxito, próximo à base dos gonóstilos; de um tufo de pêlos bem definido na face interna do gonocoxito e pela forma da carena dorsal do gonocoxito, com a parte anterior à projeção média alinhada à parte posterior, formando como uma linha contínua.

Foram incluídas 31 espécies nas análises realizadas, sendo quatro do grupo externo. As 27 espécies do grupo interno compreendem, além das espécies interpretadas por outros autores como sendo Paracentris, três espécies de Paracentris da América do Norte e representantes dos outros subgêneros que compõe o grupo Centris (Tabela I).

Centris mixta foi incluída na análise, por considerar a sua afiliação, se em Paracentris ou não, uma questão ainda não resolvida, mesmo levando em conta os caracteres estudados por Ayala (op. cit.). Isto porque alguns dos caracteres que suportam o clado Centris s. str. - Exallocentris - Xerocentris, apresentam-se, em C. mixta, em estados diferentes dos observados e codificados por Ayala para os Xerocentris como um todo. Além disso, parte dos caracteres que suportam o clado Exallocentris - Xerocentris e que são de natureza adaptativa e relacionados entre si, como a ausência de estruturas coletoras de óleo nos basitarsos anteriores e médios, foram codificados como caracteres independentes.

As espécies do grupo externo foram selecionadas para representar os subgêneros Trachina e Wagenknechtia e os gêneros Epicharis e Anthophora. Segundo a análise de Ayala (1998), os subgêneros Trachina e Wagenknechtia fazem parte dos grupos Trachina e Melacentris, respectivamente, os quais constituem um clado, irmão do clado representado pelo grupo Centris.

Epicharis forma, junto com o gênero Centris, a tribo

Tabela I. Espécies incluídas na análise filogenética do "grupo Centris." O subgênero é mencionado somente nos casos de espécies previamente relacionadas em subgêneros distintos de $C$. (Paracentris).

\author{
Grupo interno \\ Centris brethesi Schrottky, 1902 \\ C. buchholzi Herbst, 1918 \\ C. burgdorfi Friese, 1901 \\ C. caelebs Friese, 1900 \\ C. chilensis (Spinola, 1851) \\ C. cordillerana Roig-Alsina, 2000 \\ C. euphenax Cockerell, 1913 (somente macho) \\ C. flavohirta Friese, 1900 \\ C. klugii Friese, 1900 \\ C. lyngbyei Jensen-Haarup, 1908 \\ C. mixta Friese, 1904 \\ C. mourei Roig-Alsina, 2000 \\ C. neffi Moure, 2000 \\ C. nigerrima (Spinola, 1851) \\ C. toroi $\mathbf{s p . ~ n o v . ~}$ \\ C. tricolor Friese, 1900
}

\author{
C. unifasciata (Schrottky, 1913) \\ C. vogeli Roig-Alsina, 2000 \\ C. xanthomelaena Moure \& Castro, 2001 \\ C. atripes Mocsáry, 1899 \\ C. cockerelli Fox, 1899 \\ C. zacateca Snelling, 1966 \\ C. (Acritocentris) agameta Snelling, 1974 \\ C. (Exallocentris) anomala Snelling, 1966 (somente fêmea) \\ C. (Xerocentris) pallida Fox, 1899 \\ C. (Centris) leprieuri (Spinola,1851) \\ C. (Xanthemisia) aff. lutea Friese, 1900
}

\section{Grupo externo}

C. (Trachina) fuscata Lepeletier, 1841

C. (Wagenknechtia) moldenkei Toro \& Chiappa, 1989

Epicharis bicolor (Smith, 1854)

Anthophora californica Cresson, 1869 
Tabela II. Matriz com estados dos caracteres, nas espécies do "grupo Centris" e do grupo externo, utilizados para análise filogenética. Código dos caracteres em itálico. ? = estados não comparáveis, não claramente definíveis e não observados; $\mathrm{a}=[0 / 1] ; \mathrm{b}=[1 / 2] ; \mathrm{c}=[2 / 3]$.

\begin{tabular}{|c|c|}
\hline & 2 \\
\hline & 1234567890123456789012345678901234567890123456789 \\
\hline C. brethesi & $10211201120002011010 ? 101100100100001100020100 ? 010$ \\
\hline C. buchholzi & $102112011200020111001101100100100001100020100 ? 010$ \\
\hline C. burgdorfi & 212112001200020010010101110100031111011109020101210011 \\
\hline C. caelebs & 1021120012000201101011012101003110111011201211012 \\
\hline C. chilensis & $10211200120002011010 ? 101100100100001100020100 ? 010$ \\
\hline C. cordillerana & $1021 ? 2000120000200100011011101000011000110000201210011$ \\
\hline C. euphenax & ?? 1 ?? 0 ??????????010110111010121201?????????????? \\
\hline C. flavohirta & $1021120012000201101011012101012120111010300 ? 10012$ \\
\hline C. klugii & 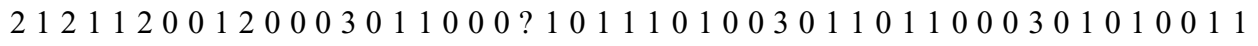 \\
\hline C. lyngbyei & 1021120012000020110001100110100011001011000201210011 \\
\hline C. mixta & $10210201110000011100 ? 10110010010000110 ? 02010100 ? 010$ \\
\hline C. mourei & 2021120012000201100101011101000311000110000201210010 \\
\hline C. neffi & 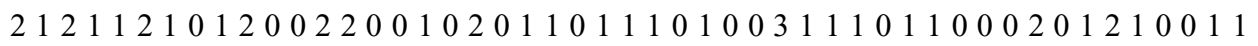 \\
\hline C. nigerrima & 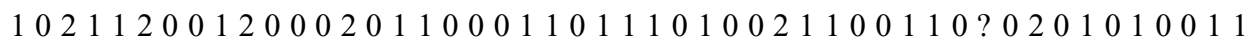 \\
\hline C. toroi & 2121121012002200102011011101003 a 1110110000201210011 \\
\hline C. tricolor & b 02112001200021110010101110100031100110000201210010 \\
\hline C. unifasciata & 1021120012000201101011012101002110111011201211012 \\
\hline C. vogeli & $? ? 21 ? 2000120000 ? 001000 ? 10111101000110101110000201210011$ \\
\hline C. atripes & 10211201020002111000010110112010000011000201210011 \\
\hline C. cockerelli & 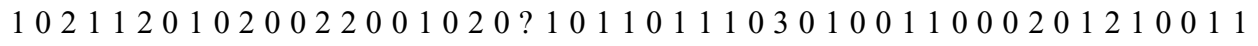 \\
\hline C. zacateca & $10211200020002001000 ? 10111110001010011010201210010$ \\
\hline C. xanthomelaena & $20211200 ? 2000201100001010001000020011000201112012$ \\
\hline C. pallida & $2011010210104210001001012111103110011190 \begin{array}{l}0 \\
2\end{array}$ \\
\hline C. anomala & $1021020010103300101 ?$ ? 1 ?? 1 ? 1 ? ? 000 ?? 011 ? ? ? 201 ? 1 ? 01 ? \\
\hline C. agameta & 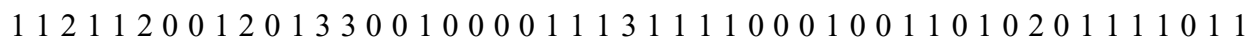 \\
\hline C. leprieuri & 20212203120113011020110100023000020001111100001119011 \\
\hline C. aff. llutea & 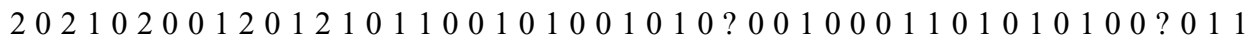 \\
\hline C. fuscata & 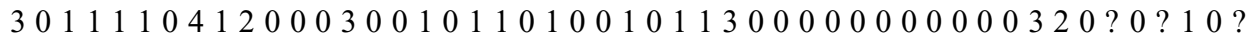 \\
\hline C. moldenkei & $2011020011105100010011001002406010000000 \mathrm{c} 10 ? 0 ? 10$ ? \\
\hline E. bicolor & $3110 ? 1000020123000 ? 00100000000 ? 040 ? ? 0000000300 ? 0 ? 00$ ? \\
\hline A. californica & 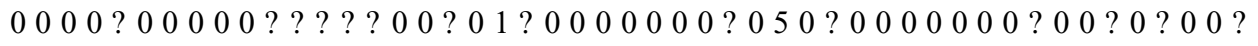 \\
\hline
\end{tabular}

Centridini, cuja monofilia é consistentemente demonstrada nas análises de Ayala (1998) e de Roig-Alsina \& Michener (1993). Anthophora californica representa a tribo Anthophorini, que no estudo de Roig-Alsina \& Michener (1993) é o grupo-irmão da tribo Centridini.

As inferências filogenéticas foram baseadas em 49 caracteres (ver relação abaixo e Tabela II), sendo que 19 apresentam mais de dois estados.

Em relação aos caracteres, além das observações gerais sobre os procedimentos seguidos para a sua seleção/exclusão, incluídas no item "Seleção e Codificação de Caracteres", cabe aqui, uma pequena discussão acerca dos dois caracteres considerados apomórficos para o clado (Paracentris - Centris s. str. - Exallocentris - Xerocentris) na análise de Ayala (1998) e as razões da sua não inclusão no presente estudo.

Esses caracteres, referentes às fêmeas, estão definidos por Ayala (1998: 17) como: "6. Mandíbulas, carena acetabular (la que forma el surco acetabular):... (2) Alcanzando la base del cuarto dente (tercero subapical)." e "8. Mandíbula, número de dientes en el rustellum [sic] (=rutellum): . . . (2) Con tres dientes.".
Ayala (op. cit.) refere-se, no caráter 6, ao sulco acetabular e não à carena acetabular, como afirma. $\mathrm{O}$ sulco acetabular começa próximo ao acetabulum, na parte superior da base da mandíbula, e estende-se em direção ao seu ápice, chegando, usualmente, próximo à base do pollex. A carena acetabular também começa próximo ao acetabulum e acompanha o sulco acetabular até a parte média da mandíbula, mas depois se afasta do sulco e se dirige para o ápice do pollex (MicHENER \& FraSER 1978: 470; ver também Fig. 1).

Esta questão é importante porque Ayala (1998) utilizou somente a posição do ápice do sulco acetabular para reconhecer o dente que corresponde ao pollex e, conseqüentemente, para estabelecer hipóteses de homologia para estruturas da mandíbula. Assim, os estados dos caracteres 8 e 9 de AyAlA (op. cit.), que se referem ao número de dentes no rutellum e no pollex, respectivamente, são dependentes do caráter 6 , isto é, de qual dente é reconhecido como pollex, pois o rutellum é, por definição, a parte apical da mandíbula, compreendendo o dente apical e os dentes subapicais que ficam entre esse dente e o pollex (MichenER \& FRASER 1978).

Ademais, a interpretação de Ayala sobre qual dente 
corresponde ao pollex, no caso dos subgêneros Xanthemisia, Acritocentris e Xerocentris, está, a meu ver, equivocada; pois, a posição da parte apical do sulco acetabular pode variar em relação ao pollex, chegando apenas até a metade da sua base (Fig. 41) ou estendendo-se até a metade da base do dente seguinte (Fig. 40).

Segundo Michener \& Fraser (1978), a posição do pollex pode ser reconhecida pela posição da parte apical do sulco acetabular, pela parte apical da carena acetabular ou, segundo eles, em algumas espécies, por um entalhe na base do pollex na sua face inferior. Em todos os subgêneros do grupo Centris, a carena acetabular e o entalhe na face interna da mandíbula indicam que o pollex é o dente mais basal, ou seja: o segundo dente subapical dos Xerocentris ou o terceiro em todos os outros subgêneros. Assim, para os caracteres 8 e 9 de Ayala (1998) não há variação interna no grupo Centris e eles não são úteis para informar sobre as relações entre os subgêneros que o compõem.

Em razão do acima exposto, foi utilizado somente o caráter número de dentes na mandíbula das fêmeas (caráter 6), sem considerar a separação em pollex e rutellum. Também não utilizada, como um caráter, a posição do ápice do sulco acetabular (caráter 6 de AyAlA op. cit.), por não considerar os estados claramente separáveis, tendo em vista a variação contínua observada.

\section{LISTA DE CARACTERES}

Fêmeas $(1-17)$

1. Palpo maxilar, número de artículos (incluindo o artículo basal ou palpígero): 0 - Seis; 1 - Cinco; 2 - Quatro; 3 - Três. Ayala (1998: caráter 1) considerou os Paracentris como apresentando 5 artículos, mas há espécies com somente quatro. Centris pallida apresenta quatro artículos, conforme Ayala considerou para os Xerocentris, mas C. mixta apresenta cinco artículos.

2. Palpo maxilar, comprimento do segundo artículo (Caráter 3 de Ayala 1998): 0 - Mais longo ou igual à largura do terceiro flagelômero; 1 - Mais curto.

3. Mandíbula, carena acetabular: 0 - Terminando no primeiro dente subapical; 1 - No segundo dente subapical; 2 No terceiro dente subapical (Fig. 1).

4. Mandíbula, dentículo da expansão trimal: 0 - Ausente; 1 Presente (Fig. 1).

5. Mandíbula, dentículo da expansão trimal: 0 - Vestigial (Fig. 3); 1 - Pequeno, formando um ângulo no ápice (Fig. 2); 2 - Grande, quase do tamanho dos dentes subapicais e com o ápice arredondado (Fig. 1).

6. Mandíbula, número de dentes: 0 - Dois; 1 - Três; 2 - Quatro.

7. Mandíbula, alargamento na base do dente apical: 0 -
Ausente; 1 - Presente (Fig. 49).

8. Clípeo, cor e forma das manchas: 0 - Inteiramente preto; 1 Manchas amarelas ocupando o disco, com duas pequenas emarginações na parte superior; 2 - Pequena mancha amarela na região central; 3 - Mancha amarela em forma de " $\mathrm{T}$ " invertido; 4 - Clípeo quase que inteiramente amarelo, com duas pequenas manchas em forma de "D" maciço, na parte superior.

9. Primeiro flagelômero, comprimento: 0 - Curto, menor do que 0,85 vez o comprimento do escapo; 1 - Longo, maior do que 0,92 vez o comprimento do escapo.

10. Basitarso anterior, elaiospata (estrutura formada por cerdas modificadas para a coleta de óleo nas flores): 0 Ausente; 1 - Presente, mas vestigial (em C. mixta, ver Neff \& Simpson 1981: Fig. 26); 2 - Presente e bem desenvolvida (ver NefF \& Simpson 1981: Figs. 9-20). Ayala (1998) utiliza também em sua análise, como um caráter independente, a presença/ausência de elaiospata nos basitarsos médios. Entretanto, estes dois caracteres são claramente relacionados à mesma função (coleta de óleo em flores) e devem ser considerados como somente um caráter na análise.

11. Pernas posteriores, placa basitibial secundária, bordo apical, parte anterior: 0 - Formando uma curva ascendente em direção à margem da placa (Figs. 4-7); 1 - Formando uma curva descendente (Figs. 8, 9).

12. Pernas posteriores, placa basitibial secundária, bordo apical, parte posterior: 0 - Formando uma curva descendente em direção à margem da placa (Figs. 5, 8, 9); 1 - Formando uma curva ascendente (Figs. 4, 6, 7).

13. Pernas posteriores, placa basitibial secundária, bordo apical, parte mediana: 0 - Reto ou suavemente arredondado, inclinado para a parte posterior (Fig. 5); 1 - Arredondado e não inclinado (Fig. 6); 2 Formando um ângulo agudo projetado no meio da placa principal (Fig. 7); 3 - Reto e não inclinado (Fig. 4); 4 - Reto e inclinado para a parte anterior (Fig. 9); 5 - Côncavo (Fig. 8).

14. Pernas posteriores, placa basitibial secundária, bordo apical, vista lateral: 0 - Arredondado (Fig. 10); 1 Formando um ângulo reto (Fig. 11); 2 - Formando uma curta projeção sobre a placa principal (Fig. 12); 3 - Formando uma projeção laminar sobre a placa principal (Fig. 13).

15. Pernas posteriores, placa basitibial secundária, depressão próximo ao bordo posterior: 0 - Ausente; 1 - Presente (Fig. 9). 
16. Basitarsos posteriores, bordo apical, projeção na parte posterior: 0 - Ausente (Figs. 15, 16); 1 - Presente (Fig. 14).

17. Basitarsos posteriores, bordo apical, ângulo próximo ao ponto da inserção do primeiro tarsômero subapical : 0 - Ausente (Fig. 16); 1 - Presente (Figs. 14, 15).

Machos (18-48)

18. Mandíbula, espaço entre primeiro e segundo dentes subapicais: 0 - Formando um ângulo reto ou agudo (Figs. 87-89); 1 - Arredondado (Figs. 86, 90).

19. Mandíbula, forma do pollex (ver Fig. 1): 0 - Triangular, com ápice agudo ou arredondado (Figs. 97, 100); 1 Quadrangular ou subquadrangular, com o bordo apical reto (em Centris pallida o bordo apical é arredondado) (Figs. 93, 102); 2 - Quadrangular, com o bordo apical côncavo (Fig. 98).

20. Área paraocular, próximo ao bordo lateral do clípeo: 0 - No mesmo plano do bordo lateral do clípeo; 1 Perpendicular ao bordo lateral do clípeo.

21. Distância clípeocular: 0 - Menor do que 0,40 vezes a largura mínima do primeiro flagelômero; 1 - Maior do que 0,60 vezes.

22. Asas posteriores, lobo jugal (Caráter 105 de RoIG-AlsinA \& MiCHENER 1993): 0 - Curto, não atingindo a veia cua; 1 - Longo, ultrapassando a veia cu-a.

23. T7, placa pigidial: 0 - Ausente; 1 - Presente.

24. T7, área não esclerosada no bordo basal: 0 - Ausente (Fig. 18); 1 - Presente (Figs. 17, 19).

25. T7, bordo apical: 0 - Com forte emarginado (Fig. 18); 1 Com suave emarginado (Fig. 19); 2 - Arredondado (Fig. 17); 3 - Reto.

26. S7, em vista ventral, largo emarginado no bordo basal: 0 Ausente (Fig. 20); 1 - Presente (Figs. 21, 112-120).

27. S7, braços laterais: 0 - Mais afilados próximo ao ápice do que na base (Fig. 20); 1 - Mais largos próximo ao ápice do que na base (Fig. 21).

28. S7, "membrana" esclerosada dorsal: 0 - Ausente (não esclerosada); 1 - Curta, não visível em vista ventral (Fig. 21); 2 - Longa, visível em vista ventral (Fig. 20).

29. S7, "membrana" esclerosada dorsal, bordo basal: 0 - Reto ou suavemente côncavo; 1 - Com um amplo emarginado de forma aproximadamente quadrangular (Fig. 21). 2 - Com um pequeno chanfro; 3 - Com duas projeções laterais (Fig. 20); 4 - Com uma pequena projeção mediana.

30. S8, forma: 0 - Com lados côncavos, formando uma projeção apical bem definida (Figs. 121-130, 133-138); 1 Subtriangular, com lados quase retos e convergentes (Figs. 131, 132).

31. S8, ápice da projeção apical em vista ventral: 0 Arredondado e afilado (Fig. 129). 1 - Arredondado e largo (Figs. 121-124); 2 - Truncado e afilado (Figs. 132-136); 3 - Truncado e largo (Figs. 124, 125, 128); 4 - Membranoso, disforme; 5 - Largo, com duas projeções laterais; 6 - Largo, com um suave emarginado.

32. S8, projeção apical, lados convergentes para o ápice, formando dois suaves ângulos na porção mediana: 0 - Ausente (Figs. 121, 128); 1 - Presente (Figs. 133138).

33. S8, ápice da projeção apical em vista lateral: 0 - Arredondado (Fig. 22); 1 - Truncado, formando dois ângulos retos, um superior e outro inferior (Fig. 24); 2 - Truncado, com o ângulo inferior agudo, projetado para trás (Fig. 23).

34. S8, ápice da projeção apical, carena mediano-apical, vista lateral: 0 - Pouco pronunciada ou ausente (Figs. 22, 23); 1 - Bem evidente, projetada acima das paredes laterais (Fig. 24).

35. S8, vista ventral, ângulo junto à base da projeção apical: 0 - Ausente (Figs. 121, 127); 1 - Presente (Figs. 133, 138).

36. Gonocoxito, cerdas longas e ramificadas na área dorsodistal, próximo à base dos gonóstilos (caráter 71 de AyALA 1998): 0 - Ausente (Figs. 31, 32); 1 - Presente (Fig. 33).

37. Gonocoxito, pilosidade simples, longa e densa, na parte distal da face interna (caráter 72 de AyAla 1998): 0 Ausente (Figs. 31, 32); 1 - Presente (Fig. 33).

38. Gonocoxito, vista ventral, parte média da carena ventral, projeção lameliforme com cerdas na face dorsal (caráter 73 de Ayala1998): 0 - Ausente; 1 - Presente (Fig. 33). Ayala (1988: Figs. 110, 141 e 144) considerou esse caráter presente em Acritocentris e Paracentris. Entretanto, pelas suas próprias ilustrações, interpreteio como ausente, o que depois foi confirmado pela análise do material estudado. A representação da genitália de Exallocentris (AyAla op. cit.: Fig. 123) também parece indicar sua ausência, mas não tive em mãos machos desse grupo para confirmar essa interpretação. 
39. Gonocoxito, face interna, metade apical: 0 - Em continuidade com a metade basal, sem uma linha indicando diferentes inclinações (Figs. 31, 32); 1 - Claramente mais horizontal do que a metade basal, formando uma linha de nível entre as duas (Fig. 33).

40. Gonocoxito, carena dorsal, suave projeção na metade apical (como que uma continuidade da linha entre a metade apical e a metade basal da face interna): 0-Ausente; 1 - Presente (Fig. 148).

41. Gonocoxito, carena dorsal, forma da projeção da parte média (caráter 74 de Ayala 1998): 0 - Ausente (Fig. 33); 1 Curta, acuminada; 2 - Longa, com os lados paralelos ou quase (Figs. 32, 153); 3 - Longa, aproximadamente triangular, com a base larga (Figs. 31, 149). Centris (Wagenknechtia) moldenkei apresenta este caráter com o estado 2, mas, tendo em vista a presença, nesse subgênero, de espécies com o estado 3 (cf. Ayala 1998: 183), foi codificado como polimórfico.

42. Gonóstilo, vista ventral (caráter 75 de AyAla 1998): 0 Longo, comprimento maior que 5,5 vezes à sua largura (Fig. 33); 1 - Curto, comprimento ca. de 4 vezes a sua largura (Fig. 32); 2 - Muito curto, comprimento subigual à sua largura (Fig. 31).

43. Gonocoxito, região dorsodistal, projeção laminar translúcida na base das cerdas longas: 0 - Ausente; 1 - Presente (Figs. 25-30).

44. Gonocoxito, região dorsodistal, projeção laminar translúcida na base das cerdas longas: 0 - Curta e estreita (Fig. 25); 1 - Curta e larga (figs 26, 33); 2 - Longa (Figs. 2730).

45. Gonocoxito, projeção dorsodistal, próximo ao gonóstilo: 0 - Ausente (Figs. 25, 31, 32); 1 - Presente (Figs. 26-30, 33).

46. Gonocoxito, projeção dorsodistal, próximo ao gonóstilo: 0 - Somente como uma carena pouco elevada (Figs. 2830); 1 - Curta, atingindo até quase a metade do gonóstilo (Fig. 27); 2 - Longa, atingindo cerca de 2/3 do gonóstilo (neste caso a área de inserção das cerdas longas forma uma linha bem definida, que se estende da base ao ápice da projeção) (Figs. 26, 33). É importante ressaltar que AyALA (1988: caráter 81) considerou os Xerocentris (que na sua análise inclui Centris mixta e C. pallida) como apresentando uma longa projeção dorsodistal, da mesma forma que os Centris s. str.; Entretanto, em C. mixta essa projeção é claramente ausente (de modo semelhante ao observado em C. buchholzi, Fig. 25) e o estado presente em $C$. pallida (Fig. 29) é evidentemente distinto do observado nos Centris s. str.
47. Gonocoxito, face interna, papilas na área distal, próximo à base do gonóstilo: 0 - Ausente; 1 - Presente (Figs. 31, 32).

48. Gonocoxito, carena dorsal, parte basal, antes da projeção: 0 - Subparalela à parte apical (Fig. 31); 1 - Alinhada com a parte apical, como uma continuação desta (Fig. 151). Em Anthophora californica a projeção média é ausente, o que parece ser uma perda secundária. Assim, essa espécie foi codificada com o estado (0), como se apresenta, em geral, nas outras espécies do gênero (BROOKS 1988).

49. Gonocoxito, região dorsodistal, número de cerdas longas e grossas (Fig. 33): 0 - Entre 4 e 10; 1 - Entre 12 e 24; 2 Mais de 30.

\section{RESULTADOS E DISCUSSÃO}

Na análise realizada com o NONA, que assume pesos iguais para os caracteres, foram obtidos oito cladogramas mais parcimoniosos, cada um com 169 passos $(\mathrm{CI}=0,48 ; \mathrm{RI}=0,62)$.

$\mathrm{Na}$ análise com o PAUP, também com pesos iguais, foram obtidos 12 cladogramas com idêntico número de passos, índices de consistência e de retenção. A diferença no número de cladogramas, em relação ao obtido com o NONA, deve-se ao fato de que o PAUP (versão 3.1) retém alguns cladogramas com resoluções de politomias não suportadas pelos caracteres, o que não ocorre no NONA (NiXON \& CARPENTER 1996). Mas, isso não afeta os consensos estritos, que são idênticos nas duas análises (Fig. 34).

$\mathrm{Na}$ análise com pesagem sucessiva, foram obtidos seis cladogramas, também com 169 passos $(\mathrm{CI}=0,48 ; \mathrm{RI}=0,62)$. $\mathrm{O}$ consenso estrito é quase idêntico ao das análises com pesos iguais. A única diferença está na maior resolução do clado " $\mathrm{C}$ " (ver Fig. 34), onde Centris brethesi aparece como grupo-irmão do clado formado por C. buchholzi e C. mixta.

$\mathrm{Na}$ análise com pesagem implícita, foram obtidos 10 cladogramas com um ajuste máximo (fit) igual a 319,9. Todos com 170 passos $(\mathrm{CI}=0,48 ; \mathrm{RI}=0,62)$. $\mathrm{O}$ consenso estrito, como nas outras análises, é bem resolvido e, de modo idêntico à análise de pesagem sucessiva, agrupa $C$. brethesi com $C$. buchholzi e C. mixta (Fig. 35). O favorecimento dessa resolução, nas duas análises com pesagem diferenciada de caracteres, deve-se ao pequeno peso conferido ao caráter 19 (Tabela III). Em algumas das análises com pesos iguais, esse caráter sustentou um clado formado por $C$. brethesi e $C$. chilensis (comparar Figs. 37 e 38).

O consenso estrito, entretanto, diferencia-se dos das outras análises, pela falta de resolução na relação entre $C$. klugii e $C$. burgdorfi; por C. vogeli estar como grupo-irmão do clado " $\mathrm{M}$ ", e pelo clado " $F$ " resultar, na base, em uma politomia com seis ramos (comparar Figs. 34 e 35).

Apesar das diferenças observadas, algumas conclusões, a respeito das relações entre os subgêneros do "grupo Centris", podem ser estabelecidas a partir dos aspectos consensuais 
Tabela III. Pesos dos caracteres após análise de pesagem implícita (PI) e de pesagem sucessiva (PS).

\begin{tabular}{ccc|ccc|ccc|ccc}
\hline Caráter & PI & PS & Caráter & PI & PS & Caráter & PI & PS & Caráter & PI & PS \\
\hline 1 & 6,0 & 6 & 14 & 4,2 & 4 & 27 & 6,0 & 3 & 40 & 10,0 & 10 \\
2 & 6,0 & 3 & 15 & 6,0 & 3 & 28 & 6,0 & 5 & 41 & 6,0 & 5 \\
3 & 7,5 & 6 & 16 & 4,2 & 2 & 29 & 6,0 & 6 & 42 & - & 10 \\
4 & 10,0 & 10 & 17 & 6,0 & 3 & 30 & 10,0 & 10 & 43 & 7,5 & 5 \\
5 & 5,0 & 4 & 18 & 7,5 & 5 & 31 & 3,7 & 6 & 44 & 5,0 & 4 \\
6 & 7,5 & 6 & 19 & 3,3 & 2 & 32 & 4,2 & 2 & 45 & 10,0 & 10 \\
7 & 10,0 & 10 & 20 & 4,2 & 2 & 33 & 5,0 & 4 & 46 & 7,5 & 6 \\
8 & 7,5 & 8 & 21 & 3,7 & 1 & 34 & 10,0 & 10 & 47 & 7,5 & 5 \\
9 & 7,5 & 5 & 22 & 10,0 & 10 & 35 & 10,0 & 5 & 48 & 10,0 & 10 \\
10 & 6,0 & 5 & 23 & - & 10 & 36 & 10,0 & 10 & 49 & 4,2 & 3 \\
11 & 7,5 & 5 & 24 & 7,5 & 5 & 37 & 10,0 & 10 & & & \\
12 & 5,0 & 2 & 25 & 5,0 & 5 & 38 & 7,5 & 5 & & & \\
13 & 5,0 & 6 & 26 & 7,5 & 5 & 39 & 4,2 & 2 & & & \\
\hline
\end{tabular}

entre os cladogramas obtidos em todas as análises empreendidas (Figs. 34, 35; o consenso entre os cladogramas obtidos em todas as análises está representado na Fig. 36). As conclusões mais importantes, no contexto deste trabalho, são: 1) As hipóteses da monofilia do "grupo Centris" e da posição basal de C. (Xanthemisia), dentro do grupo, estabelecidas primeiramente por Ayala (1998) são corroboradas; 2) O subgênero $C$. (Paracentris), como atualmente definido (SNelling 1984; Ayala 1998), é claramente parafilético; 3 ) C. mixta, considerado por SNelling (1984) e Ayala (1998) como relacionado aos $C$. (Xerocentris) (subgênero exclusivo da América do Norte, do qual faz parte C. pallida), é na realidade espécie irmã de $C$. buchholzi, pertencendo à um grupo monofilético restrito ao sul da América do Sul (Fig. 34: clado "N"). Esse resultado corrobora a posição de NEFF \& SiMPSON (1981), que sugeriram que C. mixta é relacionada à C. buchholzi ou à $C$. brethesi; 4) C. xanthomelaena está relacionada ao subgênero Centris (Fig. 34: clado "E") e não aos Paracentris, como afirmado por Vogel \& MACHADO (1991); 5) Os Paracentris da América do Norte devem ter uma origem comum com as espécies consideradas por SNelling (1974, 1984) nos subgêneros C. (Xerocentris), C. (Exallocentris) e $C$. (Acritocentris) (Fig. 34: clado "J"); 6) Outros grupos monofiléticos maiores, presentes nos resultados de todas as análises, são representados pelos clados " $G$ ", "M" e "F". Este último agrupando os dois anteriores, mais o clado "J" e quatro espécies de C. (Paracentris) (C. vogeli, C. lyngbyei, $C$. cordillerana e $C$. nigerrima), que não apresentam uma posição claramente definida.

Para eliminar a condição parafilética do subgênero $C$. (Paracentris), mantendo somente grupos monofiléticos, os subgêneros $C$. (Xerocentris), $C$. (Acritocentris) e $C$. (Exallocentris), todos descritos por SNELLiNG (1974), são considerados sinônimos de C. (Paracentris) Cameron, 1903 e é proposta a revalidação do subgênero $C$. (Penthemisia) Moure,
1950, mas com um sentido mais restrito do que o original (Fig. 35).

Centris xanthomelaena provavelmente deve ser colocada em um novo subgênero. Essa espécie constitui, junto com o subgênero C. (Centris), um grupo monofilético (Fig. 36). É possível que $C$. xanthomelaena seja o ramo mais basal dentro de $C$. (Centris) s. str. Mas, como esse subgênero parece ser muito uniforme, com várias autapomorfias, que estão ausentes em C. xanthomelaena, é preferível, antes de uma análise mais completa do conjunto das espécies de C. (Centris) s. str., mantêla fora desse subgênero.

\section{Centris (Paracentris) Cameron, 1903}

Paracentris Cameron, 1903: 235-236. Espécie-tipo: Paracentris fulvohirta Cameron, 1903; por monotípia.

Centris (Penthemisia) Moure, 1950: 390 (partim); Snelling, 1956: 5; Toro, 1986: 127 (partim)(lista das espécies do Chile).

Hemisia (Penthemisia); Michener, 1951: 3 (partim)(chave para subgêneros).

Centris (Trichocentris) Snelling, 1956: 4-5. Espécie-tipo: Centris rhodoleuca Cockerell, 1923, designação original; Snelling, 1966: 2.

Centris (Paracentris); Snelling, 1966: 5 (sinonímia com Penthemisia); Snelling, 1974: 6 (sinonímia com Trichocentris); Snelling, 1984: 5 (partim)(chave para espécies da América do Norte); Ayala, 1998: 1280 (partim); Moure, 2000 [1999]: 147 (descrição de novas espécies); Roig-Alsina, 2000: 171 (partim)(chave para espécies da Argentina e descrição de novas espécies).

Centris (Xerocentris) Snelling, 1974: 3. Espécie-tipo: Centris californica Timberlake, 1940, designação original; Snelling, 1984: 4-5. Syn. nov.

Centris (Exallocentris) Snelling, 1974: 35. Espécie-tipo: Centris anomala Snelling, 1966, designação original; Snelling, 1984: 13. Syn. nov.

Centris (Acritocentris) Snelling, 1974: 36. Espécie-tipo: Centris ruthannae Snelling, 1966, designação original; Snelling, 1984: 9. Syn. nov.

Abelhas com 12 a $20 \mathrm{~mm}$ de comprimento. Tegumento inteiramente preto, ou com o metassoma ou os tergos metassomáticos apicais avermelhados. Os machos de grande 


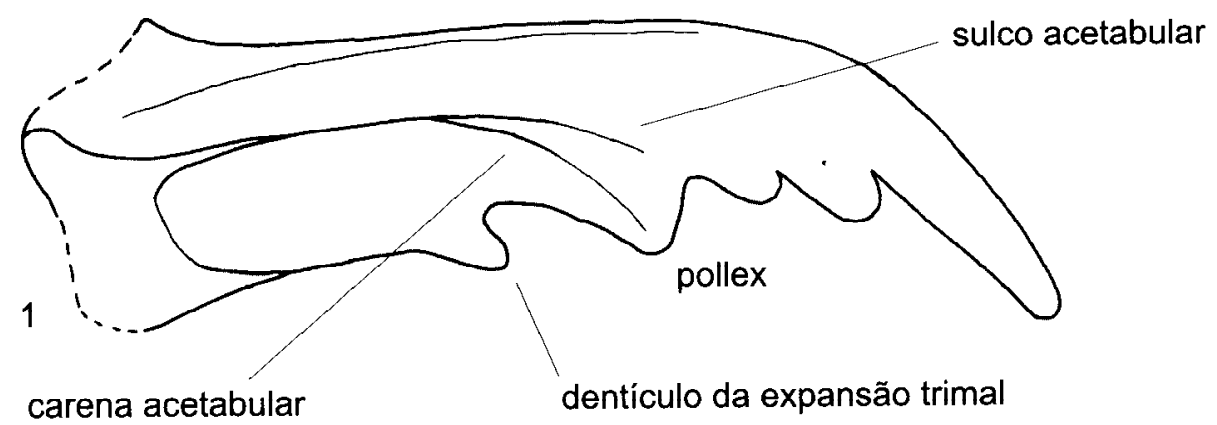

2

3

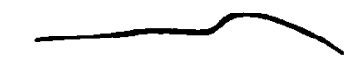

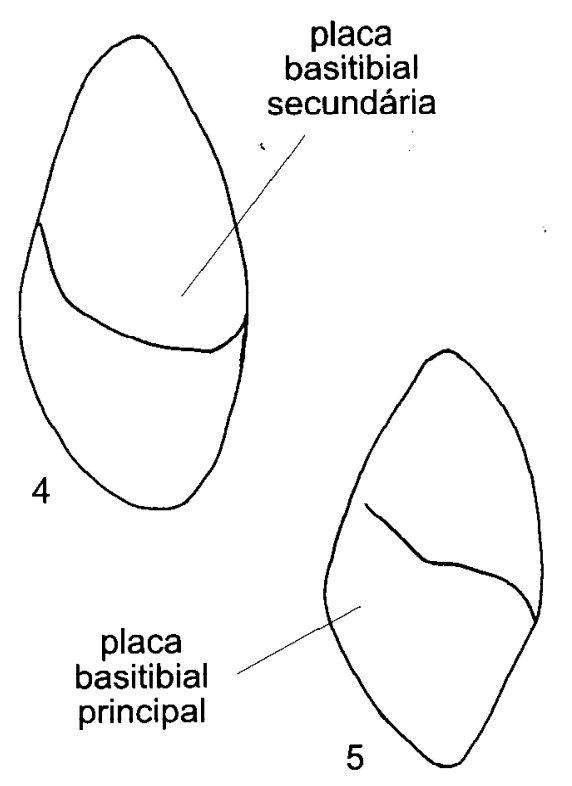
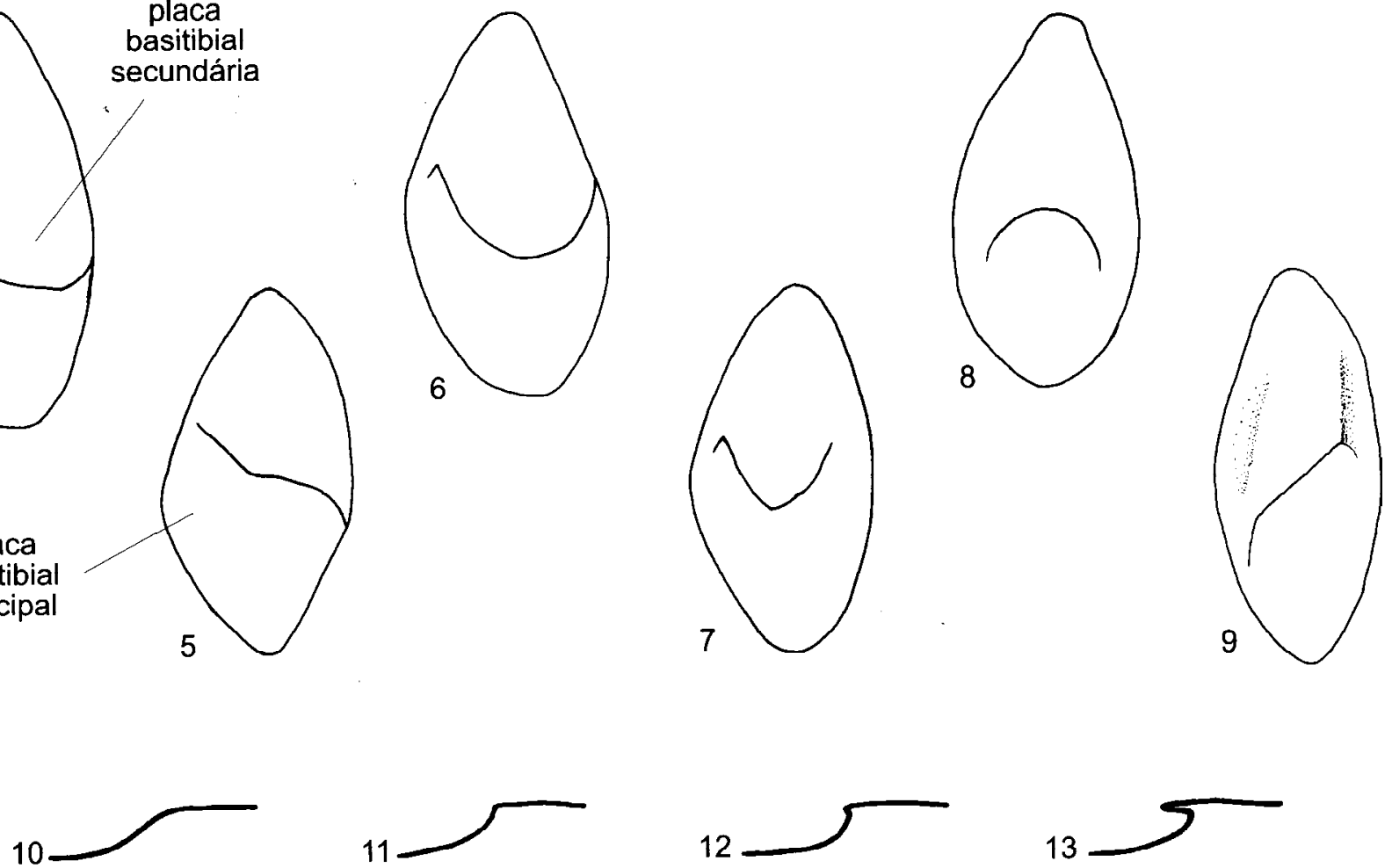

12
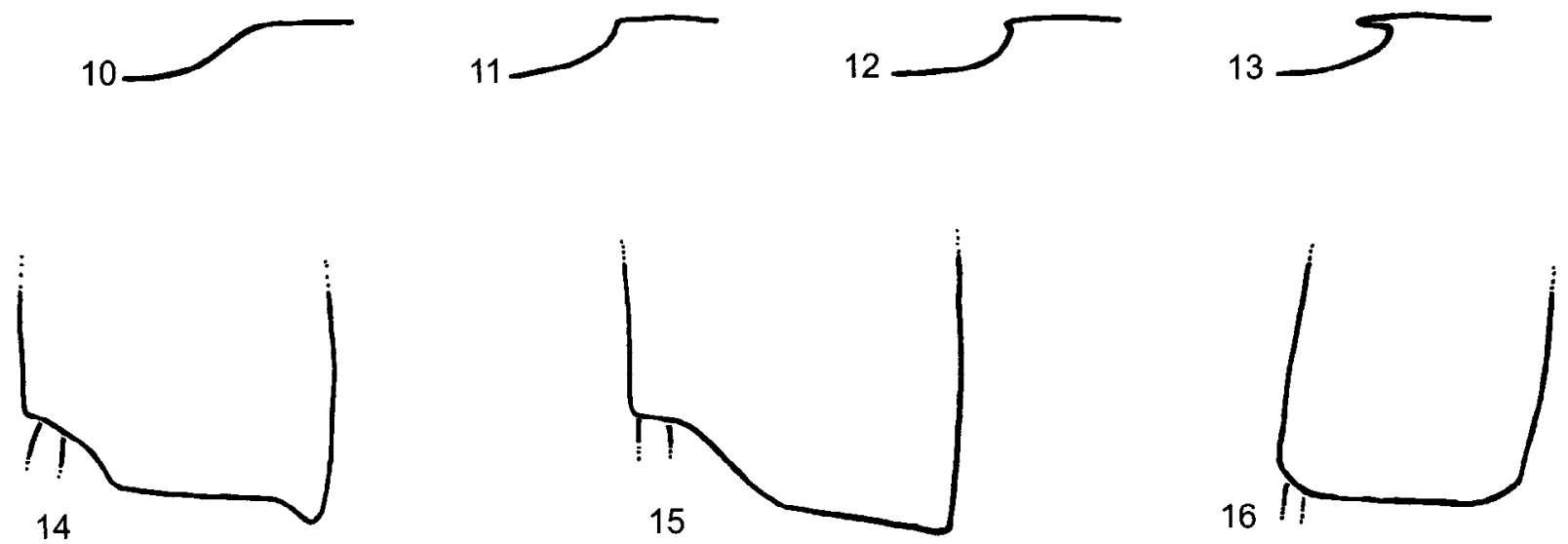

Figs. 1-16. 1, Mandíbula de fêmea de Centris (Centris) leprieuri; 2, Dentículo da expansão trimal da mandíbula de C. (Paracentris) burgdorfi; 3, C. (Penthemisia) mixta; 4, Placa basitibial esquerda, C. (Paracentris) agameta; 5, C. (Trachina) fuscata; 6, C. (C.) leprieuri; 7, C. (Xanthemisia) aff. lutea; 8, C. (Wagenknechtia) moldenkei; 9, C. (Paracentris) pallida; 10, Bordo apical da placa basitibial secundária em vista lateral, C. (Penthemisia) mixta; 11, C. (Xanthemisia) aff. lutea; 12, C. (Paracentris) burgdorfi; 13, C. (C.) leprieuri; 14, Bordo apical do basitarso posterior das fêmeas, C. (Paracentris) caelebs; 15, C. (P.) unifasciata; 16, C. (P.) pallida. 
parte das espécies apresentam o labro e disco do clípeo amarelos (em C. pallida o clípeo é inteiramente preto ou há uma pequena mancha clara na parte central). Membrana das asas hialina ou castanha, semi-translúcida. Fêmeas: mandíbula com quatro dentes, exceto C. pallida, com três. Bordo apical da placa basitibial secundária com forma de "S" deitado (Figs. 60-69) ou aproximadamente reto, inclinado para a parte posterior (Fig. 4) ou reto e inclinado para a parte anterior (Fig. 9); formando uma curta projeção sobre a placa principal (Fig. 11) ou formando uma projeção laminar, em C. klugi, C. anomala e C. agameta (Fig. 13). Machos: T7, área não esclerosada no bordo basal bem definida (Fig. 17; exceto em C. lyngbyei). S7 com largo emarginado no bordo basal (Figs. 107-120; exceto em C. atripes e C. cockerelli); membrana esclerosada dorsal curta, não visível em vista ventral (Fig. 21). S8, projeção apical longa, com forma variável no ápice; truncado e largo (Figs. 124-127), truncado e afilado $(131,132,136,138)$ ou arredondado e afilado (Figs. 128; 135); arredondado e largo somente em C. atripes e C. zacateca. Gonocoxito, projeção dorsodistal somente como uma carena pouco elevada (Figs. 28-30) ou atingindo até quase a metade do gonóstilo (Fig. 27); gonóstilo longo; projeção laminartranslúcida em geral longa (Figs. 27-30), curta e estreita somente em $C$. klugi e C. nigerrima e curta e larga somente em $C$. agameta; projeção média da carena dorsal longa e estreita, com lados quase paralelos (Fig. 148), larga e subtriangular somente em C. flavohirta, C. klugii e, às vezes, em C. pallida; número variável de cerdas longas e grossas da região dorsodistal, usualmente mais de 12 , menos de 10 somente em C. tricolor, C. mourei e C. zacateca.

Este subgênero apresenta distribuição anfitropical, ocorrendo principalmente em áreas xéricas da América do Sul e América do Norte. São conhecidas na América do Sul as seguintes espécies: Centris burgdorfi Friese, 1901; C. caelebs Friese, 1900; C. cordillerana Roig-Alsina, 2000; C. euphenax Cockerell, 1913; C. flavohirta Friese, 1900; C. garleppi (Schrottky, 1913); C. klugii Friese, 1900; C. lyngbyei JensenHaarup, 1908; C. mourei Roig-Alsina, 2000; C. neffi Moure, 2000; C. nigerrima (Spinola, 1851); C. toroi sp. nov.; C. tricolor Friese, 1900; C. unifasciata (Schrottky, 1913); C. urens Moure, 2000; C. vogeli Roig-Alsina, 2000 e C. willineri Moure, 2000. Das espécies da América do Norte foram incluídas no presente estudo: Centris agameta Snelling, 1974; C. anomala Snelling, 1966; C. atripes Mocsáry, 1899; C. cockerelli Fox, 1899; C. pallida Fox, 1899 e C. zacateca Snelling, 1966. Além dessas, devem pertencer a esse subgênero outras espécies da América do Norte, relacionadas por SNeLling (1984) nos subgêneros Paracentris, Acritocentris e Xerocentris: Centris albiceps Friese, 1899; C. angustifrons Snelling, 1966; C. aterrima Smith, 1854; C. caesalpiniae Cockerell, 1897; C. callifornica Timberlake, 1940; C. ectypha Snelling, 1974; C. ferrisi Cockerell, 1924; C. fisheri Snelling, 1974; C. griseola Snelling, 1984; C. harbinsoni Snelling, 1974; C. hoffmanseggiae Cockerell, 1897; C. laevibullata Snelling, 1966; C. lanosa Cresson, 1872; C. mexicana Smith, 1854; C. nigrocaerulea Smith, 1874; $C$. rhodomelas Timberlake, 1940; C. rhodopus Cockerell, 1897; C. ruthannae Snelling, 1966; C. satana Snelling, 1984; C. tiburonensis Cockerell, 1923 e C. vanduzeei Cockerell, 1923.

Chave para as espécies sul-americanas de Centris (Paracentris)

\section{Fêmeas}

1. Dente apical das mandíbulas alargado na base (Figs. 49, 51). Placa basitibial estreita, bordo anterior da placa secundária quase paralelo ao bordo anterior da placa principal (Figs. 65, 67)

Dente apical das mandíbulas afilado. Placa basitibial mais alargada no meio e bordo da placa secundária arredondado . .3

2. T4 preto. T5 e T6 vermelho-ferrugíneos, mas faixa apical do T6, sob as cerdas da fímbria pré-pigidial, castanhoescura Centris neffi Moure

T4, T5 e T6 vermelho-ferrugíneos C. toroi sp. nov.

3. Tegumento inteiramente preto 4 Metassoma inteiramente vermelho-ferrugíneo ou, ao menos, os tergos apicais . 5

4. Membrana das asas escura. Mandíbula curta e robusta, comprimento 1,6-1,7 vezes a largura da base. Cabeça larga, largura entre 5,9 e $6,3 \mathrm{~mm}$. Olhos um pouco convergentes para baixo, $\mathrm{DIOS} / \mathrm{DIOI}=1,0-1,1$ C. burgdorfi Friese

Membrana das asas quase hialina, com um suave tom méleo. Comprimento da mandíbula 2,0-2,1 vezes a largura da base. Largura da cabeça entre 4,8 e 5,4. Olhos divergentes para baixo, $\mathrm{DIOS} / \mathrm{DIOI}=0,9$

C. nigerrima (Spinola)

5. Metassoma inteiramente vermelho-ferrugíneo 6

Ao menos os três tergos basais pretos 11

6. Pilosidade amarelo-palha ou esbranquiçada na cabeça e mesossoma

Pilosidade predominantemente preta ou castanho-escura na cabeça (no máximo com tufos de pêlos claros no vértice e próximo aos alvéolos antenais e no labro). $\mathrm{O}$ mesossoma, quando com pilosidade clara, apenas na região dorsal e, ás vezes, nas partes superiores dos mesepisternos .8

7. Pilosidade preta na escopa. Olhos um pouco divergentes para baixo, DIOS/DIOI =0,9. Distância ocelocular 1,7 vezes o diâmetro do ocelo médio. Distância entre alvéolos antenais 3,5 vezes o diâmetro alveolar C. vogeli Roig-Alsina

Pilosidade amarelo-palha na escopa. Olhos um pouco convergentes para baixo, DIOS/DIOI $=1,0-1,1$. Distância ocelocular 1,9-2,1 vezes o diâmetro do ocelo médio. Distância entre alvéolos antenais 3,0- 

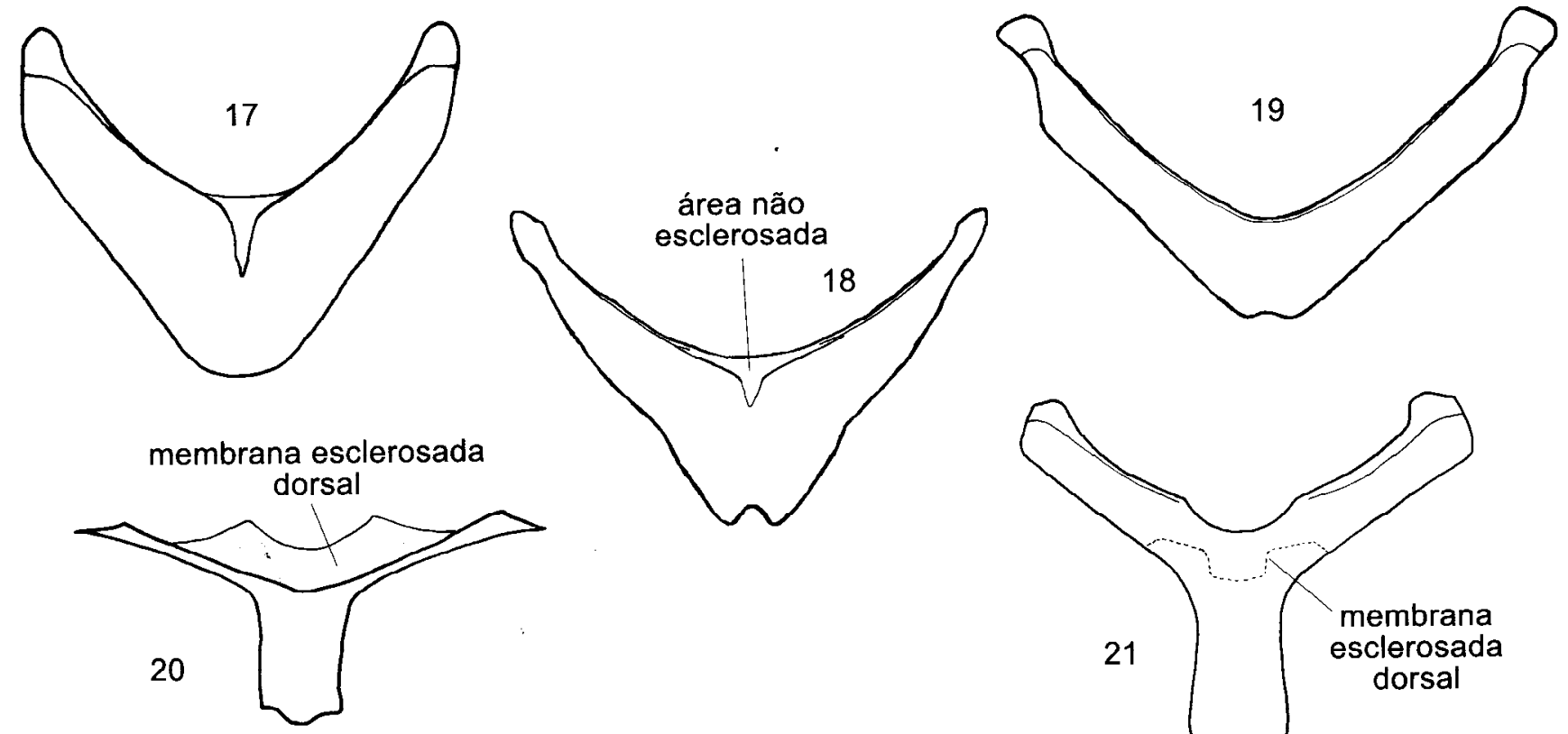

membrana esclerosada dorsal
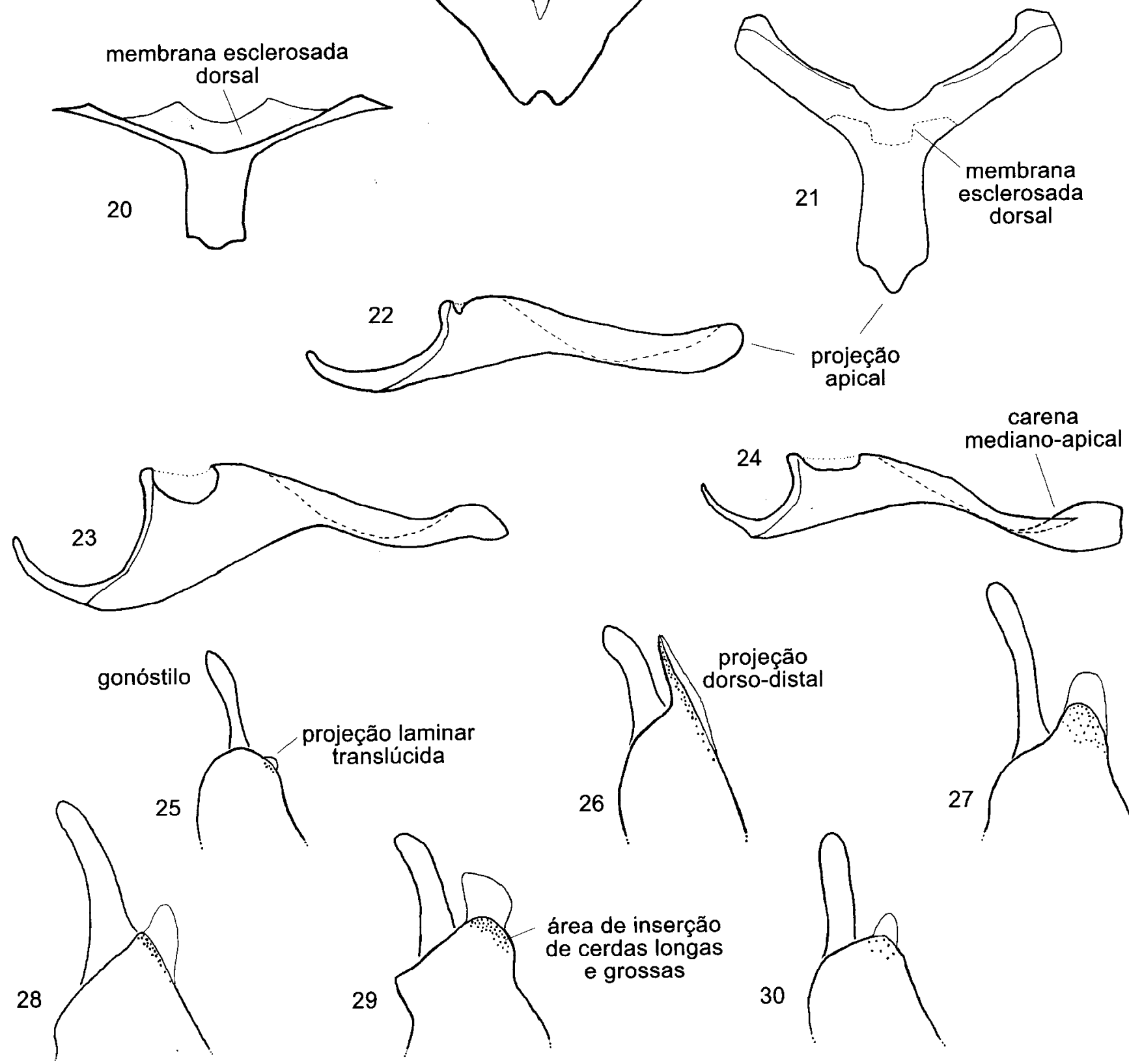

projeção laminar translúcida

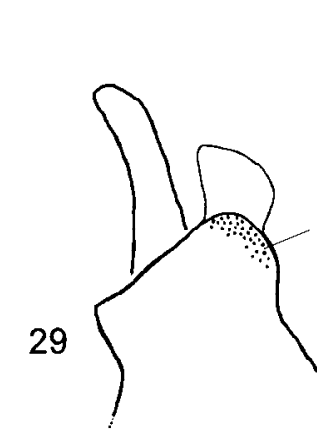

área de inserção de cerdas longas e grossas

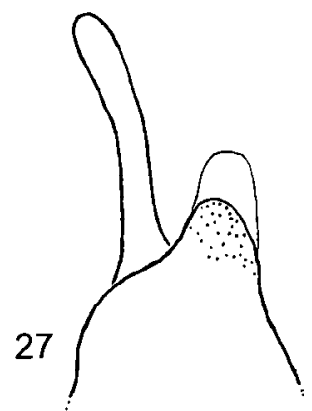

Figs. 17-30. 17, T7, vista dorsal, macho de Centris (Paracentris) flavohirta; 18, C. (Xanthemisia) aff. lutea; 19, C. (C.) leprieuri; 20, S7, vista ventral, macho de C. (C.) leprieuri; 21, C. (Paracentris) pallida; 22, S8, vista lateral, macho de C. (Penthemisia) buchholzi; 23, C. (Paracentris) flavohirta; 24, C. (Paracentris) toroi sp. nov.; 25, Ápice do gonocoxito, vista lateral, C. (Penthemisia) buchholzi; 26, C. xanthomelaena; 27, C. (Paracentris) unifasciata; 28, C. (P.) burgdorfi; 29, C. (P.) pallida; 30, C. (P.) zacateca. 
3,1 vezes o diâmetro alveolar C. klugii Friese

8. Pilosidade ferrugínea ou esbranquiçada e curta no disco do T2; amarelo-palha-esbranquiçada na laterais do $\mathrm{T} 1$

Pilosidade preta, longa e ramificada no disco do $\mathrm{T} 2$ e laterais do T1

9. Placa basitibial secundária com declive acentuado no bordo posterior e bordo apical arredondado (Fig. 61). Pilosidade preta na metade inferior do lóbulo pronotal. Distância interocelar 2,3-2,4 vezes o diâmetro do ocelo médio C. tricolor Friese

Placa basitibial secundária com declive suave no bordo posterior e bordo apical quase reto (Fig. 60). Pilosidade do lóbulo pronotal inteiramente amarelo-palha. Distância interocelar 2,1 vezes o diâmetro do ocelo médio . C. mourei Roig-Alsina

10. Área malar longa, comprimento 0,3 vezes a largura da base da mandíbula. Clípeo com pontuação fina-moderada, cerrada-densa; carena mediano-longitudinal lisa estreita, com cerca de $0,4 \mathrm{~mm}$ de largura. Largura da cabeça: 4,6-4,8 mm. Distância ocelocular 1,7-1,9 vezes o diâmetro do ocelo médio. Distância alveolocular 2,3-2,5 vezes o diâmetro do alvéolo da antena

C. cordillerana Roig-Alsina

Área malar curta, comprimento $0,1-0,2$ vezes a largura da base da mandíbula. Clípeo com pontuação fina, dispersa-esparsa; larga faixa mediano-longitudinal lisa e brilhante (às vezes um pouco enrugada devido à preservação). Largura da cabeça: 5,1-5,2 mm. Distância ocelocular 1,5-1,6 vezes o diâmetro do ocelo médio. Distância alveolocular 1,7-2,0 vezes o diâmetro do alvéolo da antena .....

C. lyngbyei Jensen-Haarup

11. Fímbrias pré-pigidial e pigidial ferrugíneo-claras. T1 a T4 pretos, ás vezes o terço apical do T4 com suave tom avermelhado. Faixa mediano-longitudinal do clípeo lisa e brilhante C. flavohirta Friese

Fímbrias pré-pigidial e pigidial pretas a castanhas, quando muito com suave tom ferrugíneo. T1 a T3 pretos. T4 preto ou com terço apical ou inteiramente vermelhoferrugíneo. Faixa mediano-longitudinal do clípeo lisa ou com várias microcarenas ou com uma suave carena mediana 12

12. T4 vermelho-ferrugíneo. Pilosidade preta no escutelo e às vezes também na metade posterior do mesoscuto ........ C. caelebs Friese

T4 inteiramente preto ou apenas com o terço apical suavemente avermelhado. Pilosidade amarelo-palha no mesoscuto e escutelo ....C. unifasciata (Schrottky)

\section{Machos}

1. Segundo dente subapical das mandíbulas subquadrangular, com o bordo apical côncavo (Figs. 98, 101). Disco do clípeo finamente enrugado, sem brilho ....................... 2

Segundo dente subapical das mandíbulas triangular ou quando subquadrangular, com o bordo apical reto (Figs. 97, 102). Disco do clípeo liso e brilhante ou ao menos com uma faixa mediano-longitudinal lisa (às vezes pode estar um pouco enrugado devido à preservação).

2. Disco do clípeo e do labro amarelos. Tergos metassomáticos pretos.... C. neffi Moure

Clípeo e labro inteiramente pretos. T5 a T7 vermelhoferrugíneos C. toroi sp. nov.

3. T1, T2 e metade basal do T3 pretos, com pilosidade preta, longa e plumosa. Metade apical do T3 e tergos metassomáticos apicais ferrugíneos, com pilosidade ferrugínea, longa e plumosa ......C. euphenax Cockerell Metassoma inteiramente preto .................................................. 4 Metassoma inteiramente vermelho-ferrugíneo ..................... 9

4. Pilosidade do mesoscuto preta .............................................. 5

Pilosidade do mesoscuto amarelo-palha, esbranquiçada ou não ... 6

5. Espécimens maiores, largura da cabeça entre 5,6 e 6,3 mm. Tegumento inteiramente preto. Membrana das asas castanho-escura C. burgdorfi Friese

Espécimens menores, largura da cabeça entre 4,9 e 5,2 mm. Disco do clípeo e do labro amarelos. Membrana das asas quase hialina, com um suave tom méleo

C. nigerrima (Spinola)

6. Pilosidade plumosa, longa e esbranquiçada cobrindo todo o corpo. Disco do clípeo e do labro de cor amarelo pálida. Membrana das asas quase hialinas, com um suave tom méleo C. flavohirta Friese

Pilosidade preta ao menos nas pernas e metassoma. Cor do disco do clípeo e da membrana das asas variável ..... 7

7. Membrana das asas castanha, escura. Labro e clípeo inteiramente pretos. Mandíbula curta e robusta, seu comprimento 1,5 vezes a largura na base, em vista lateral. Largura da cabeça entre 5,6 e 6,3 mm.

C. burgdorfi Friese

Membrana das asas quase hialina, com um suave tom méleo. Disco do clípeo e do labro amarelos. Mandíbula longa, seu comprimento 1,9-2,2 vezes a largura na base, em vista lateral. Largura da cabeça entre 4,5 e 4,9 mm .... 8

8. S8, ápice da projeção apical estreito e com lados paralelos (Fig. 138) .C. unifasciata (Schrottky) 


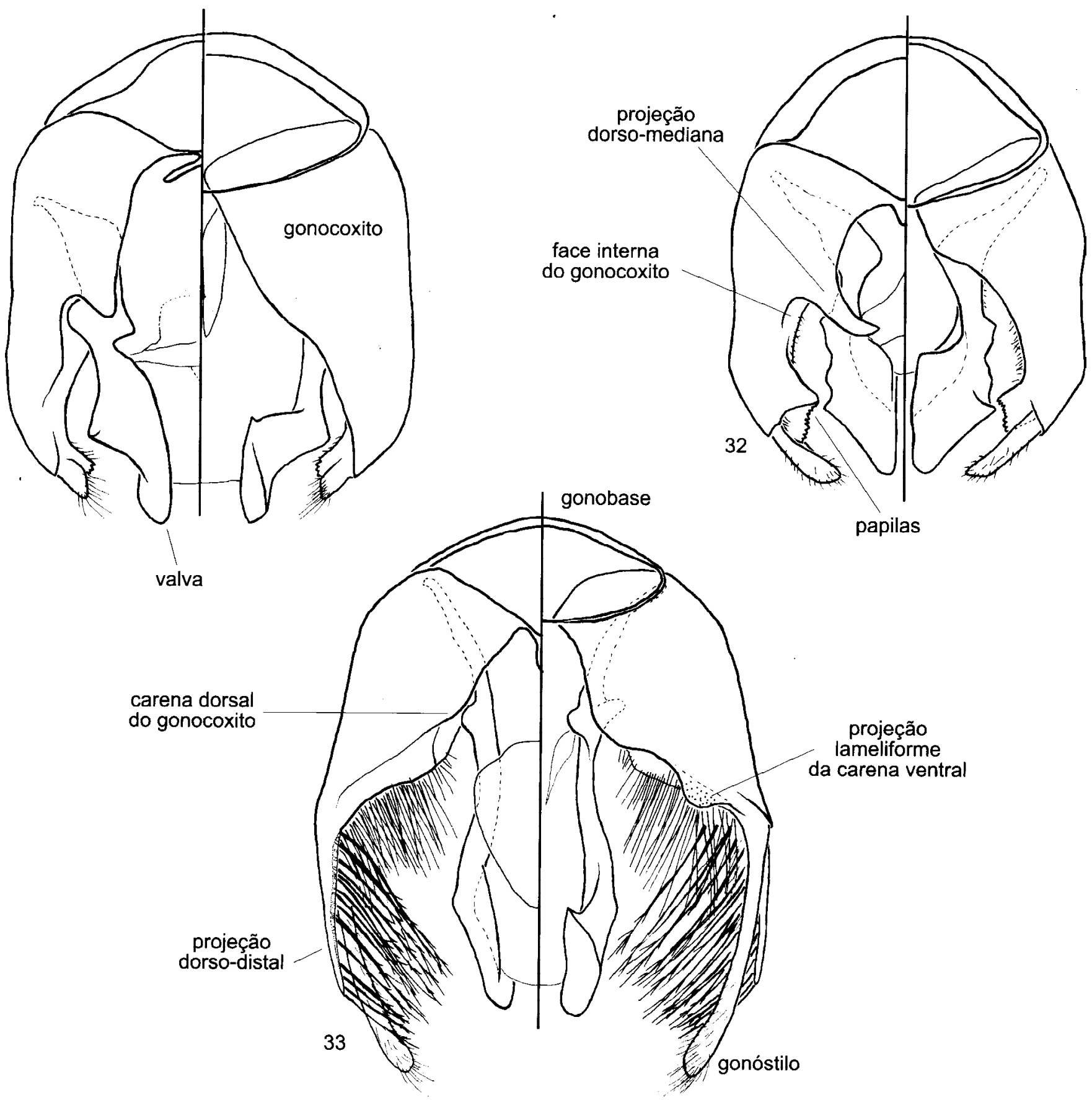

Figs. 31-33. Cápsula genital, macho, vistas dorsal e ventral. 31, Centris (Trachina) fuscata; 32, C. (Wagenknechtia) moldenkei; 33, C. (Centris) leprieuri. 
S8, ápice da projeção apical largo, com lados convergentes (Fig. 130) C. caelebs Friese

9. T2 com pilosidade ferrugínea, não ramificada, geralmente curta. Olhos quase paralelos, DIOS/DIOI = 0,99-1,03

T2 com pilosidade preta, longa e plumosa. Olhos divergentes para baixo, DIOS/DIOI $=0,8-0,9$, ou quase paralelos em C. klugi, DIOS/DIOI = 0,9-1,0, mas nesse caso a pilosidade da cabeça, mesossoma e pernas, clara, esbranquiçada 11

10. Labro e clípeo inteiramente pretos ..... C. mourei Roig-Alsina Disco do labro e do clípeo amarelos ... C. tricolor Friese

11. Pilosidade amarelo-palha-esbranquiçada em praticamente toda a cabeça e mesossoma (ás vezes com cerdas escuras nas paroculares, fronte e genas) ................ 12

Pilosidade escura, preta ou castanha, na região ventral do mesossoma e na cabeça (quando com pêlos claros, somente no vértice e labro) 13

12. Olhos divergentes para baixo, DIOS/DIOI $=0,8-0,9$. Pilosidade castanho-escura a preta nas pernas médias e posteriores. Comprimento das mandíbulas igual à 2,1 vezes a largura da base, em vista lateral. S7, projeção apical larga e truncada no ápice (Fig. 115) ... C. vogeli Roig-Alsina

Olhos quase paralelos, DIOS/DIOI $=0,9-1,0$. Pilosidade esbranquiçada nas pernas médias e posteriores. Comprimento das mandíbulas igual à 1,7 a 1,8 vezes a largura da base, em vista lateral. S7, projeção apical estreita e arredondada no ápice (Fig. 110)

C. klugii Friese

13. Área malar longa, comprimento igual à 0,3 vezes a largura da base da mandíbula, em vista lateral. Metassoma com pilosidade longa, com cerca de $0,7 \mathrm{~mm}$ de comprimento no disco do T2. Espécimens menores, largura da cabeça entre 4,3 e 4,5 mm. S7, projeção apical estreita (Fig. 117)

C. cordillerana Roig-Alsina

Área malar curta, comprimento igual à $0,1-0,2$ vezes a largura da base da mandíbula, em vista lateral. Metassoma com pilosidade mais curta, com cerca de $0,4-0,5 \mathrm{~mm}$ de comprimento no disco do T2. Espécimens maiores, largura da cabeça entre 5,0 e $5,1 \mathrm{~mm}$. S7, projeção apical larga (Fig. 111) ......... C. lyngbyei Jensen-Haarup

As espécies sul-americanas do subgênero C.(Paracentris)

Centris (Paracentris) burgdorfi Friese, 1901

(Figs. 41, 62, 72, 87, 109, 127, 145, 158)

Centris burgdorfi Friese, 1901: 346-347.

Centris burgdorfi paraguayensis Friese, 1901: 347; Roig-Alsina, 2000: 185 (sinonímia).
Hemisia burgdorfi ocellata Schrottky, 1908: 139-140; Roig-Alsina, 2000: 185 (sinonímia).

Centris (Paracentris) paraguayensis; Wittmann \& Hoffman, 1990: 21. Centris (Paracentris) burgdorfi; Roig-Alsina, 2000: 185.

Redescrição

Lectótipo, macho. Dimensões (mm). Comprimento total 15,0 $(18,4)$; largura da cabeça 5,63 (5,60-6,27); comprimento da cabeça 3,41 (3,29-3,96); largura do mesossoma, incluindo tégulas, 6,55 (6,46-7,31); comprimento da asa, do esclerito costal ao ápice, $12,97(14,71)$.

Tegumento. Predominantemente preto. Castanho-escuro nas pernas. Membrana das asas castanha, semi-translúcida. Clípeo com faixa mediano-longitudinal sem pontos, um pouco enrugada, provavelmente devido à preservação (lisa em outros exemplares); pontuação alveolada, moderada, cerrada-esparsa.

Pilosidade. Predominantemente preta. Castanho-escura nos mesepisternos, parte das pernas e região apical dos T4, 5 e 6 . (em indivíduos coletados mais recentemente a coloração da pilosidade é quase que uniformemente preta).

Forma e proporções. Olhos levemente divergentes em baixo, DIOS 2,42, DIOI 2,52 (2,33:2,52-2,54:2,66). Distância ocelocular 1,04-1,49 vezes o diâmetro do ocelo médio, $0,55: 0,37(0,44: 0,42$ $-0,52: 0,41)$. Distância interocelar $\mathbf{1 , 7 1 - 1 , 8 4}$ vezes o diâmetro do ocelo médio, $0,65: 0,37(0,70: 0,38$ - 0,72:0,42). Distância entre alvéolos antenais 2,44-2,69 vezes o diâmetro alveolar, 0,89:0,34 $(0,88: 0,36-0,97: 0,36)$. Distância alveolocular $1,00-1,12$ vezes o diâmetro alveolar, 0,38:0,34 (0,36:0,36). Escapo 1,06-1,15 vezes mais longo que o primeiro flagelômero, 1,08:0,98 (1,18:1,03). Primeiro flagelômero um pouco menor ou igual aos três seguintes juntos, $0,98: 1,01(1,08: 1,08)$. Comprimento da área malar 0,09-0,12 vezes a largura da mandíbula, $0,13: 1,10$ $(0,11: 1,22)$. Mandíbula um pouco gasta, seu comprimento 1,501,53 vezes a largura da base, $1,68: 1,10(1,87: 1,22)$. Parte da segunda abcissa de $\mathrm{M}$, anterior à $1 \mathrm{a} \mathrm{m}-\mathrm{cu}, 0,36-0,42$ vezes o seu comprimento total, $0,38: 1,08(0,43: 1,20)$.

Esternos pré-genitais e genitália. Figs. 109, 127 e 145.

Fêmea. Diagnose. Comprimento total, 15,2-19,8. Largura da cabeça, 5,88-6,27. Tegumento inteiramente preto a castanhoescuro. Membrana das asas castanha, semi-translúcida. Clípeo com pontuação alveolada, moderada-muito grossa, subcontígua-esparsa. Tegumento liso e brilhante entre os pontos, faixa mediana longitudinal e bordo apical lisos e brilhantes. Pilosidade predominantemente preta, no mesoscuto, preta ou amarelo-palha. Olhos um pouco convergentes para baixo, DIOS:DIOI 3,11:2,95 - 3,35:3,04. Distância ocelocular 2,12-2,30 vezes o diâmetro do ocelo médio, $0,85: 0,40-0,92: 0,40$. Distância interocelar cerca de 1,97-2,16 vezes o diâmetro do ocelo médio, 0,79:0,40 - 0,82:0,38. Comprimento do escapo igual ou um pouco maior do que o primeiro flagelômero, 1,22:1,22 $-1,27: 1,21$. Comprimento da área malar $0,11-0,12$ vezes a largura da mandíbula, $0,14: 1,27-0,16: 1,34$. Comprimento da mandíbula 1,56 a 1,68 vezes a largura de sua base, 2,21:1,42-2,26:1,34. Segundo dente subapical pequeno (Fig. 41).

Tipos. Lectótipo, macho, aqui designado, com as seguintes 


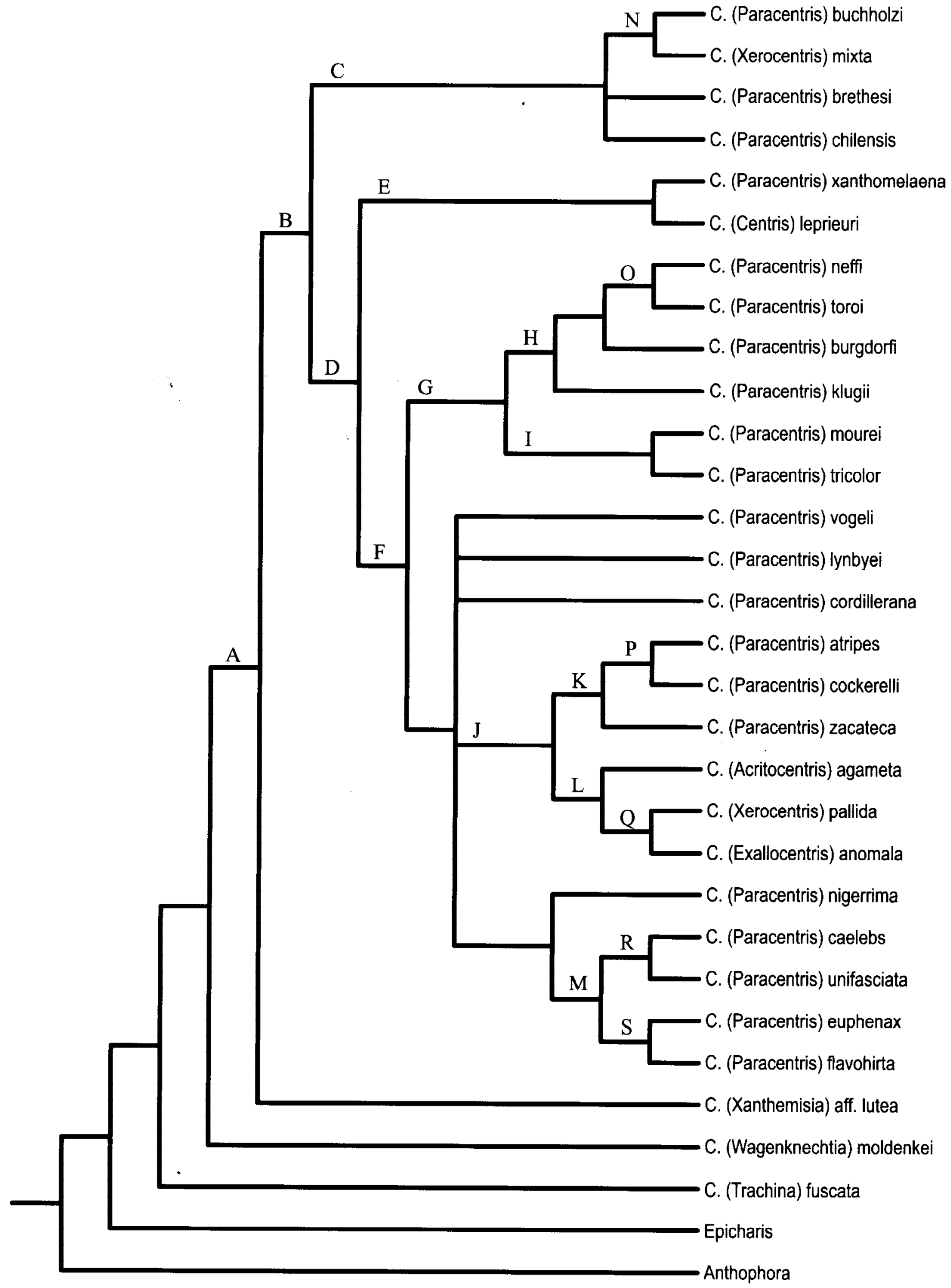

Fig. 34. Relações filogenéticas internas do grupo Centris. Consenso estrito dos cladogramas obtidos nas análises realizadas com pesos iguais. Os subgêneros das espécies de Centris estão indicados de acordo com Snelling (1984) e Ayala (1998), para demonstrar o caráter parafilético de Paracentris, no escopo dado por esses autores. Os nós presentes nos resultados de todas as análises estão identificados com letras maiúsculas. 
etiquetas: "Paraguay, Villa Rica, 1900, Burgdorf”, "Centris burgdorfi Fr., macho (símbolo), 1904 Friese det." (etiqueta manuscrita com ano e "Friese det." impressos), "Type" (etiqueta vermelho escuro), "Coll. Friese", “Zool. Mus. Berlin” e "LECTOTYPE, Centris burgdorfi Friese, F. Zanella, 2002" (etiqueta amarela)(MNHU). FrIESE (1901) menciona mais um macho e duas fêmeas na descrição original, da mesma localidade, coletor e ano de coleta. Dentre o material recebido do Museu de Berlim, há uma fêmea com etiqueta de coleta semelhante à do lectótipo e com uma etiqueta de identificação, onde consta: "C. burgdorfi paraguayensis". No entanto, essa fêmea não deve pertencer à série-tipo dessa subespécie, pois, segundo FRIESE (1901), o tipo de C. burdorfi paraguayensis é um macho. Além disso, conforme a sua descrição, a pilosidade do mesoscuto é amarela; mas, no espécimen em questão, é predominantemente preta, tendo apenas dois tufos de pêlos amarelos na parte anterior. A designação do lectótipo para Centris burgdorfi Friese estabelece de forma definitiva a identidade da espécie, tendo em vista a variabilidade na coloração da pilosidade, que levou Friese (1901) e SCHROTTKY (1908) a proporem subespécies distintas.

Comentários. Friese (1901) descreveu como subespécie distinta a forma com pilosidade amarela no mesonoto e SchrotTKy (1908) descreveu, também, como subespécie distinta, exemplares com pilosidade predominantemente preta e dois tufos de pelos amarelos. Roig-Alsina (2000), ao estudar uma série de fêmeas de um mesmo agregado de ninhos em Ituzaingó, Corrientes, Argentina, verificou a ocorrência de todas as três formas de padrões de coloração, propondo a sinonímia entre as subspécies.

Distribuição geográfica. Leste da América do Sul, no Paraguai, nordeste da Argentina e no Brasil, do Ceará ao Rio Grande do Sul (Fig. 158). Os espécimens coletados no Rio Grande do Sul apresentam a pilosidade do mesonoto amarela e alguns dos exemplares de Villarica, Paraguay, apresentam estados intermediários no padrão de coloração da pilosidade, sendo predominantemente preta, com dois tufos de pêlos amarelos, ou predominantemente amarela, com um tufo preto. RoIG-Alsina (2000) coletou em Ituzaingo, Corrientes, Argentina, uma série de fêmeas com pilisodade preta ou amarela no mesoscuto e formas intermediárias. A ocorrência de $C$. burgdorfi na Caatinga deve ser melhor verificada, pois, em uma das localidades onde foi coletada no nordeste do Brasil (Ceará: Barbalha), existe um enclave de floresta úmida e em vários levantamentos realizados em áreas de vegetação de caatinga esta espécie não foi coletada.

Material adicional examinado. BRASIL. Ceará: 7 F, Barbalha, V/ 1969, M. Alvarenga leg. (AMNH). Pernambuco: 1 F e 2 M, Petrolina, idem, idem (AMNH). Goiás: $1 \mathrm{~F}$, São Antônio do Descoberto [sic] (=Santo Antônio do Descoberto, 912m), 11/II/1977, idem (CTMI), idem. Distrito Federal: $3 \mathrm{M}$, Serra do Contagem [sic] (=Chapada do Contagem), 14/II/1977, J. L. Neff leg. (CTMI), sendo um em Lupinus sp. e outro em Sphaeralcea sp. 1 F, de mesmo local, data e coletor (CTMI), em Krameria latifolia. Minas Gerais: 1 F, Belo Horizonte, 1-6/ XI/1919, R. G. Harris leg. (CUIC). 1 F, Belo Horizonte, Pq. Mangabeiras,
12/XI/1996, J. Damasceno leg. (UFMG). 1 F, Sabará, Clube A. Scharlé, 29/IX/1996, F. Silveira leg. (UFMG). São Paulo: 1 F, Luiz Antônio, E. E. Jataí, 22/III/1999, 9-10h, M. C. Gaglianone leg. (CFZ), em Stigmaphylum lalandianum. Paraná: 1 F, Vila Velha, 31/I/1974, Rozen \& Thompson leg. (AMNH). Rio Grande do Sul: 1 F, Rosário do Sul, 29/ XI/1985, J. R. Cure leg. (MCNZ) em Labiatae. $1 \mathrm{M}$, Alegrete, 25/XI/ 1985, idem (MCNZ). PARAGUAI. Central: 1 M, Asunción, 5/I/1920, s. c. (CUIC). Guairá: $1 \mathrm{M}$, Villa Rica, 1900, Burgdorf leg. (SMNH). $1 \mathrm{~F}$, Villa Rica, 1900, Burgdorf leg. (MNHU). $1 \mathrm{~F}$ e $2 \mathrm{M}$, com etiquetas semelhantes (NHMW). $1 \mathrm{~F}$ e 1M, Villarica, 1900, Burgdorf leg. (AMNH).

Centris (Paracentris) caelebs Friese, 1900

(Figs. 47, 63, 78, 93, 112, 130, 148, 159)

Centris caelebs Friese, 1900: 47; 1901: 324.

Paracentris fulvohirta Cameron, 1903: 236. Syn. nov.

Centris (Paracentris) fulvohirta; Moure, 2000 [1999]: 151 (lectótipo).

\section{Redescrição}

Lectótipo, fêmea. Dimensões (mm). Comprimento total 15,0 (14,5-15,3); largura da cabeça 5,12 (4,96-5,27); comprimento da cabeça $3,23(3,35)$; largura do mesossoma, incluindo tégulas, $6,76(6,58-6,88)$; comprimento da asa, do esclerito costal ao ápice, 12,02 (11,39).

Tegumento. Vermelho-ferrugíneo nos T4 a 6 e nos S5 e 6. Preto a castanho-escuro no restante. Membrana das asas translúcida com um suave tom méleo. Placa pigidial preta, ao menos na metade apical. Clípeo com faixa mediano-longitudinal lisa e brilhante (em um dos outros exemplares, um pouco enrugada).

Pilosidade. Amarelo-palha-esbranquiçada na cabeça e metade anterior do mesoscuto; nas genas entremeada com longas cerdas castanho-escuras. Preta a castanho-escura no restante, incluindo a dos lóbulos pronotais e dos tergos e esternos avermelhados. Fímbrias pigidial e pré-pigidial castanhas (em outros exemplares, escura), com um suave tom ferrugíneo. Preta, semi-erecta e ramificada no disco do T2.

Forma e proporções. Distância interocular superior 0,930,95 vezes a inferior, $2,74: 2,88$ (2,57:2,76 - 2,72:2,84). Distância ocelocular 1,55-1,63 vezes o diâmetro do ocelo médio, $0,62: 0,38$ $(0,59: 0,37-0,62: 0,40)$. Distância interocelar 2,22-2,39 vezes o diâmetro do ocelo médio, 0,89:0,38 (0,89:0,40 - 0,91:0,38). Distância entre alvéolos antenais 3,25-3,66 vezes o diâmetro alveolar, 1,03:0,30 (1,01:0,31 - 1,06:0,29). Distância alveolocular 2,12-2,33 vezes o diâmetro alveolar, 0,70:0,30 (0,66:0,31). Comprimento do escapo $0,93-0,96$ vezes o do primeiro flagelômero, 1,03:1,09 (1,10:1,18 - 1,10:1,15). Primeiro flagelômero 1,37-1,47 vezes mais longo que os três seguintes juntos, 1,09:0,74 (1,18:0,86). Comprimento da área malar 0,210,22 vezes a largura da mandíbula, 0,22:1,03 (0,24:1,08). Comprimento da mandíbula $2,10-2,15$ vezes a largura da base, $2,21: 1,03(2,23: 1,06)$. Célula marginal 3,28-3,52 vezes mais longa que larga, 2,06:0,59 (2,10:0,64-2,18:0,62). Parte da segunda abcissa de $\mathrm{M}$, anterior à $1 \mathrm{a} \mathrm{m}-\mathrm{cu}, 0,40-0,49$ vezes o seu comprimento total, $0,40: 1,00(0,49: 1,00)$.

Paralectótipo, macho. Dimensões (mm). Comprimento total 13,3 (15,4); largura da cabeça 4,69 $(4,81)$; comprimento da cabeça 2,86 (3,05); largura do mesossoma, incluindo tégulas, 6,39 (6,58); 


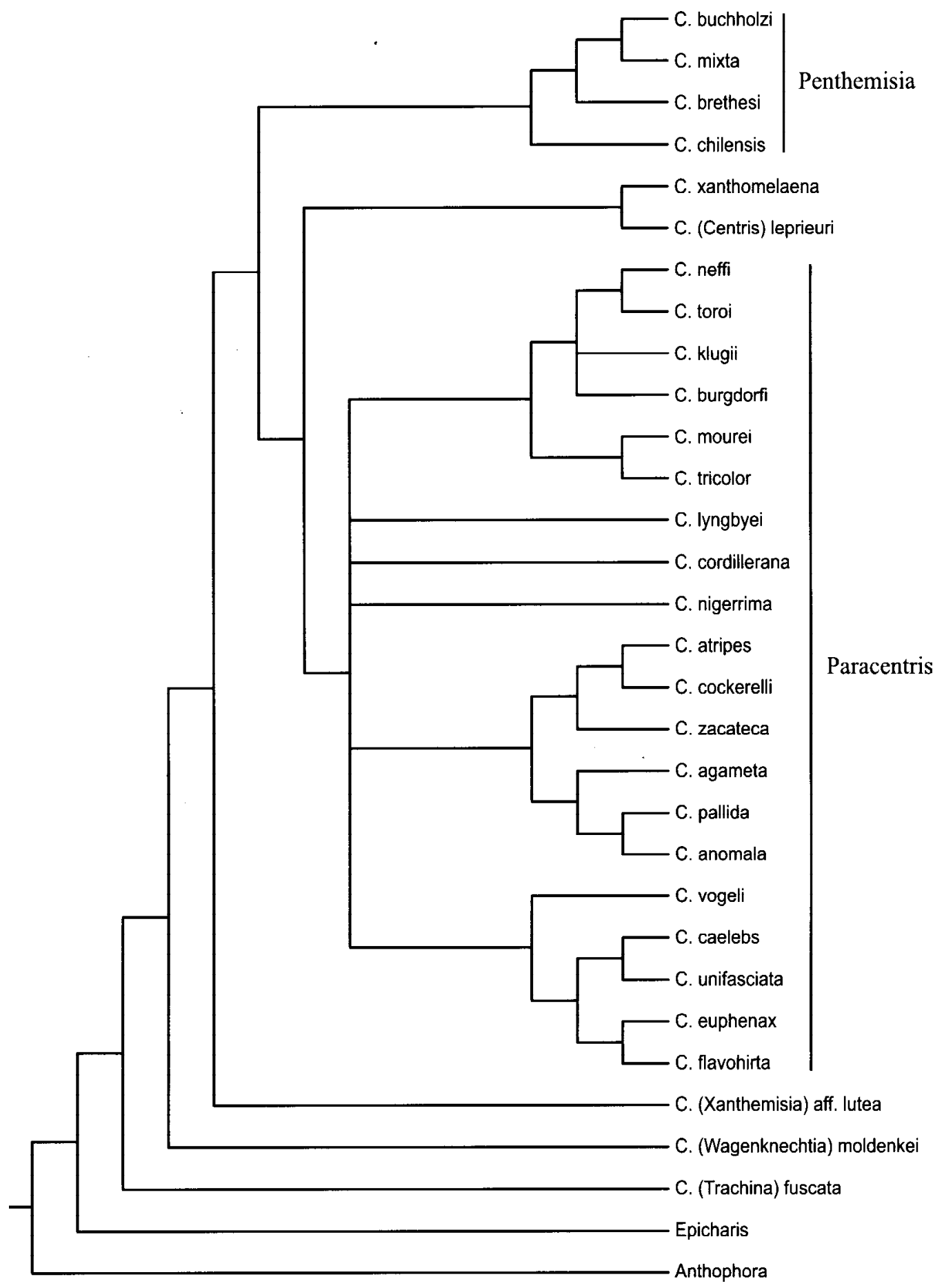

Fig 35. Relações filogenéticas internas do grupo Centris. Consenso estrito dos cladogramas obtidos nas análises realizadas com pesagem implícita. Os subgêneros Penthemisia e Paracentris estão representados conforme as propostas de modificações na sistemática do gênero feitas neste trabalho. 
asa gasta, comprimento do esclerito costal ao ápice $(11,63)$.

Tegumento. Amarelo no disco do clípeo e do labro. Preto no restante. Tergos metassomáticos com brilho verde-azulado. Membrana das asas translúcida com um tom castanho-claro. Clípeo com pontuação pilígera fina e esparsa-dispersa nas áreas laterais; faixa mediano-longitudinal lisa e brilhante, com largura aproximada de 0,53 $\mathrm{mm}$.

Pilosidade. Amarelo-palha no vértice, região dorsal do pronoto, tégulas, mesoscuto, escutelo e laterais do metanoto; tufos nas laterais do T1; tendendo a esbranquiçada no clípeo, área supra-clipeal, lobo pronotal e metade superior do mesepisterno, na metade inferior entremeada compêlos escuros. Esbranquiçada no labro e, nas genas, entremeada com longas cerdas castanhas. Preta e castanho-escura no restante. Preta, longa, semi-erecta e ramificada no disco do T2.

Forma e proporções. Distância interocular superior 0,77$\mathbf{0 , 8 0}$ vezes a inferior, $1,87: 2,33(1,82: 2,36)$. Distância ocelocular 0,75-0,78 vezes o diâmetro do ocelo médio, $0,31: 0,40(0,30: 0,40)$. Distância interocelar 1,80 vezes o diâmetro do ocelo médio, 0,72:0,40. Distância entre alvéolos antenais 2,87-2,97 vezes o diâmetro alveolar, 0,86:0,29 (0,86:0,30). Distância alveolocular 1,03-1,07 vezes o diâmetro alveolar, 0,30:0,29 (0,32:0,30). Comprimento do escapo $0,94-0,96$ vezes o do primeiro flagelômero, 0,94:0,98(0,95:1,01). Primeiro flagelômero 1,23-1,32 vezes mais longo do que os três seguintes, $0,98: 0,74(1,01: 0,82)$. Comprimento da área malar $0,12-0,13$ vezes a largura da mandíbula, 0,11:0,91(0,12:0,94). Comprimento da mandíbula $\mathbf{1 , 8 6}-\mathbf{1 , 9 2}$ vezes a largura da sua base, $1,75: 0,91(1,75: 0,94)$. Célula marginal 3,41-3,63 vezes mais longa que larga, 1,98:0,58 $(2,18-0,60)$. Parte da segunda abcissa de $M$, anterior à $1 \mathrm{a} \mathrm{m}-\mathrm{cu}$, 0,43-0,46 vezes o seu comprimento total, $0,43: 1,00(0,49: 1,07)$.

Esternos pré-genitais e genitália. S8, ápice largo, com bordos laterais convergentes (Fig. 130). S7 (Fig. 148). Cápsula genital (Fig. 159).

Variação. As fêmeas coletadas no Peru foram tentativamente agrupadas em C. caelebs. Elas diferem do tipo pela pilosidade preta nas genas e amarela em todo o mesoscuto. Em $C$. unifasciata (Schrottky, 1913), uma espécie muito semelhante que ocorre também nos Andes peruanos, chegando até o norte do Chile, a cor da pilosidade das genas é variável e a do escutelo é amarela. As duas espécies apresentam grande variação de tamanho, padrões de coloração da pilosidade e proporções (ver itens forma e proporções) e talvez constituam um complexo de espécies muito semelhantes e difíceis de serem reconhecidas, pelo menos com o limitado número de indivíduos examinados. Como julguei insuficiente o material em mãos para se fazer um estudo mais detalhado, além de fugir ao escopo do presente trabalho, decidi manter as espécies já descritas e apenas chamar a atenção para o problema (ver também nota em C. unifasciata).

Tipos de Centris caelebs. Lectótipo, aqui designado e descrito para evitar confusões no uso do nome, tendo em vista a variação observada. Fêmea, com as seguintes etiquetas: "Cotype" (etiqueta vermelha), "America merid." (etiqueta verde manuscrita), “Centris caelebs n. sp., fềmea (símbolo), det. Friese 1898" (nome da espécie e símbolo do sexo manuscritos", "typus" (etiqueta rosa) e "LECTOTYPE, Centris caelebs Friese, F. Zanella, 2002" (etiqueta amarela) (ZSMC). Paralectótipo, macho, com etiquetas semelhantes às da fêmea, mais uma etiqueta verde pequena com dois números manuscritos e ilegíveis e uma etiqueta amarela "PARALECTOTYPE, Centris caelebs Friese, F. Zanella, 2002" (ZSMC). Segundo FrIESE (1900), esses exemplares foram coletados no Equador por Sichel. Paralectótipo, fêmea, com as seguintes etiquetas: "Colle. P. Magretti, N. America, exColle.Rühl" ("N. America" manuscrito), "Centris caelebs n. sp., fềmea (símbolo), det. Friese 1898" (nome da espécie e notação n. sp. e fêmea manuscritos), "Museo Civico di Genova" e uma etiqueta amarela "PARALECTOTYPE, Centris caelebs Friese, F. Zanella, 2002” (MCSN).

Tipo de Paracentris fulvohirta. Lectótipo, macho, com as seguintes etiquetas: "Type”, "B. M. TYPE HYM., 1//3. 904." (data manuscrita), "Paracentris fulvohirta Cam. Type, Ecuador" (etiqueta manuscrita), "Machachi, Ecuador, 9-10.000 feet. Ed. Whymper.", "Cameron Coll. 1904-29.", "lectotype fulvohirta Det.J.S.Moure 1957" ("lectotype fulvohirta" e "57" manuscritos) (BNHM).

Distribuição geográfica. Trata-se de uma espécie das regiões altas dos Andes equatorianos (Fig. 159), coletada em altitudes próximas a $3000 \mathrm{~m}$. Há um registro antigo para a região de Guayaquil, no litoral, mas a sua ocorrência próximo ao nível do mar deve ser confirmada. Os registros para o norte do Peru, referem-se a fêmeas com pilosidade preta nas genas e amarela em todo o mesoscuto (ver nota no item "variação").

Material adicional examinado. EQUADOR. Pichincha: $2 \mathrm{~F}, 80 \mathrm{~km}$ NW Quito, 2950m, 1/IV/1989, Camargo leg. (RPSP). Guayas: $1 \mathrm{~F}$, Guayaqil, 1901, Buchwald leg. (NHMW). PERU: 1 F, Valle Llaca, 3300m, 20/V/1941, idem (IMLA). Cajamarca: 3 F, Cajamarca, próximo Cochapampa, 3216m, 25/V/1998, Claus Rasmussen leg. (CCRD). cf. Lima: 1 F, Rio Pativilla (possivelmente Pativilca), 3300-3900m, s. d., W. Weyrauch leg. (IMLA), em Calceolaria.

\section{Centris (Paracentris) cordillerana Roig-Alsina, 2000} (Figs. 99, 117, 135, 152, 161)

Centris (Paracentris) cordillerana Roig-Alsina, 2000: 184-186.

Macho. Diagnose. Comprimento total, 13,1-14,2; largura da cabeça, 4,35-4,51. Tegumento predominantemente preto. Vermelho-ferrugíneo no metassoma [RoIG-Alsina (2000) menciona ter observado um macho com o metassoma preto]. Disco do clípeo e do labro amarelos. Pilosidade predominantemente preta, mais longa que em $C$. tricolor. Amarelo-palha-esbranquiçada na região dorsal do pronoto, incluindo lobo pronotal, mesoscuto, escutelo, laterais do metanoto e parte superior dos pré-episternos; pequenos tufos nas laterais do T1 e uns poucos pêlos no vértice. Preta, longa, com cerca de $0,70 \mathrm{~mm}$, ereta e ramificada no disco do T2. Olhos divergentes para baixo, DIOS:DIOI 2,04:2,50 - 2,16:2,59. Comprimento do escapo 0,87-0,94 vezes o do primeiro flagelômero, 0,82:0,94-0,88:0,94. Primeiro flagelômero 1,27 vezes 


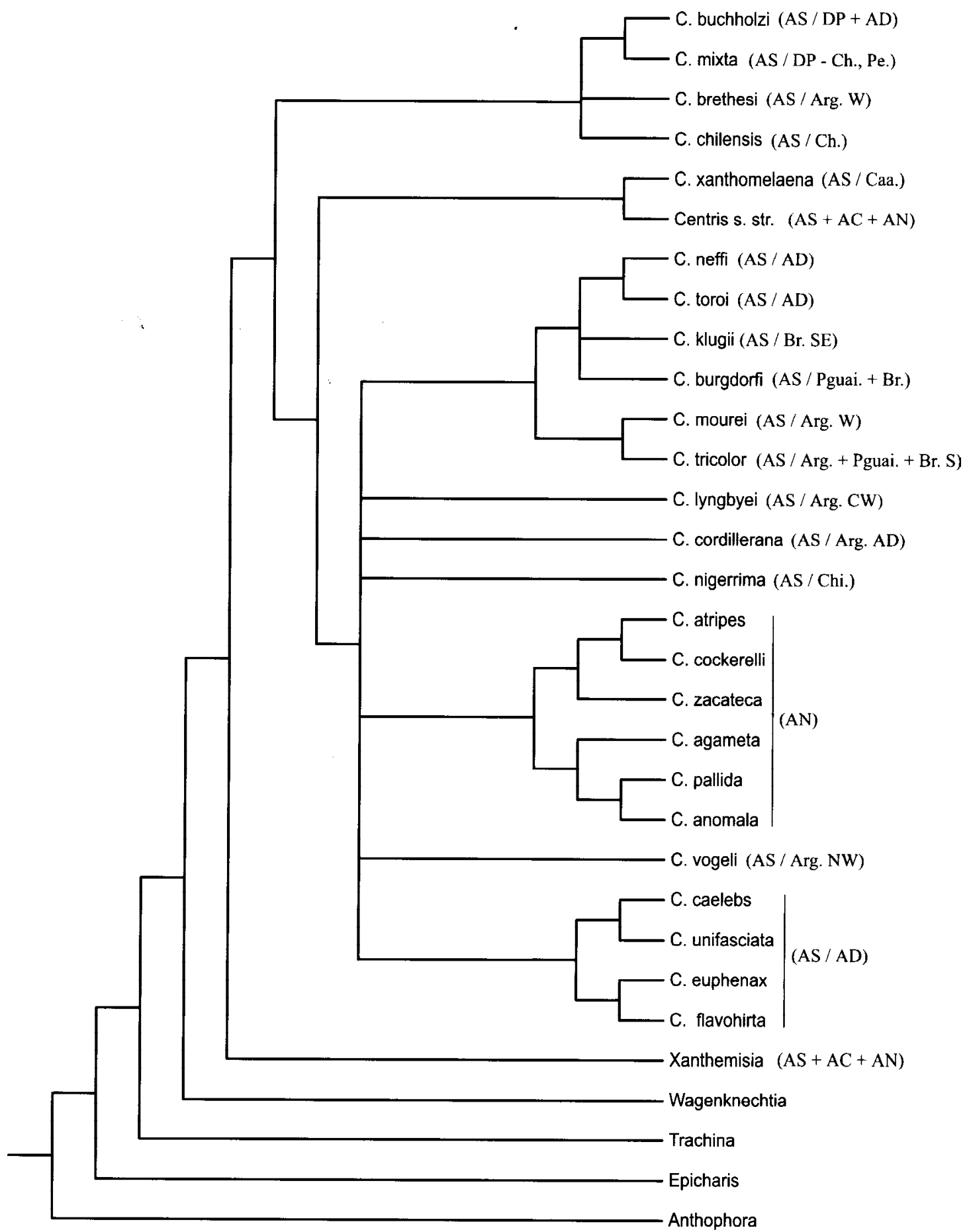

Fig. 36. Relações filogenéticas internas do grupo Centris. Consenso estrito dos cladogramas obtidos em todas as análises realizadas. Abreviações após o nome das espécies: AS - América do Sul; AC - América Central; AN - América do Norte; Arg - Argentina; Chi - Chile; Pguai - Paraguai; Br - Brasil; Pe - Peru; DP - Desertos da costa do Pacífico; AD - Andes; Caa - Caatinga; W - Oeste, S - Sul; SE - Sudeste; NW - Noroeste e CW - Centrooeste. 
mais longo que os três seguintes juntos, 0,94:0,74. Comprimento da área malar 0,27 vezes a largura da mandíbula, 0,22:0,82. Comprimento da mandíbula 2,22-2,28 vezes a largura de sua base, 1,82:0,82-1,87:0,82.

Fêmea. Diagnose. Comprimento total, 13,3-15,0; largura da cabeça, 4,57-4,78. Tegumento predominantemente preto na cabeça e mesossoma. Vermelho-ferrugíneo no metassoma, incluindo a placa pigidial. Clípeo com pontuação alveolada, fina-moderada, cerrada-densa; faixa mediana longitudinal sem pontos com carena suave e largura aproximada de 0,41- 0,44 $\mathrm{mm}$. Pilosidade preta na cabeça e metassoma. No disco do T2, semi-erecta, ramificada e mais longa do que em C. tricolor, com cerca de $0,30 \mathrm{~mm}$ de comprimento. Olhos um pouco divergentes para baixo, DIOS:DIOI 2,57:2,80 - 2,74:2,98. Distância ocelocular 1,74-1,86 vezes o diâmetro do ocelo médio, 0,60:0,35-0,70:0,37. Distância interocelar cerca de 2,34 vezes o diâmetro do ocelo médio, 0,82:0,35 - 0,89:0,38. Distância alveolocular 2,31-2,48 vezes a o diâmetro alveolar, 0,67:0,290,72:0,29. Primeiro flagelômero 1,32 vezes mais longo que os três seguintes juntos, 0,98:0,74. Comprimento da área malar 0,26-0,27 vezes a largura da mandíbula, 0,24:0,91-0,25:0,92. Comprimento da mandíbula 2,42 vezes a largura de sua base, 2,23:0,92.

Tipos. Holótipo, fêmea, de Mina Aguilar, Jujuy, Argentina, $4500 \mathrm{~m}$ de altitude (MACN), e parátipos, machos e fêmeas, de Jujuy, Tucumán e Mendoza (não examinados).

Distribuição geográfica. No noroeste da Argentina, em locais de grande altitude (Fig. 161). Roig-Alsina (2000) cita sua ocorrência nas províncias de Jujuy, San Juan e Mendoza, com registros em locais de 2900 a $4800 \mathrm{~m}$ de altitude.

Material examinado. ARGENTINA. Jujuy: 1 F, El Aguilar, 4500m, 12/I/1972, D. J. Brothers leg. (SEMK). Catamarca: 1 F, C. Minas Capillitas, 3000m, 18/II/1973, J. L. Neff leg. (CTMI), em Solanum. 1 M, ibidem, 19/XII/1972, idem (CTMI). Tucumán: $1 \mathrm{M}$, El infernillo, 3000m, 17/XII/1973, idem (CTMI), em Astralagus.

\section{Centris (Paracentris) euphenax Cockerell, 1913}

(Figs. 94,113, 131, 160)

Centris euphenax Cockerell, 1913: 109-110.

\section{Redescrição}

Holótipo, macho. Dimensões (mm). Comprimento total 14,8; largura da cabeça 4,98; comprimento da cabeça 3,48; largura do mesossoma, incluindo tégulas, 6,89; comprimento da asa, do esclerito costal ao ápice, 11,88.

Tegumento. Preto na cabeça, mesossoma, pernas, T1 e 2, $\mathrm{S} 1$ e 2 e metade basal do T3 e S3. Disco do labro e do clípeo amarelo claro. Tergos e esternos apicais ferrugíneos (T4-7 e S4-6). Faixa apical do T3 e S3 também ferrugínea. Tergos com bordos apicais translúcidos. Membrana das asas translúcida com um suave tom castanho. Clípeo liso e brilhante no disco.
Pilosidade. Longa. Preta na cabeça, incluindo a das áreas amarelas do labro e clípeo, no mesossoma, pernas e nos tergos e esternos metassomáticos pretos. Ferrugínea nos tergos e esternos apicais (T4-7 e S4-6).

Forma e proporções. Olhos divergentes para baixo, DIOS 2,24, DIOI 2,84. Distância ocelocular 1,10 vezes o diâmetro do ocelo médio, 0,44:0,40. Distância interocelar 1,85 vezes o diâmetro do ocelo médio, 0,74:0,40. Distância entre alvéolos antenais 3,25 vezes o diâmetro alveolar, 1,04:0,32. Distância alveolocular 1,47 vezes o diâmetro alveolar, 0,47:0,32. Flagelômero basal 1,14 vezes mais longo que os três seguintes juntos, 1,16:1,02. Comprimento da área malar 0,25 vezes a largura da mandíbula, $0,25: 1,02$. Comprimento da mandíbula 1,98 vezes a largura de sua base, 2,02:1,02. Palpo maxilar com cinco artículos. Parte da segunda abcissa de $\mathrm{M}$, anterior à $1 \mathrm{a} \mathrm{m-cu,} 0$, 35 vezes o seu comprimento total, 0,38:1,08.

Esternos pré-genitais. Figs. 113, 131.

Fêmea. Não conhecida.

Tipo. Holótipo, macho, com as seguintes etiquetas manuscritas: "Pachacayo. Peru. March.27, over 12000 p, CHT Towsend.", "Centris euphenax Ckll. TYPE"e "ac33337" (AMNH). Pela descrição de Cockerell, é possível supor que não há mais exemplares na série-tipo.

Centris (Paracentris) flavohirta Friese, 1900

(Figs. 48, 64, 79, 95, 114, 132, 149, 160)

Centris flavohirta Friese, 1900: 47; 1901: 324.

Centris autrani Vachal, 1904: 16. Roig-Alsina, 2000: 186 (sinonímia). Centris (Paracentris) flavohirta; Moure, 2000 [1999]: 150; Roig-Alsina, 2000: 186

\section{Redescrição}

Holótipo, macho. Dimensões (mm). Comprimento total 12,7 $(15,2)$; largura da cabeça 4,45 (4,75); comprimento da cabeça 3,17 (2,92); largura do mesossoma, incluindo tégulas, 6,15 (6,39); comprimento da asa, do esclerito costal ao ápice, 10,44 (11,07).

Tegumento. Predominantemente preto. Creme no disco do labro e do clípeo. Castanho nas pernas. Tergos metassomáticos com brilho metálico verde-azulado e bordo apical translúcido. Membrana das asas hialina. Clípeo liso e brilhante na parte plana frontal.

Pilosidade. Amarelo-palha-esbranquiçada cobrindo todo o corpo. Mais clara no labro, clípeo, fronte, genas e regiões laterais e ventral do mesossoma. Entremeada com longas cerdas escuras nas paroculares, genas e fronte, acima dos alvéolos antenais.

Forma e proporções. Olhos divergentes para baixo, DIOS 2,11, DIOI 2,62 (2,06:2,54-2,17:2,62). Distância ocelocular 1,051,23 vezes o diâmetro do ocelo médio, $0,43: 0,35(0,38: 0,36)$. Distância interocelar 2,00-2,19 vezes o diâmetro do ocelo médio, 0,70:0,35 (0,79:0,36). Distância entre alvéolos antenais 3,143,31 vezes o diâmetro alveolar, 0,91:0,29 (0,96:0,29). Distância alveolocular 1,27-1,38 vezes o diâmetro alveolar, 0,40:0,29 $(0,38: 0,30)$. Comprimento do escapo $\mathbf{0 , 7 8 - 0 , 8 9}$ vezes o do 


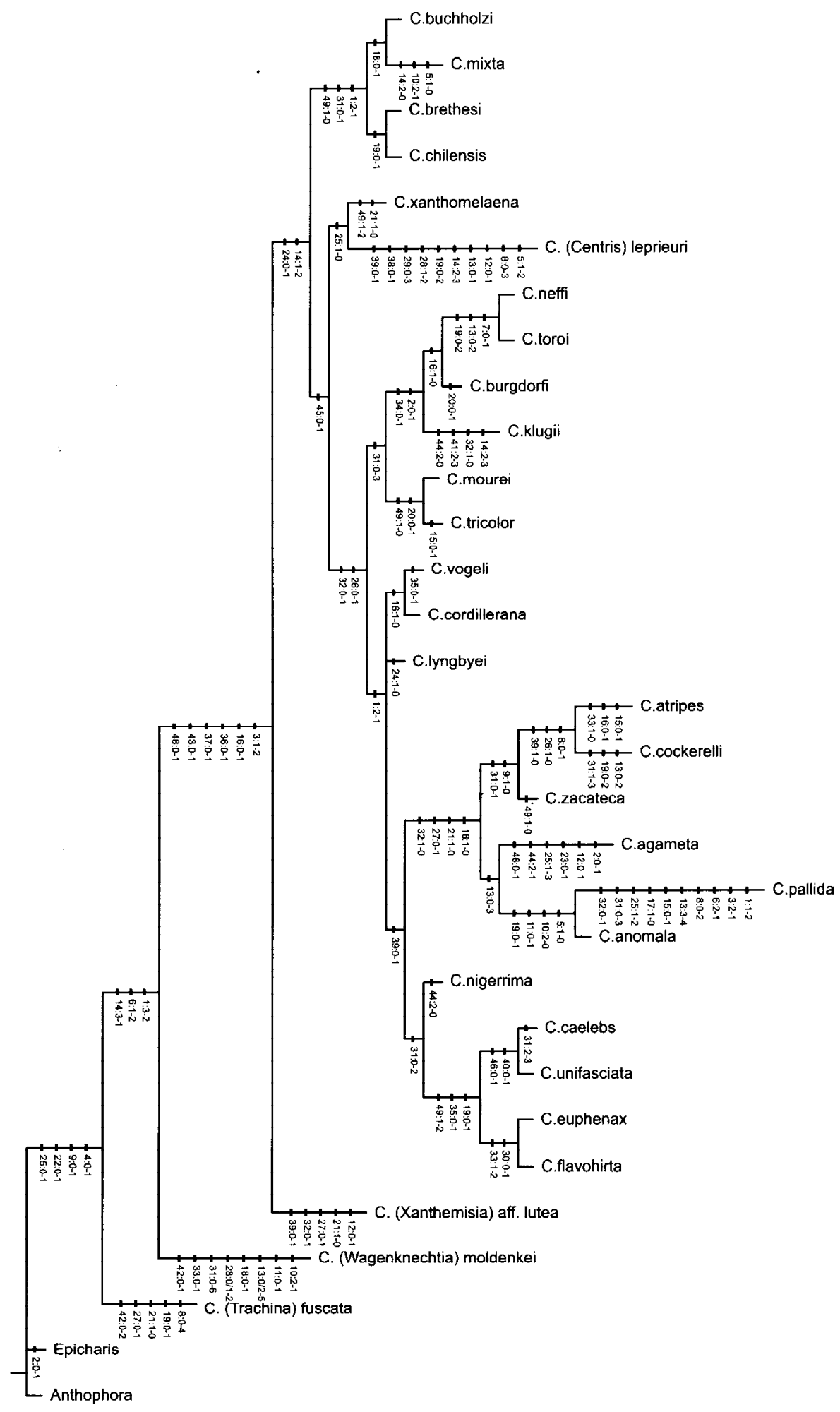

Fig. 37. Relações filogenéticas internas do grupo Centris. Um dos cladograma mais parcimoniosos produzidos na análise com pesos iguais. Somente estão plotados os caracteres cuja otimização não é ambígua. 
primeiro flagelômero, $0,91: 1,08(0,92: 1,17-1,01: 1,13)$. Primeiro flagelômero 1,05-1,19 vezes mais longo que os três seguintes juntos, 1,08:0,96 (1,13:1,08 - 1,17:0,98). Comprimento da área malar 0,15-0,19 vezes a largura da mandíbula, 0,18:0,94 (0,14:0,96 - 0,19:0,98). Comprimento da mandíbula 1,90-1,91 vezes a largura de sua base, 1,80:0,94 (1,87:0,98). Palpo maxilar com cinco artículos. Parte da segunda abcissa de $\mathrm{M}$, anterior à $1 \mathrm{a}$ $\mathrm{m}$-cu, $0,40-0,45$ vezes o seu comprimento total, 0,38:0,94 $(0,47: 1,04)$.

Esternos pré-genitais e genitália. S7 e S8 (Figs. 114 e 132). Projeção dorso-mediana do gonocoxito subtriangular(Fig. 149).

Fêmea. Diagnose. Comprimento total, 12,0-14,9; largura da cabeça, 4,75-5,18. Tegumento predominantemente preto. Vermelho-ferrugíneo nos S5 e 6 e T5 e 6. Terço apical do T4 translúcido e um pouco avermelhado. T1 a 3 e parte preta do T4 com brilho metálico verde-azulado. Disco do clípeo liso e brilhante, praticamente sem pontos. Pilosidade amareloesbranquiçada na cabeça, parte dorsal do pronoto, mesoscuto e escutelo; ás vezes também nas áreas laterais do metanoto, látero-basais do propódeo e superior dos mesepisternos. Esbranquiçada e entremeada com longas cerdas escuras nas genas. Fímbrias pré-pigidial e pigidial vermelho-ferrugíneas. Preta, ereta e ramificada no T2. Castanho-clara no T5. Castanho a preta no restante do corpo. Comprimento do escapo 0,850,90 vezes o primeiro flagelômero, $1,08: 1,27-1,03: 1,15$. Primeiro flagelômero 1,40-1,50 vezes mais longo que os três seguintes juntos, 1,15:0,82 - 1,29:0,86. Comprimento da área malar 0,220,24 vezes a largura da mandíbula, 0,26:1,08 - 0,26:1,20. Comprimento da mandíbula 2,04-2,12 vezes a largura de sua base, 2,20:1,08-2,50:1,18. Mandíbula (Fig. 48).

Tipo. Holótipo, macho, com as seguintes etiquetas: "Bolívia" (etiqueta manuscrita), "Centris flavohirta n. sp., macho (símbolo), det. Friese 1898" (nome da espécie e símbolo do sexo manuscritos), "Type" (etiqueta vermelho-escura), "Coll. Friese” e "Zool. Mus. Berlin” (MNHU). Segundo Friese (1900), o exemplar foi coletado por Staudinger.

Tipos de Centris autrani Vachal, 1904. Lectótipo, macho, aqui designado, com as seguintes etiquetas: "Argentina, Prov. Tucumán, Lara 4000m, C. A. BAER, 2 - 1903”," "MUSEUMPARIS, Tucumán, A. Baer 1903" (Província, coletor e data manuscritos), "Centris autrani n. sp. Vachal" (etiqueta manuscrita), "TYPE" (etiqueta vermelha) e "LECTOTYPE, Centris autrani Vachal, F. Zanella, 2002" (etiqueta amarela). Paralectótipos, também examinados: 1 fêmea e 7 machos, do mesmo local, data e coletor do holótipo, todos com etiqueta amarela adicional "PARALECTOTYPE, Centris autrani Vachal, F. Zanella, 2002" (MNHN). O nome Centris autrani foi usado várias vezes para se referir a outra espécie, descrita no presente trabalho como C. toroi; essa confusão originou-se por Vachal ter incluído na série-tipo de C. autrani uma fêmea do Chile. A designação de lectótipo, aqui proposta, e a sua descrição, não deixam dúvidas quanto à identidade de $C$. autrani, como sinônimo de $C$. flavohirta.
Distribuição geográfica. Na vertente oriental dos Andes, de Cuzco, no Peru, a Tucumán, na Argentina (Fig. 160). Foi registrada de $600 \mathrm{~m}$, em Tapia, a $3000 \mathrm{~m}$ de altitude, em Lara; as duas localidades em Tucumán.

Material adicional examinado. PERU: Cuzco: 2 F, Cuzco, 24/??/ 1950, L. Peña leg. (SEMK). BOLÍVIA: La Paz: $1 \mathrm{M}$, La Paz, II/1932 (talvez 1922, ilegível), F. Jaffuel leg. (AMNH). 2 M, ibidem, II/1922, idem (CAS). Cochabamba: $5 \mathrm{~F}$ e $40 \mathrm{M}$, Cochabamba, 2600m, 18/XII/ 1949, M. Zischa leg. (SEMK). 3 M, ibidem, ibidem, 25/XII/1949, idem (SEMK). 24 M, ibidem, 2000m, 20/II/1950, idem (SEMK). 19 F e 26 M, Las Vacas [non Las Vacas, Chile], 9/II/1950, L. E. Pena leg. (SEMK). ARGENTINA: Salta: 1 M, Valle Encantado, 9/I/1994, C. Schlindwein leg. (CFZ). Tucumán: $1 \mathrm{~F}$, Los Cardones, 2/III/1973, J. L. Neff leg. (CTMI), em Dalea hofsteni. 1 F, Tapia, 600m, III-IV/1903, A. Baer (MNHN)

\section{Centris (Paracentris) garleppi (Schrottky, 1913)}

Hemisia garleppi Schrottky, 1913: 708.

Centris (Penthemisia) garleppi; Moure, 1950: 392.

Hemisia (Penthemisia) garleppi; Michener, 1951: 4.

Centris (Paracentris) garleppi; Moure, 2000 [1999]: 153.

De acordo com a descrição de SchrottKy (1908), as fềmeas desta espécie diferenciam-se das de $C$. caelebs pela pilosidade clara em todo o dorso do tórax, incluindo o escutelo; de $C$. toroi $\mathbf{s p . ~ n o v . , ~ p e l a s ~ c e r d a s ~ v e r m e l h o - a m a r r o n z a d a s ~ n o s ~ t e r g o s ~}$ de cor vermelho-ferrugínea do ápice do metassoma, e de $C$. unifasciata e $C$. neffi, devido ao T6 ser vermelho-ferrugíneo e não preto. Essas espécies, junto com C. flavohirta, ocorrem nos Andes, em grandes altitudes, e são muito semelhantes entre si, sendo às vezes separadas apenas por detalhes da coloração dos tergos e da pilosidade. Assim, só a análise do tipo pode esclarecer se se trata realmente de uma espécie distinta.

Tipo. Fêmea de Apurimac, Peru, Otto Garlepp leg. (não examinado). Segundo Moure (2000) se encontra em sua coleção, mas provavelmente pertence ao Muzeu de Zoologia da Universidade de São Paulo.

Centris (Paracentris) klugii Friese, 1900

(Figs. 43, 57, 74, 89, 110, 128, 146, 157)

Centris klugii Friese, 1900: 45.

Centris klugi Friese, 1901: 314.

Hemisia (Penthemisia) klugi; Michener, 1951: 4.

Fêmea. Diagnose. Comprimento total, 12,8-13,8; largura da cabeça, 4,75-5,05. Tegumento preto na cabeça e mesossoma. Castanho escuro nas pernas. Vermelho-ferrugíneo no metassoma, incluindo a placa pigidial. Pilosidade predominantemente amarelo-palha, inclusive as cerdas da escopa; mais clara na região ventral do mesossoma e cabeça, exceto no vértice; com um suave tom ferrugíneo nas fímbrias pré-pigidial e pigidial. Castanho escura, semi-erecta e não ramificada no disco do $\mathrm{T} 2$. Olhos um pouco convergentes 


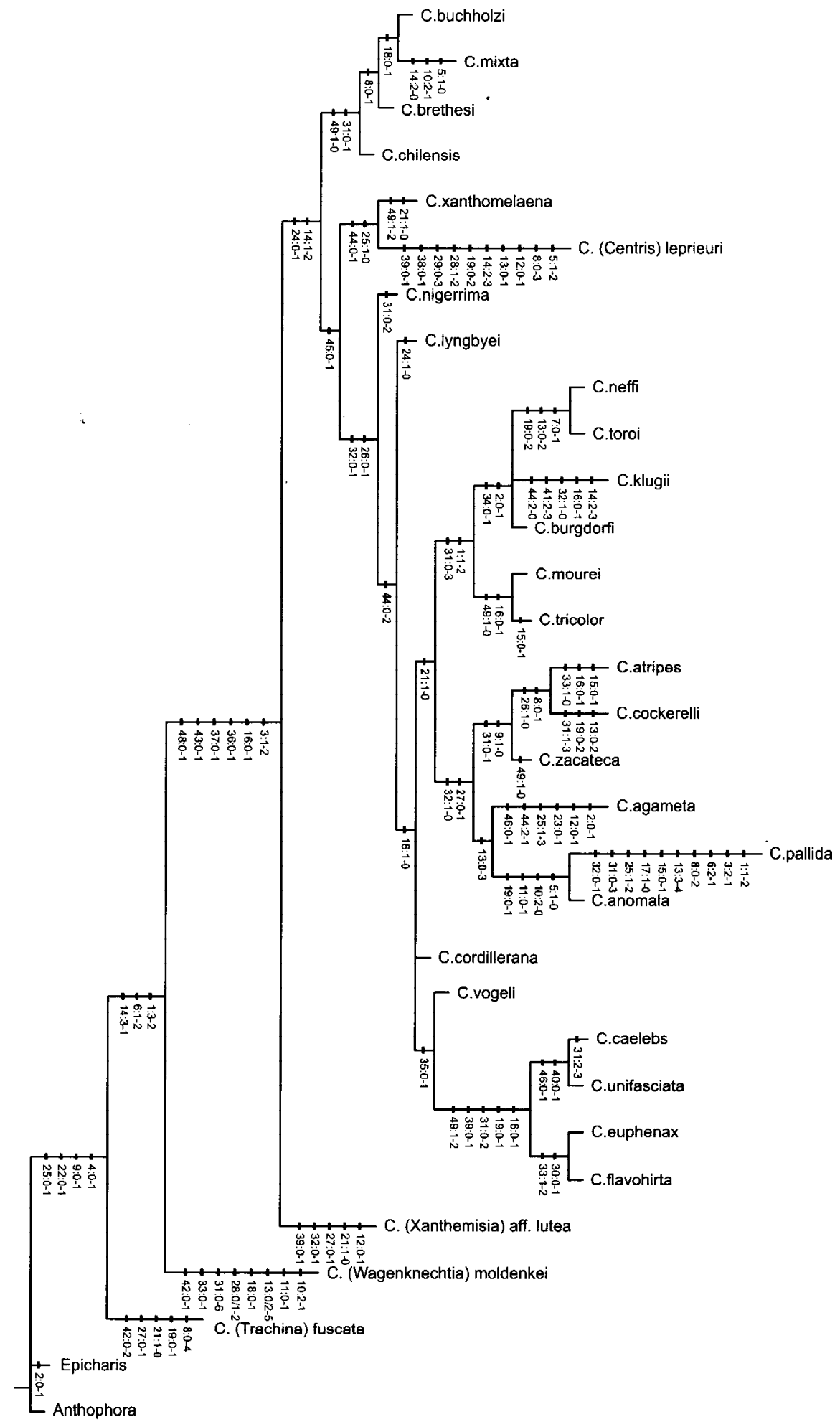

Fig. 38. Relações filogenéticas internas do grupo Centris. Um dos cladograma mais parcimoniosos produzidos na análise com pesagem implícita. Somente estão plotados os caracteres cuja otimização não é ambígua. 


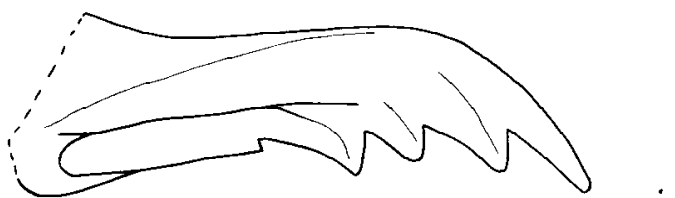

39
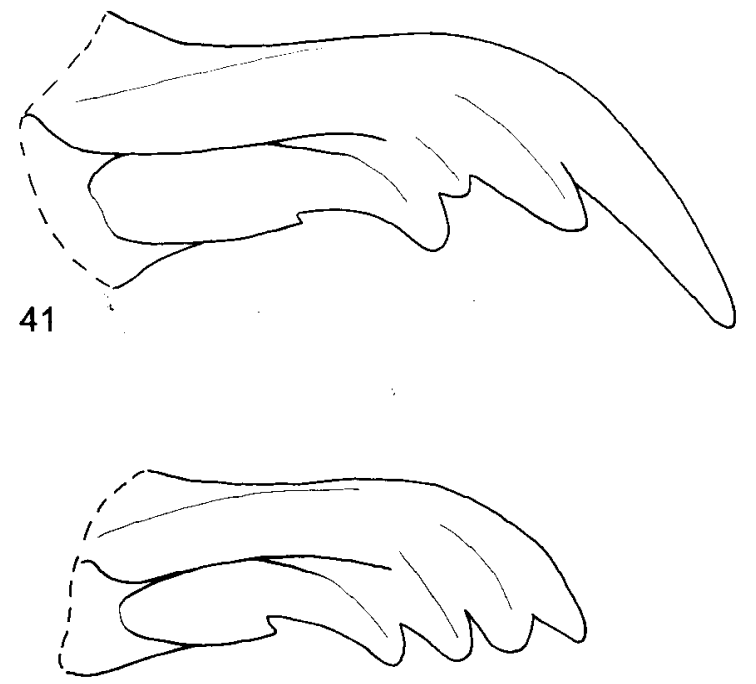

43

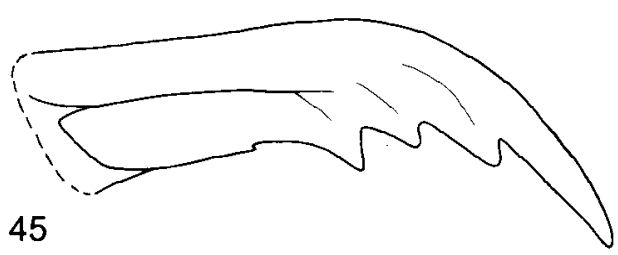

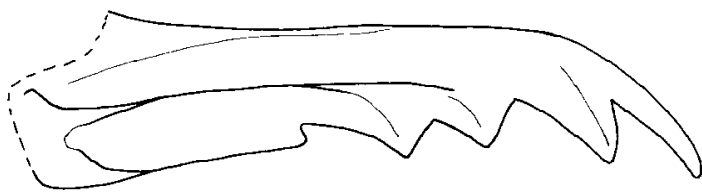

40

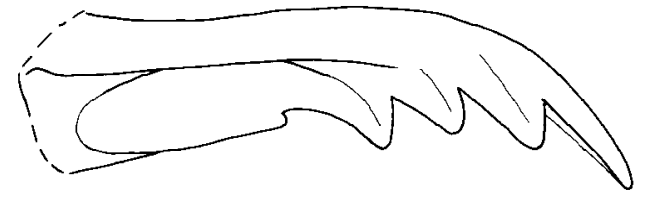

42

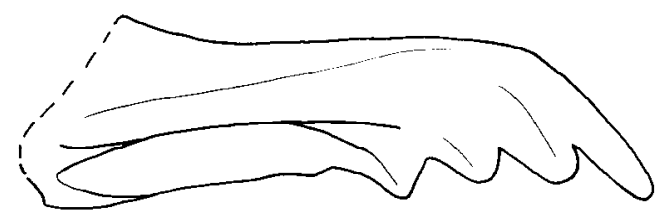

44

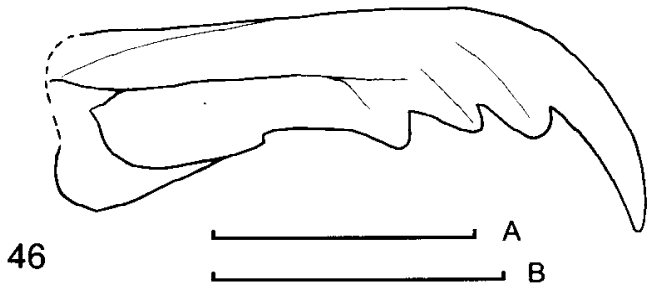

Figs. 39-46. Centris, mandíbula das fêmeas, vista superior. 39, C. (Penthemisia) brethesi; 40, C. (Penthemisia) buchholzi; 41, C. (Paracentris) burgdorfi; 42, C. (Penthemisia) chilensis; 43, C. (Paracentris) klugii; 44, C. (Penthemisia) mixta tamarugalis; 45, C. (Paracentris) mourei; 46, C. (Paracentris) tricolor. Escalas $=1 \mathrm{~mm}$, A corresponde às figuras $39-41 \mathrm{e} 45$, e $\mathrm{B}$ às restantes.

para baixo, DIOS:DIOI, 2,54:2,42 - 2,74:2,52. Distância ocelocular 1,94-2,12 vezes o diâmetro do ocelo médio, $0,70: 0,36$ $-0,66: 0,31$. Distância entre alvéolos antenais 2,97-3,10 vezes o diâmetro alveolar, 0,92:0,31-0,96:0,31. Comprimento do escapo 1,02-1,07 vezes o do primeiro flagelômero, $0,96: 0,94-1,08: 1,01$. Primeiro flagelômero 1,23-1,27 vezes mais longo que os três seguintes juntos, 1,01:0,82 - 0,94:0,74. Comprimento da área malar $0,17-0,19$ vezes a largura da mandíbula, $0,18: 1,03-$ $0,18: 0,96$. Comprimento da mandíbula 1,84 a 1,98 vezes a largura de sua base, 1,90:1,03-2,04:1,03.

Macho. Diagnose. Comprimento total, 12,3-13,9; largura da cabeça, 4,45-4,69. Tegumento predominantemente preto na cabeça e mesossoma. Castanho escuro nas pernas, mais claro nos tarsos. Vermelho-ferrugíneo no metassoma. Disco do clípeo e do labro amarelos. Clípeo com pontuação alveolada finamoderada, densa-dispersa; faixa lisa mediano-longitudinal com largura entre 0,36 e $0,60 \mathrm{~mm}$. Pilosidade predominantemente amarelo-palha-esbranquiçada, mais amarelada na região dorsal do mesossoma e tarsos. Castanho-escura a preta, semi-erecta e ramificada no disco do T2. Cerdas escuras na cabeça restritas às laterais do clípeo, paroculares e fronte, abaixo dos ocelos. Distância ocelocular 1,11-1,14 vezes o diâmetro do ocelo médio, 0,41:0,37-0,41:0,36. Distância entre alvéolos antenais 2,572,72 vezes o diâmetro alveolar, 0,77:0,30 - 0,79:0,29. Escapo 1,06-1,12 vezes mais longo que o primeiro flagelômero, $0,89: 0,86$ $-0,96: 0,84$. Primeiro flagelômero com comprimento semelhante ao dos três seguintes juntos, $0,84: 0,86-0,86: 0,84$. Comprimento da mandíbula 1,73-1,80 vezes a largura de sua base, 1,48:0,82 1,54:0,89. Projeção apical do S7 longa e estreita (Fig. 110). 


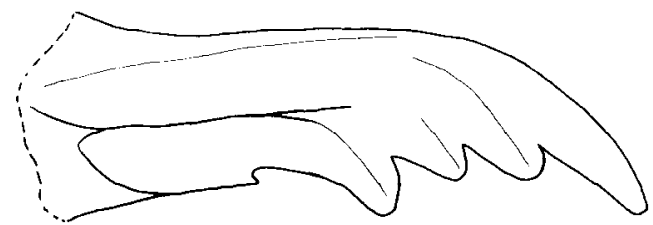

47

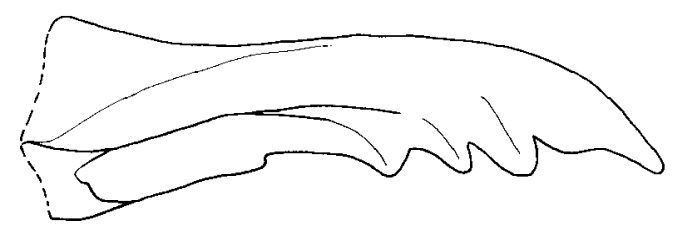

49

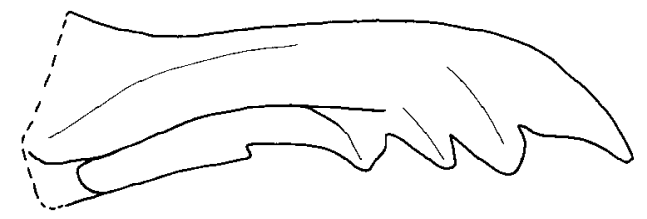

51

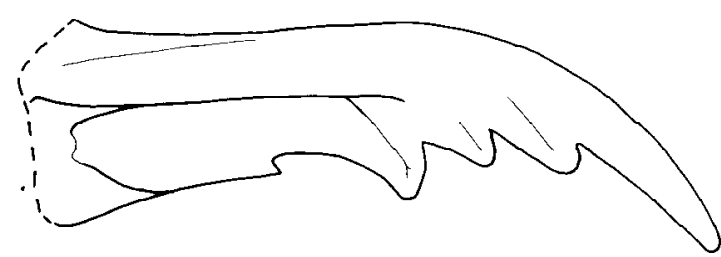

48

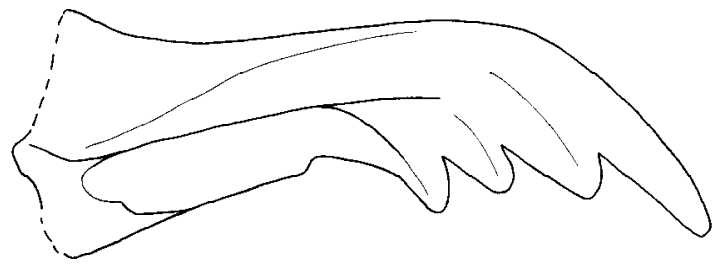

50

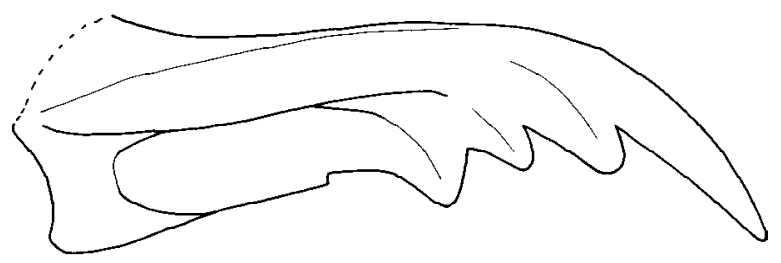

52

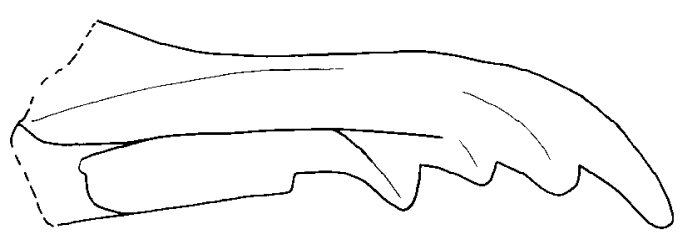

53

Figs. 47-53. Centris, mandíbula das fêmeas, vista superior. 47, C. (Paracentris) caelebs; 48, C. (P.) flavohirta; 49, C. (P.) neffi; 50, C. (P.) nigerrima; 51, C. (P.) toroi sp. nov.; 52, C. (P.) unifasciata; 53, C. (P.) lyngbyei. Escala $=1 \mathrm{~mm}$.

Projeção dorso-mediana do gonocoxito subtriangular (Fig. 146).

Tipos. Duas fêmeas do Brasil, sendo uma do Pará (Museu de Budapest) (não examinados). O exemplar macho de Campinas com etiqueta de "typus", relacionado na lista de material examinado, certamente não pertenca à série-tipo, pois FrIESE (1900) menciona ter estudado somente fêmeas.

Distribuição geográfica. No segundo planalto paranaense, a cerca de $970 \mathrm{~m}$ de altitude, e regiões serranas do Sudeste e Centro-Oeste do Brasil, com registro a $1650 \mathrm{~m}$, em Campos do Jordão, São Paulo (Fig. 157). Foi examinada também uma fềmea com etiqueta indicando ter sido coletada no Pará, mas assim como a que FRIESE (1900) cita na descrição da espécie, não há indicação da localidade.
Material examinado. BRASIL. Pará: $1 \mathrm{~F}$, s. l., 1890, s. c. (SEMK). Goiás: $1 \mathrm{~F}$ e $1 \mathrm{M}$, Alto Paraíso (Alto Paraíso de Goiás, 1186m), 13/II/ 1977, J. L. Neff leg. (CTMI), em Sesbania sp. e Hyptis sp., respectivamente. Minas Gerais: 1 M, Barbacena, 19/XI/1905, Ducke leg. (BMNH). 1 M, Diamantina, 1370m, 10/II/1983, G. Melo \& A. Soares leg. (CGM). $1 \mathrm{~F}$ e $1 \mathrm{M}$, Lima Duarte, Parque Florestal do Ibitipoca, 19 e 21/II/1990, F. Silveira leg. (UFVB). 1 F, Poços de Caldas, Morro do Ferro, 19/I/1966, Catarina leg. (RPSP). 1 M, ibidem, 19/I/1969, Penha leg. (RPSP). 1 F, Serra do Cipó, 7/XI/1990, Faria \& Mazucato leg. (RPSP), etiqueta adicional "Centris (Paracentris) klugii Friese 1900, Det. Moure 1991”. São Paulo: 1 M, Campinas, 19?? (ilegível), Hemper leg. (MNHU), etiquetas adicionais "Centris klugii Fr., macho (símbolo), 1909 Friese det.", com carga de terra nas tíbias. 4 F, Campos do Jordão, III/1906, H. Lüderwaldt leg. (MZSP), uma delas com etiquetas adicionais "Hemisia klugi (Friese) C. Schrottky det. 1910" e "Centris klugii det. Ducke 13". 1 F, ibidem, 6/II/1986, Barbieri leg. (RPSP). 2 F, ibidem, Eug. Lefevre, 1200 m, 22/III/1963, Guimarães, Rabello, Barroso \& L. T. F. leg. (MZSP). 1 M, ibidem, Faz. Guarda, 1650 m, 31/III/1963, Papavero, Guimarães \& L. T. F. leg. (MZSP). Paraná: 3 M,Vila Velha (Ponta Grossa), estrada Curitiba-Vila Velha Km 87, 1/XI/1968, R. S. \& R. G. S. 
expedition (BMNH), todos com etiqueta adicional "Centris tricolor Fr., Pe. J. S. Moure 1972",

Centris (Paracentris) lyngbyei Jensen-Haarup, 1908 (Figs. 53, 69, 80, 95, 111, 129, 147, 161)

Centris lyngbyei Jensen-Haarup, 1908: 107-108.

Centris tricolor; Friese, 1909: 128 (sinonimia).

Centris (Paracentris) lyngbyei; Roig-Alsina, 2000: 186.

\section{Redescrição}

Lectótipo, macho. Dimensões (mm). Comprimento total 14,5 $(13,5-15,2)$; largura da cabeça 5,09 $(4,98-5,06)$; comprimento da cabeça 3,59 (3,32); largura do mesossoma, incluindo tégulas, $6,73(6,06)$; comprimento da asa, do esclerito costal ao ápice, $11,39(11,05)$.

Tegumento. Preto a castanho-escuro na cabeça, mesossoma e pernas. Amarelo no labro e disco do clípeo. Vermelhoferrugíneo no metassoma. Membrana das asas translúcidas, com um suave tom méleo. Clípeo liso e brilhante na parte plana frontal, praticamente sem pontos.

Pilosidade. Predominantemente castanho-escura a preta na cabeça, região lateral e ventral do mesossoma, pernas e metassoma. Preta no labro e clípeo, inclusive nas áreas amarelas. Amarelo palha no vértice, pronoto, tégulas, mesonoto, chegando até cerca de um terço dos mesepisternos, áreas laterais do metanoto e látero-basais do propódeo; predominantemente no T1. Castanho-clara na área mediana do metanoto e basais e látero-apicais do propódeo. Preta, semiereta e ramificada nos T2-6 e áreas laterais e apicais do T1.

Forma e proporções. Olhos um pouco divergentes para baixo, DIOS 2,21 e DIOI 2,64 (2,24:2,52). Distância ocelocular 0,89-1,00 vezes o diâmetro do ocelo médio, $0,41: 0,46(0,40: 0,40)$. Distância interocelar 1,70-1,90 vezes o diâmetro do ocelo médio, $0,76: 0,46(0,74: 0,40-0,78: 0,41)$. Distância entre alvéolos antenais 3,07-3,37 vezes o diâmetro alveolar, 1,01:0,30 (0,94:0,28 $-0,94: 0,30$ ). Distância alveolocular $\mathbf{1 , 2 7}-\mathbf{1 , 4 3}$ vezes o diâmetro alveolar, $0,43: 0,30(0,38: 0,30-0,40: 0,28)$. Comprimento do escapo 0,95-0,98 vezes o do primeiro flagelômero, $0,98: 1,03(0,98: 1,00)$. Primeiro flagelômero 1,13-1,28 vezes mais longo que os três seguintes juntos, 1,03:0,91 $(1,02: 0,80)$. Comprimento da área malar $0,14-0,17$ vezes a largura da mandíbula, $0,14: 0,96(0,12: 0,88$ $-0,16: 0,92)$. Comprimento da mandíbula $2,09-2,18$ vezes a largura de sua base, 2,04:0,96(1,96:0,94-1,92:0,88). Palpo maxilar com quatro artículos. Parte da segunda abcissa de $\mathrm{M}$, anterior à $1 \mathrm{a}$ m-cu, $0,31-0,38$ vezes o seu comprimento total, $0,41: 1,08$ $(0,30: 0,96-0,36: 1,00)$.

Esternos pré-genitais e genitália (do espécimen do mesmo local e data que o lectótipo). S7 com bordos laterais divergentes e bordo apical truncado com pequena projeção mediana (Fig. 111). S8 com bordos laterais convergentes para o ápice (Fig. 129). Cápsula genital com gonobase mais longa do que em $C$. tricolor (Fig. 147).

Fêmea. Diagnose. Comprimento total, 15,0-16,2; largura da cabeça 5,15-5,23. Tegumento preto a castanho-escuro na cabeça, mesossoma e pernas. Vermelho-ferrugíneo no metassoma, incluindo a placa pigidial. Clípeo com pontuação fina, esparsa-dispersa, tegumento liso e brilhante entre os pontos e faixa mediano-longitudinal sem pontos larga (às vezes um pouco enrugada devido à preservação). Pilosidade amarelopalha-clara no labro, entremeada com cerdas escuras (em outros exemplares inteiramente castanho escura a preta). Castanhoescura a preta na cabeça, metanoto, pernas e região ventral do corpo e metassoma. Preta, semi-erecta e ramificada no T1 e T2. Fímbrias pré-pigidial e pigidial castanho-escuras a pretas. Olhos um pouco divergentes para baixo, DIOS: DIOI, 2,64:2,88 $2,64: 3,04$. Distância ocelocular 1,52-1,56 vezes o diâmetro do ocelo médio, 0,61:0,40-0,64:0,41. Comprimento do escapo 0,870,93 o do primeiro flagelômero, $1,08: 1,16$ - 1,04:1,20. Primeiro flagelômero 1,41-1,47 vezes mais longo que os três seguintes juntos, 1,16:0,82 - 1,20:0,84. Comprimento da área malar 0,150,16 vezes a largura da mandíbula, 0,16:0,98 - 0,16:1,06. Comprimento da mandíbula 2,23-2,39 vezes a largura de sua base, 2,34:0,98-2,36:1,06. Palpo maxilar com cinco artículos.

Tipos. Lectótipo, aqui designado, macho, com as seguintes etiquetas: "Chacr. de Coria, Prov. de Mendoza, Rep. Argentina, Jensen-Haarup" (etiqueta impressa com data manuscrita a lápis no verso, "2/11 06"), "Type Coll. J.-Hrp.", "HOLO, TYPE" (etiqueta vermelha, "HOLO" manuscrito), "Centris Lyngbyei n. sp. J.-Hrp., Jensen-Haarup det" ("Jensen-Haarup det" impresso), "Centris tricolor Fr., fêmea (símbolo), 1907 Friese det." (nome da espécie e símbolo do sexo, manuscritos) e "LECTOTYPE, Centris lyngbyei Jensen-Haarup, F. Zanella, 2002" (etiqueta amarela) (ZMUC). A designação do lectótipo e sua descrição são feitas com o intuito de clarificar o uso do nome, pois essa espécie tem sido confundida com Centris tricolor por vários pesquisadores, por serem muito semelhantes.

JENSEN-HAARUP (1908) menciona apenas quatro fêmeas, entretanto acredito ter havido um erro, ou do autor ou na edição do trabalho, na indicação do sexo; pois na descrição, são relacionados caracteres que dizem respeito apenas aos machos, como por exemplo: a coloração amarela do labro e clípeo e o tegumento liso e brilhante do disco do clípeo. Entre o material analisado, há dois indivíduos coletados na mesma data que o lectótipo; é possível que pertençam à série-tipo, mas não apresentam nenhuma etiqueta do autor da espécie com indicação a esse respeito.

Distribuição geográfica. Até o momento conhecida apenas de San Juan e Mendoza, Argentina (Fig. 161).

Material adicional examinado. ARGENTINA. San Juan: 1 F, Iglesia, 31/X/1992, 11:30h, Michelete leg. (RPSP). $1 \mathrm{~F}$, ibidem, 17/XI/1993, 16:00h, idem (RPSP), em Prosopis strombulifera, etiqueta adicional: "C. (Paracentris) tricolor Fr. 1899, macho (símbolo), Det. Moure, 1994.". $1 \mathrm{~F}$, Valle de Zonda, 12/X/1994, idem (RPSP). Mendoza: $1 \mathrm{~F}$, Chacras de Coria, 10/XII/1904, P. Jörgensen leg. (ZMUC). 1 M, idem, 2/XI/1906, Jensen-Haarup leg. (ZMUC), etiqueta adicional: "Centris tricolor". $2 \mathrm{M}$, ibidem, 8/I/1908, P. Jörgensen leg. (ZMUC). 1 F, ibidem, 16/I/1908, idem (ZMUC). Vários exemplares, provavelmente de Mendoza, depositados no ZMUC e coletados por P. Jörgensen nas datas a seguir: 6 


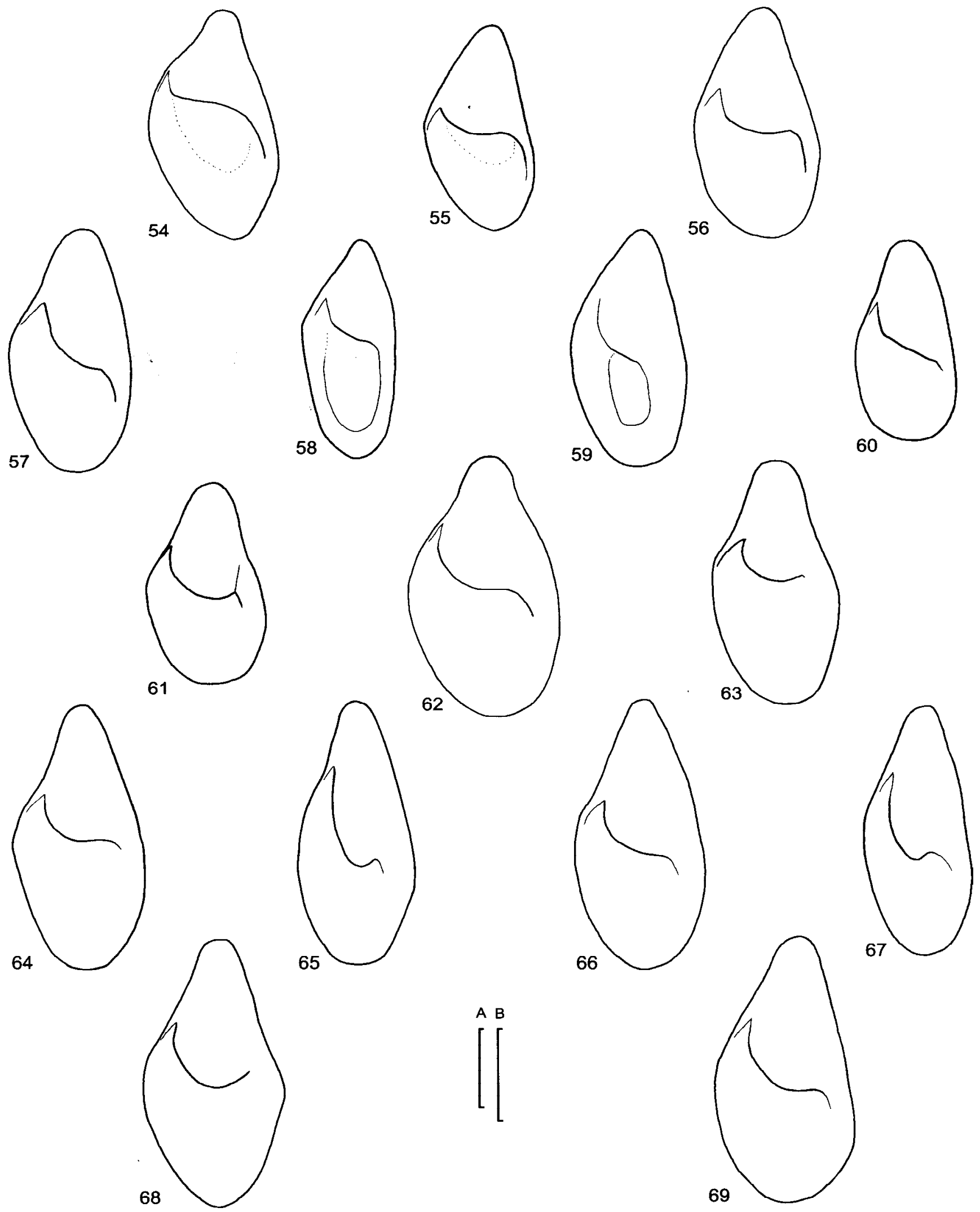

Figs. 54-69. Centris, placa basitibial esquerda, fêmeas. 54, C. (Penthemisia) brethesi; 55, C. (Penthemisia) buchholzi; 56, C. (Penthemisia) chilensis; 57, C. (Paracentris) klugii; 58, C. (Penthemisia) mixta mixta; 59, C. (Penthemisia) mixta tamarugalis; 60, C. (Paracentris) mourei; 61, C. (P.) tricolor; 62, C. (P.) burgdorfi; 63, C. (P.) caelebs; 64, C. (P.) flavohirta; 65, C. (P.) neffi; 66, C. (P.) nigerrima; 67, C. (P.) toroi sp. nov.; 68, C. (P.) unifasciata; 69, C. (P.) lyngbyei. Escalas $=0,5 \mathrm{~mm}, \mathrm{~A}$ corresponde à figura $62 \mathrm{e} \mathrm{B}$ às restantes. 
M, 7/XII/1904; 2 F, 20/XII/1904; 1 M, 5/XII/1907; 2 M, 5/XI/1908 e 4 M, 26/XI/1908; o macho de 1907, com as seguintes etiquetas adicionais: "5/12 1907 Mendoza, Centris Lyngbyei, n. sp fêmea (símbolo)", "Para, TYPE" e "Centris tricolor Fr." (ZMUC). 2 M, ibidem, 18/X/1908, idem (NHMW), etiqueta adicional: "Centris tricolor Lep. det. Jörgensen". 1 M, idem, 2/XI/1906, s. c. (NHMW), etiquetas adicionais: "Centris tricolor Fr., macho (símbolo), 1907, Friese det." e "Typus".

\section{Centris (Paracentris) mourei Roig-Alsina, 2000}

(Figs. 45, 60, 76, 91, 107, 125, 143, 159)

Centris (Paracentris) mourei Roig-Alsina, 2000: 184.

Fêmea. Diagnose. Comprimento total, 13,1-15,5; largura da cabeça, 4,75-5,24. Tegumento predominantemente castanhoescuro a preto. Vermelho-ferrugíneo no metassoma, incluindo a placa pigidial. Pilosidade amarelo-palha na parte superior do mesossoma. Castanho-escura a preta na cabeça e metade inferior do lobo pronotal. Ás vezes com tufo de pêlos claros entre os alvéolos antenais. Semidecumbente, curta, não ramificada e de coloração ferrugínea no disco do T2. Olhos um pouco convergentes para baixo, DIOS:DIOI, 2,47:2,32 - 2,72:2,54. Distância ocelocular 1,32-1,68 vezes o diâmetro do ocelo médio, $0,62: 0,37-0,53: 0,40$. Distância interocelar $2,08-2,12$ vezes o diâmetro do ocelo médio, 0,85:0,37 - 0,77:0,37. Comprimento do escapo praticamente igual ao do primeiro flagelômero, 0,91:0,91-1,01:1,00. Primeiro flagelômero $1,06-1,15$ vezes mais longo que os três seguintes juntos, 0,95:0,80-0,91:0,79. Comprimento da área malar 0,14 vezes a largura da mandíbula, 0,13:0,91-0,14:1,01. Placa basitibial secundária com bordo apical formando uma linha mais reta do que em C. tricolor e com declive menos acentuado no bordo posterior (Fig. 60).

Macho. Diagnose. Comprimento total, 12,7-13,6; largura da cabeça, 4,69-5,12. Tegumento semelhante ao da fêmea, incluindo o labro e clípeo pretos. Pilosidade somelhante à da fêmea (um espécimen de Catamarca com tufos de pêlos claros no vértice e labro). Olhos quase paralelos, DIOS:DIOI, 2,10:2,06 $-2,30: 2,28$. Distância ocelocular 1,05-1,22 vezes o diâmetro do ocelo médio, 0,42:0,40-0,50:0,41. Distância interocelar cerca de 1,80-1,84 vezes o diâmetro do ocelo médio, 0,70:0,38 0,74:0,41. Distância alveolocular $1,17-1,31$ vezes a o diâmetro alveolar, 0,34:0,26-0,34:0,29. Primeiro flagelômero 0,91-0,95 vezes os três seguintes juntos, 0,86:0,91 - 0,89:0,98. Comprimento da área malar $0,16-0,17$ vezes a largura da mandíbula, 0,14:0,84-0,14:0,89.

Tipos. Holótipo, fêmea, de Illiar, La Rioja, Argentina (MACN) e vários parátipos, machos e fêmeas de diversas províncias da Argentina, depositados nas seguintes instituições: MACN, IMLA e Instituto Argentino de Investigación de Zonas Aridas, Mendoza (não examinados).

Distribuição geográfica. No noroeste da Argentina, de Tucumán à Mendoza (Fig. 159). Tem registros até $2000 \mathrm{~m}$ de altitude, em Tucumán. Roig-Alsina (2000) cita registros adicionais em Jujuy, Chaco, San Juan e Buenos Aires.
Material adicional examinado. ARGENTINA. Catamarca: $6 \mathrm{~F}$ e 1 M, Andalgalá, 24/XII/1971, D. J. Brothers leg. (SEMK). $1 \mathrm{~F}$ e $1 \mathrm{M}$, ibidem, 22/III/1973, J. Neff leg. (CTMI), em Larrea cuneifolia; do mesmo local, coletor e depositados no CTMI: $1 \mathrm{M}, 18 / \mathrm{X} / 1973$, em Prosopis chilensis; 1 F, 1/XI/1973, em Tricomaria usillo; 1 F, 7/II/1972, em Pithecoctenium synanchoides; 1 F, 31/I/1973, em Larrea cuneifolia; 1 F, 8/II/1972, em Tricomaria usillo, e 1 M, 26/II/1973, em Atamisquea emarginata. 1 M, 16 K E Catamarca, 25/XI/1968, L. Pena leg. (AMNH). 1 M, Joyango-Colpes site, 8/XI/1972, J. Neff leg. (CTMI), em Prosopis chilensis. 3 M, 5/XI/1951, Fritz Plaumann leg. (SEMK). Tucumán: 2 F, s. l., M. Arnau leg. (SEMK). 1 M, San Vincente, 28/I/1986, J. Neff leg. (CTMI), em Caesalpinia coluteifolia. $1 \mathrm{~F}$, Tucumán, $2000 \mathrm{~m}, s . c$. (SMNH). Santiago del Estero: $1 \mathrm{M}$, Canto Gallo (possivelmente, Campo Gallo), III/1943, A. F. Prosen leg. (SEMK). 1 F e 1 M, Colonia Dora, X/ 1939, s. c. (SEMK). 1 M, ibidem, X/1941, A. F. Prosen leg. (SEMK). 3 F e 4 M, Depto. Matará, Desvio 511, 24/X/1928, M. Gomez (SEMK). 7 F, El Carco $[s i c](=E l$ Charco), II/1956, s. c. (SEMK). 1 F, Fernandez, 900 Km, II/1957, s. c. (SEMK). La Rioja: 2 F, estación Amado, X/1934, M. Gomez leg. (SEMK). 1 F, Illiar, 30/X/1928, Mateo Gomez leg. (SEMK). 55 F, ibidem, II/1934, M. Gomez leg. (SEMK). 2 F, Mascasim, II/1958, F. H. Walz leg. (RPSP). 2 M, ibidem, XI/1961, idem (RPSP). $1 \mathrm{M}$, Patquia, X/1932, K. Hayward leg. (BMNH). Córdoba: 1 F, Cruz del Eje, Guanaco muerto, s. d., s. c. (AMNH). 1 F, El Sauce, XII/1938, M. Viana leg. (SEMK). Mendoza: $1 \mathrm{~F}$, Alto Percoso, 21/XII/1908, P. Jörgensen leg. (ZMUC). $4 \mathrm{~F}$ e $1 \mathrm{M}$, Chacras de Coria, 26/II. 10/XII /1904 e 16/I/ 1908, idem (ZMUC). 6 F e 10 M, ibidem, 13. 17/I. 16/II. 17/II. 14/XII/ 1907, Jensen-Haarup leg. (ZMUC), um dos machos com carga de terra nas tíbias posteriores. $1 \mathrm{M}$, Est. Pedregal, 1/XII/1906, Jensen-Haarup leg. (ZMUC). 6 F e 8 M, s. l., 12. 20/XII/1904. 3. 4/IV. 26/XI /1908, P. Jörgensen leg. (ZMUC). $1 \mathrm{M}$, s. l., s. d., s. c. (AMNH), etiqueta adicional "Centris lynbyei Jens., macho (símbolo), 1910 Friese det.". San Luis: 1 M, San Francisco [sic](=San Francisco del Monte de Oro), 6/II/1958, Willink \& Tonsic leg. (IMLA).

\section{Centris (Paracentris) neffi Moure, 2000}

(Figs. 49, 65, 81, 98, 116, 134, 151, 162)

Centris (Paracentris) neffi Moure, 2000 [1999]: 148-150; Roig-Alsina, 2000: 188

Fêmea. Diagnose. Comprimento total, 12,2-14,1; largura da cabeça, 4,17-4,81. Tegumento predominantemente preto, com um tom castanho nas pernas; Vermelho-ferrugíneo nos T5 e $6 \mathrm{e}$ S6, incluindo a placa pigidial. Faixa apical do T6, sob as cerdas da fímbria pré-pigidial, castanho-escura. Pilosidade predominantemente preta, inclusive no T5 e 6 e fímbrias prépigidial e pigidial; preta ou predominantemente esbranquiçada nas genas. Amarelo-palha-esbranquiçada na fronte, vértice, região dorsal do pronoto, mesoscuto e escutelo; no labro, clípeo e paroculares, entremeado a cerdas pretas. Mandíbula com dente apical largo na base (Fig. 49). Placa basitibial estreita (Fig. 65).

Macho. Diagnose. Comprimento total, 12,2-12,7; largura da cabeça, 4,54-4,84. Tegumento predominantemente preto, incluindo tergos apicais. Amarelo no disco do labro e do clípeo. Disco do clípeo finamente enrugado, com pouco brilho. Pilosidade preta. Amarelo-palha-esbranquiçada no labro, na área amarela e partes adjacentes do clípeo, área supra-clipeal, fronte, vértice, área dorsal do pronoto, mesoscuto, escutelo, laterais do metanoto, látero-basais do propódeo e parte da base e laterais do T1. Distância ocelocular $0,83-1,00$ vezes o diâmetro do ocelo médio, 0,34:0,41-0,36:0,36. Comprimento do escapo 


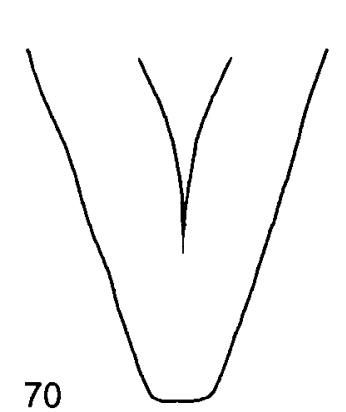

70

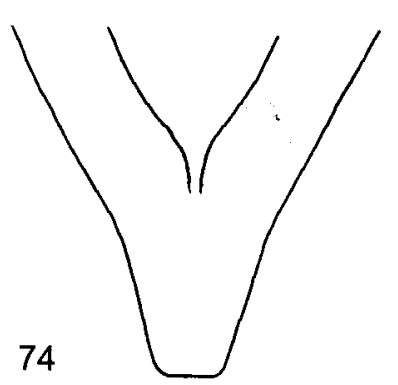

74
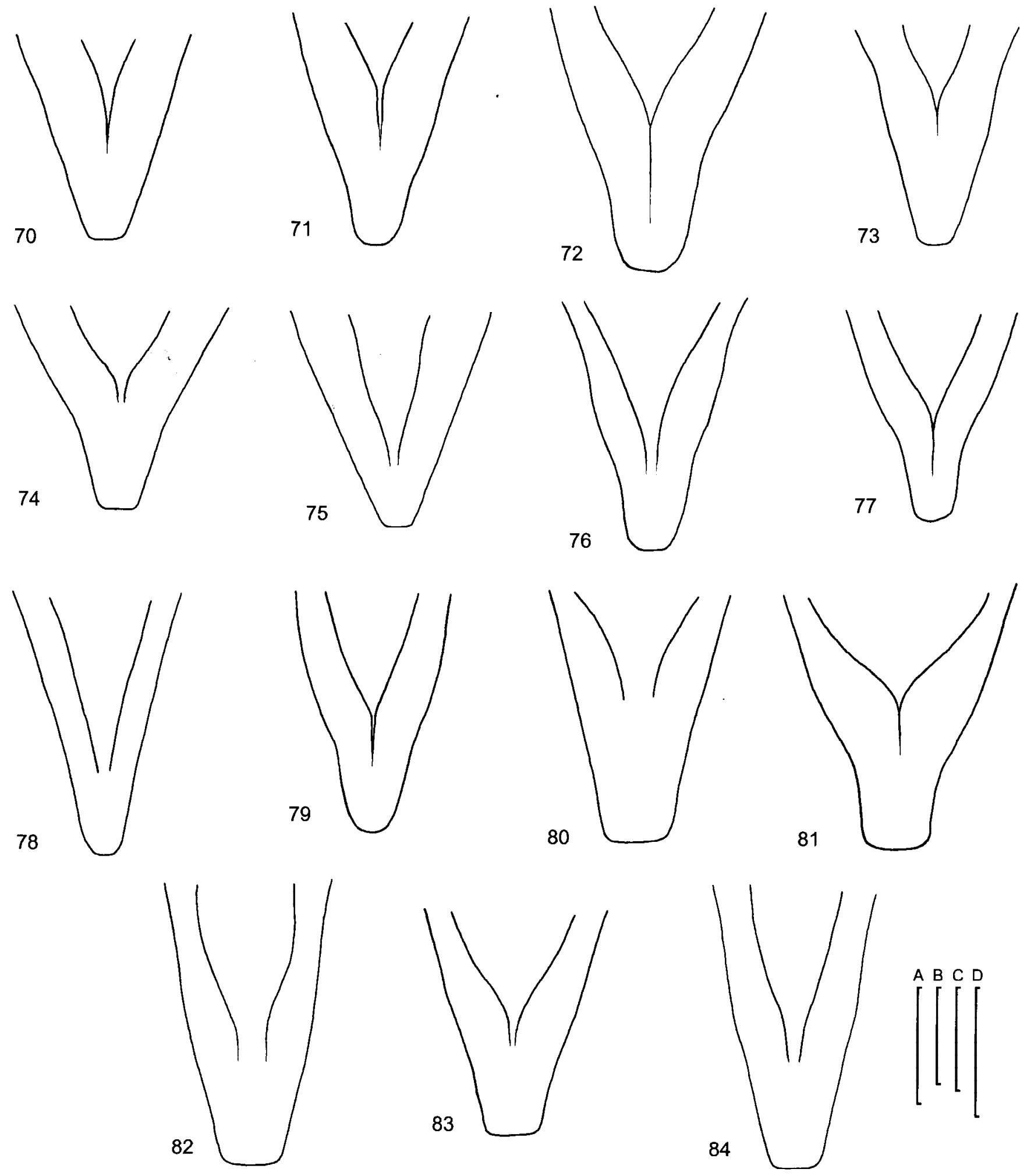

Figs. 70-84. Centris, placa pigidial, fêmeas. 70, C. (Penthemisia) brethesi; 71, C. (Penthemisia) buchholzi; 72, C. (Paracentris) burgdorfi; 73, C. (Penthemisia) chilensis; 74, C. (Paracentris) klugii; 75, C. (Penthemisia) mixta tamarugalis; 76, C. (Paracentris) mourei; 77, C. (P.) tricolor; 78, C. (P.) caelebs; 79, C. (P.) flavohirta; 80, C. (P.) lyngbyei; 81, C. (P.) neffi; 82, C. (P.) nigerrima; 83, C. (P.) toroi sp. nov.; 84, C. (P.) unifasciata . Escalas $=0,5 \mathrm{~mm}$, A corresponde às figuras $70,71,78,80,81$ e $83, \mathrm{~B}$ às figuras 72 e $75, \mathrm{C}$ às figuras $73,74,76,77,82$ e 84 , e D corresponde à figura 79 . 
0,90-0,94 vezes o do primeiro flagelômero, $0,91: 1,01-0,90: 0,96$. Comprimento da mandíbula 2,37-2,44 vezes a largura de sua base, 1,94:0,82 - 2,10:0,86. Segundo dente subapical da mandíbula subquadrangular, com o bordo apical côncavo (Fig. 98). Projeção apical do S8 com lados retos ou quase, suavemente convergentes (Fig. 134).

Tipos. Holótipo fềmea, três parátipos fềmeas e três parátipos machos, coletados por Neff em Cuesta Minas Capillitas, Catamarca, Argentina, e depositados na Coleção de Entomologia Pe. Jesus S. Moure, no Departamento de Zoologia da Universidade Federal do Paraná.

Distribuição geográfica. Na vertente oriental do Andes, com registros na região central do Peru e em Catamarca, Argentina, em altitudes próximas à $3000 \mathrm{~m}$ (Fig. 162). RoIG-Alsina (2000) registra essa espécie também em Quebrada Volcán, Jujuy, e em El Infernillo, Tucumán.

Comentários. Moldenke identificava esta espécie, assim como Centris toroi sp. n., como Centris autrani (ver etiquetas de identificação abaixo e comentários adicionais em C. toroi)

Material examinado. PERU. 2 F, Vilcabamba (Rio Tarma), 2800m, 7 e 8/V/1949, Weyrauch leg. (IMLA), uma em Tropaeolum. Cajamarca: 3 $\mathrm{F}$, Cajamarca, NW of Baños del Inca, $2740 \mathrm{~m}, 27 / \mathrm{IV} / 1998$, Claus Rasmussen leg. (CCRD). 1 F, Cajamarca, Celendin, 2600-2700 m, 20/IV/ 1998, idem (CCRD). Junin: 1 M, Huancayo, Colca, 3800m, 24/11/ 1997, Claus Rasmussen leg. (CCRD). Apurimac: 2 F e 1 M, 5 Mi. N. of Andahuaylas, 7/III/1951, Ross e Michelbacher leg. (CAS), as fêmeas com a seguinte etiqueta adicional: "Centris autrani Vachal, fêmea (símbolo), det. Moldenke'76". ARGENTINA: Catamarca: $1 \mathrm{M}$, Cuesta Minas Capillitas, 3000m, 28/II/1975, J.L. Neff leg. (CAS), etiquetas adicionais: "Centris unifasciata (Schrottky 1913" e "Centris autrani Vachal, macho (símbolo), det Moldenke '76". Do mesmo local, coletor e depositados no CTMI: 2 F, 4/II/1973; 3 F, 18/II/1973, em Adesmia cytisoides e Calceolaria; $1 \mathrm{~F}$ e 3 M, 27/I/1974, em Calceolaria; 2 M, 3/ I/1973 e 1/I/1974, em Lathyrus macropus.

Centris (Paracentris) nigerrima (Spinola, 1851) (Figs. 50, 66, 82, 100, 118, 136, 154, 158)

Hemisia nigerrima Spinola, 1851: 166-167. Centris nigerrima; Friese, 1901: 322.

Hemisia (Penthemisia) nigerrima; Michener, 1951: 4. Centris (Penthemisia) nigerrima; Moure, 1950: 392.

Centris (Paracentris) nigerrima; Roig-Alsina, 2000: 188.

Fêmea. Diagnose. Comprimento total, 13,9-16,5; largura da cabeça, 4,81-5,36. Tegumento predominantemente preto. Castanho escuro nas pernas. Brilho azulado nos tergos metassomáticos. Membrana das asas translúcida, com um suave tom méleo. Clípeo com faixa mediano-longitudinal lisa, brilhante, sem pontos, com largura aproximada entre 0,53 e 0,62 mm (ás vezes enrugado, provavelmente devido à preservação). Pilosidade inteiramente preta (em alguns exemplares apresenta um tom amarronzado). Olhos divergentes para baixo, DIOS:DIOI, 2,46:2,83 -2,86:3,04. Distância interocelar 2,10-2,32 vezes o diâmetro do ocelo médio, 0,86:0,41 - 0,79:0,34. Distância alveolocular 3,27-3,57 vezes o diâmetro alveolar, 0,98:0,30 -
1,07:0,30. Comprimento do escapo $0,82-0,89$ vezes o do primeiro flagelômero, 1,03:1,25 - 0,96:1,08. Comprimento da mandíbula $1,97-2,06$ vezes a largura de sua base, 2,09:1,06-2,12:1,03. Célula marginal 3,05-3,10 vezes mais longa que larga, 1,80:0,59 $-1,61: 0,52$. Placa pigidial estreita (Fig. 82).

Macho. Diagnose. Comprimento total, 13,4-15,3; largura da cabeça, 4,93-5,18. Tegumento amarelo claro no disco do labro e do clípeo. Preto no restante. Membrana das asas translúcida, com um suave tom méleo. Pilosidade como nas fêmeas. Olhos divergentes para baixo, DIOS:DIOI, 1,99:2,50 $2,16: 2,64$. Distância interocelar $1,71-1,76$ vezes o diâmetro do ocelo médio, 0,70:0,41 - 0,67:0,38. Distância alveolocular 1,201,39 vezes o diâmetro alveolar, 0,36:0,30-0,43:0,31. Comprimento do escapo 0,85-0,93 vezes o do primeiro flagelômero, 0,91:1,07 $-0,96: 1,03$. Comprimento da mandíbula 1,84 a 1,88 vezes a largura de sua base, 1,80:0,98 - 1,90:1,01. Célula marginal 3,21-3,37 vezes mais longa que larga, 1,86:0,58-2,02:0,60.

Tipos. A descrição original não permite saber se foram incluídas uma ou mais fêmeas na série-tipo. A localidade-tipo é Coquimbo, Chile. Provável local de depósito: "Museo Regionale Scienze Naturali” em Turim, Itália (não examinados).

Distribuição geográfica. De Coquimbo a Malleco, no Chile (Fig. 158). Segundo Toro (1986) ocorre também na província de Atacama. Há ainda alguns registros para o outro lado dos Andes, em Tucumán e Córdoba, na Argentina, em Tarija, na Bolívia e no Peru, sem localidade definida. SснRотткy (1913: 261) menciona a ocorrência desta espécie em Mendoza e RoIGAlsina (2000) cita-a para a província de Neuquén, próximo a Nirihuau, e para Chubut, em Los Alerces. A sua ocorrência do lado oriental dos Andes é um caso interessante de ser estudado, pois ela é, aparentemente, muito mais abundante no Chile, onde está registrada somente até $1500 \mathrm{~m}$ de altitude.

Material examinado. PERU. 1 M, s. l., s. d., s. c. (MLUH). BOLÍVIA: $1 \mathrm{~F}$, Nogueche, 15-17/XII/1953, L. E. Pena leg. (SEMK). Tarija: 2 M, Chapare, El Palmar, 900m, 15/IX/1956, L. Peña leg. (SEMK). CHILE: IV Região: $1 \mathrm{~F}$ e $1 \mathrm{M}$, Canela Baja, 24/X/1961, L. E. Pena leg. (AMNH). 2 F, Choapa, Quebrada el Teniente, 24/X/1983, J. L. Neff leg. (CTMI), em Calceolaria sp. 1 F, Elqui, La Serena $40 \mathrm{~km} \mathrm{~S}$, idem, idem (CTMI. 1 fêmea. Elqui, Vicunha, $5 \mathrm{~km} \mathrm{~S}$, idem, idem (CTMI), em Hoffmannseggia sp. $1 \mathrm{M}, 10 \mathrm{Km}$ E. Fray Jorge Natl, 28/XII/1966, M. E. Irwin leg. (EME). 1 F, Fray Jorge coast, 4-5/XI/1957, L. Peña leg. (SEMK). 1 M, Fray Jorge Park, SSW of Tangue, 21/X/1966, C. O. Berg leg. (CUIC). 1 F, Illapel, 17/X/1933 (BMNH). 1 M, Hda. Illapel, 26/X/1954, 6001000 m, L. E. Pena leg. (SEMK). 1 M, Las Breas, 22/X/1989, E. Chiappa leg. (CFZ). 6 F e 4 M, La Serena, 8, 10 e 13/XII/1955, Wagenknecht leg. (SEMK). $1 \mathrm{~F}$ e $1 \mathrm{M}$, Serena (provavelmente La Serena), 3 e 25/XI/1945, s. c. (BMNH). 1 F, La Serena, 10/XI/1964, L. E. Peña leg. (AMNH). 1 F, ibidem, 28/XII/1988, L. Ruz leg. (CFZ). 1 F, Llano de la Higuera, 14/X/ 1957, L. Peña leg. (SEMK). 3 F e 4 M, Lomas de Peñuelas, 20 e 26/XI/ 1955, Wagenknecht leg. (SEMK). $1 \mathrm{~F}$, Pajonales, 30/XI/1955, idem (SEMK). 3 M, ibidem, 1000m, 16/X/1956, idem (SEMK). $1 \mathrm{~F}$, Pangue, S. Vicuna, 900m, 3/X/1961, L. E. Pena leg. (AMNH). 2 M, Peñuelas, 18/ XII/1955, Wagenknecht leg. (SEMK). 2 F e 2 M, Portezuelo Tres Cruces, $1900 \mathrm{~km}$ from Vicuña, 30-31/X/1957, L. Peña leg. (SEMK). $1 \mathrm{~F}$, Puerto Oscuro, 26/X/1961, L. E. Pena leg. (AMNH). 1 F, Vicuña, 21/III/1938, s. c. (BMNH). V Região: $2 \mathrm{~F}$ e 1 M, Casablanca, 15/XII/1954, Wagenknecht leg. (SEMK). 1 F, El Roble, coast range, in Nothofagus 


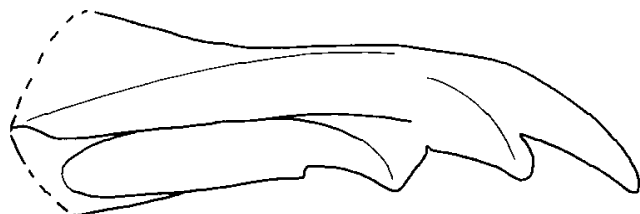

85

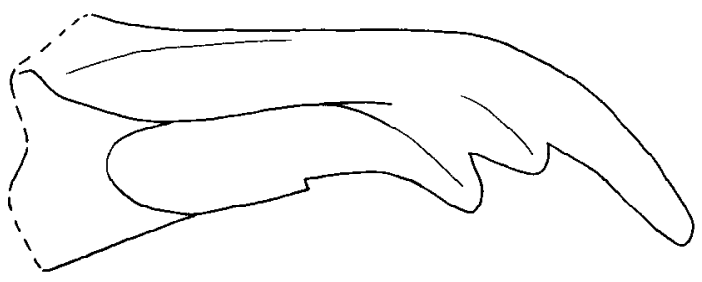

87
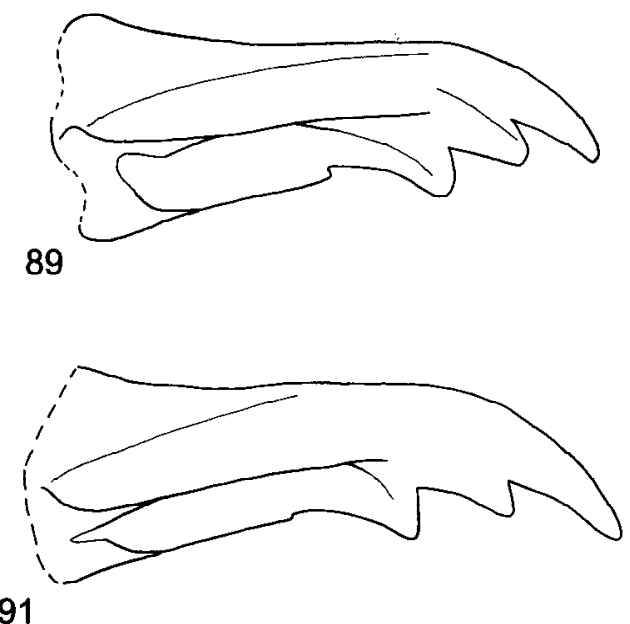

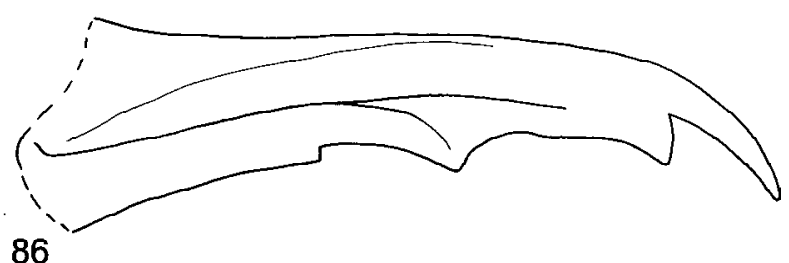

86

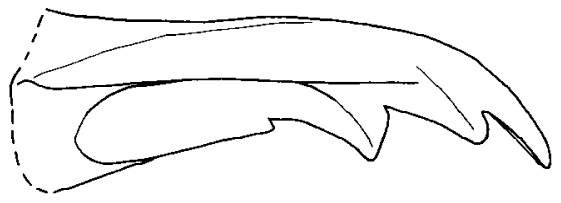

88
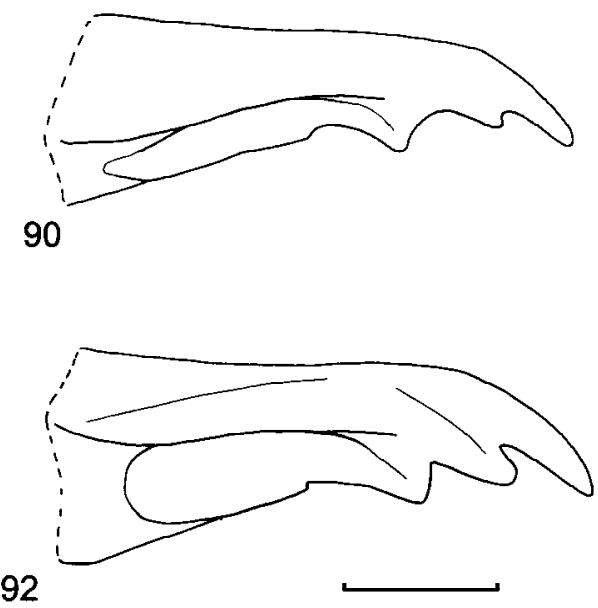

Figs. 85-92. Centris, mandíbula dos machos, vista superior. 85, C. (Penthemisia) brethesi; 86, C. (Penthemisia) buchholzi; 87, C. (Paracentris) burgdorfi; 88, C. (Penthemisia) chilensis; 89, C. (Paracentris) klugii; 90, C. (Penthemisia) mixta tamarugalis; 91, C. (Paracentris) mourei; 92, C. (Paracentris) tricolor. Escala $=0,5 \mathrm{~mm}$.

forest, 12/III/1966, L. E. Peña leg. (AMNH). 1 F e 1 M, El Quisco, XI/ 1950, L. Pena leg. (SEMK). 1 F e 78 M, Guardia Vieja, XI/1953, idem (SEMK). 2 F, Llai-Llai, 1/I/1927, F. \& M. Edwards (BMNH). 3 F, Limache, 16/III/1927, s. c. (ZMUC). 1 M, Olmué, 9/II/1920, P. Herbst leg. (ZMUC). 1 F, Viña del Mar, 12/XII/1915, idem (ZMUC). Santiago: 1 M, Algorrobo, XI/1950, L. Pena leg. (SEMK). 9 M, Apoquindo, 1/I/1964, s. c. (MZSP). $1 \mathrm{~F}$ e $21 \mathrm{M}$, ibidem, I/1964, L. E. Pena leg. (AMNH). $1 \mathrm{~F}$ e $1 \mathrm{M}$, El Canelo, XII/1952, L. E. Pena leg. (CUIC). 1 M, ibidem, 1100m, 6/X/ 1968, J. Vallencio leg. (UCCC). $18 \mathrm{~F}$ e $55 \mathrm{M}$, ibidem, XI/1952, L. E. Pena leg. (SEMK). $1 \mathrm{~F}$ e $1 \mathrm{M}$, ibidem, XII/1950 e 31/I/1949, idem (SEMK). 2 F e 36 M, Las Condes, X/1953, L. E. Pena leg. (SEMK). 1 M, ibidem, 1000m, idem, L. Pena leg. (EME). 3 M, Leyda, III e 28/XII/ 1948, L. Pena leg. (SEMK). 1 M, Llolleo, 13/XII/1953, L. Pena leg. (EME). 1 F, Los Queñes, 9/I/1985, Magunacelaya leg. (CFZ). 1 F, Quebrada de La Plata, 510m, 16/III/1960, Irwin leg. (EME). $1 \mathrm{~F}$, Quebrada de San Ramón, I/1975, L. E. Pena leg. (AMNH). 3 F e 2 M, Quebrada el Arbol ravine in Aculeo, costal range, X/1969, L. Pena leg. (AMNH). 2 F, Quilicura, X/1979, idem (AMNH). 1 F e 1 M, San Cristobal, XII/-9 (?), s. c. (ZMUC). 20 M, Santiago, 1/I/1964, L. E. Pena leg. (AMNH). VI Região: $1 \mathrm{~F}$, La Correana, rio Tinguiririca, 1400m, 16-20/II/1977, L. E. Pena leg. (AMNH). $1 \mathrm{M}$, Las Nieves, 750m, 15/XI/1947, idem (SEMK).
4 F e 21 M, Peumo, X, XI/1951 e 28/XII/1950, L. E. Pena leg. (SEMK). VII Região: 1 M, Pte. Malcho in Parral area, I/1979, L. E. Peña leg. (AMNH). 4 M, Teatinos, Pre-Andes, 15/II/1961, idem (AMNH). 1 M, Tregualemu on coast W. Cauquenes, 26/I/1967, idem (AMNH). $1 \mathrm{~F}$ e 80 M, Rio Teno, Cordillera Curicó, 1300m, 7-14/II/1965, idem (AMNH). VIII Região: 1 M, Chillán, 8/I/1980, Martinez leg. (CFZ). $1 \mathrm{~F}$, Contulmo, 25/II/1968, Sanfeliú leg. (MZSP). 1 M, Fray Gorge, 7/XII/1983, Quezada leg. (UCCC). $1 \mathrm{M}$, Isla Quiriquina, 11/XI/1959, Muñoz leg. (UCCC). $1 \mathrm{~F}$, Las Cabras, S. Chillan Vulcano, 1500m, 6-31/I/1963, L. E. Pena leg. (AMNH). 1 F, Las Trancas, 23/I/1955, 1200-11400m, idem (SEMK). 1 M, San Pedro, 15/XII/1956, Cid leg. (UCCC). 2 M, Tregualemo [sic] (Trogualemo), XII/1953, L. E. Pena leg. (SEMK). 3 F e 3 M, s. l., III/ 1904 e 6/I/1906, P. Herbst (ZMUC). 1 F e 3M, s. l., III/03. I/1904. 2/I. 7/III/1906, idem (NHMW). IX Região: 1 F, Angol, 8/XII/1940, E. Martinez leg. (SEMK). $1 \mathrm{M}$, ibidem, 12/XII/1937, s. c. (CUIC). $1 \mathrm{M}$, Marimenuco, I/1964, L. E. Pena leg. (AMNH). ARGENTINA. Catamarca: $1 \mathrm{M}$, Fundo San Lorenzo de Queime, E. Concepcion, I/ 1970, L. Pena leg. (AMNH). Tucumán: 1 M, Quelme E. of Concepción, I/1970, L. Pena leg. (AMNH). Córdoba: 2 F e 1 M, Fundo Malcho, I/ 1957, L. Peña leg. (SEMK). 
Centris (Paracentris) toroi sp. nov.

(Figs. 51, 67, 83, 101, 119, 137, 153, 162)

Centris autrani; Vachal, 1904: 16 (partim).

Centris (Paracentris) flavohirta; Roig-Alsina, 2000: 186 (partim).

Vachal (1904) descreveu Centris autrani, a partir de exemplares coletados em Tucumán, Argentina, e mencionou ter estudado uma fêmea de uma variedade de Arica, Chile. Os exemplares da Argentina correspondem à espécie descrita por (Friese, 1900) como C. flavohirta. A espécie aqui descrita como Centris toroi é do norte do Chile e apresenta pilosidade preta em todo o metassoma, o que está de acordo com as características dadas por VACHAL (op. cit.) para distinguí-la da forma típica de Centris autrani. As ilustrações apresentadas por Ayala (1998) como sendo de um exemplar de C. autrani devem corresponder a espécie aqui descrita. Essa identificação errônea certamente deve-se a inclusão do exemplar de Arica na descrição de Vachal (ver também etiquetas de identificação nos tipos).

\section{Descrição}

Holótipo, macho. Dimensões (mm). Comprimento total 13,8 $(11,9)$; largura da cabeça 4,75 $(4,51)$; comprimento da cabeça 2,98 (2,62); largura do mesossoma, incluindo tégulas, 6,21(5,91); comprimento da asa, do esclerito costal ao ápice, 10,76 $(10,05)$.

Tegumento. Predominantemente preto, incluindo o labro e clípeo. Vermelho-ferrugíneo nos T5, 6 e 7 e S5 e 6. Membrana das asas translúcidas com um tom méleo. Disco do clípeo finamente enrugado, com pouco brilho.

Pilosidade. Predominantemente preta, inclusive nos escleritos metassomáticos avermelhados. Amarelo-palhaesbranquiçada no vértice, mesoscuto, escutelo e laterais do metanoto; entremeada com pelos pretos na base e laterais do T1; uns poucos pêlos na parte dorsal do pronoto.

Forma e proporções. Olhos divergentes para baixo, DIOS 2,04, DIOI 2,46 (2,00:2,39). Distância ocelocular 0,89-0,97 vezes o diâmetro do ocelo médio, $0,34: 0,38(0,34: 0,35)$. Distância interocelar 2,16-2,29 vezes o diâmetro do ocelo médio, $0,82: 0,38$ $(0,76: 0,35-0,80: 0,35)$. Distância entre alvéolos antenais 3,443,60 vezes o diâmetro alveolar, $0,91: 0,26(0,86: 0,25-0,90: 0,25)$. Distância alveolocular 1,65-1,68 vezes o diâmetro alveolar, $0,43: 0,26(0,42: 0,25)$. Comprimento do escapo 0,97-0,98 vezes o do primeiro flagelômero, $0,94: 0,96(0,86: 0,89)$. Primeiro flagelômero $1,14-1,20$ vezes mais longo que os três seguintes juntos, 0,96:0,84 (0,89:0,74). Comprimento da área malar 0,200,22 vezes a largura da mandíbula, $0,17: 0,84(0,18: 0,82)$. Comprimento da mandíbula 2,26-2,29 vezes a largura de sua base, $1,90: 0,84(1,88: 0,82)$. Segundo dente subapical da mandíbula subquadrangular, com bordo apical côncavo (Fig. 101). Palpo maxilar com quatro artículos. Parte da segunda abcissa de $\mathrm{M}$, anterior à $1 \mathrm{a} \mathrm{m}$-cu, $0,40-0,45$ vezes o seu comprimento total, $0,38: 0,95(0,34: 0,86-0,38: 0,84)$.

Esternos pré-genitais e genitália. Figs. 119, 137 e 153.

Alótipo, fêmea. Dimensões (mm). Comprimento total 12,8
$(12,7-13,1)$; largura da cabeça 4,69 $(4,63-4,70)$; comprimento da cabeça 2,80 (2,92); largura do mesossoma, incluindo tégulas, $6,09(5,85-6,27)$; comprimento da asa, do esclerito costal ao ápice, $9,81(9,33)$.

Tegumento. Predominantemente preto. Vermelhoferrugíneo nos T4, 5 e 6 e S 5 e 6, incluindo a placa pigidial. Disco do clípeo com microcarenas longitudinais vermiculadas. Membrana das asas translúcida, com um tom méleo.

Pilosidade. Predominantemente preta, inclusive nas genas, T5 e 6 e fímbrias pré-pigidial e pigidial. Amarelo-palhaesbranquiçada no vértice, região dorsal do pronoto, mesoscuto e escutelo; no labro, clípeo, paroculares e fronte, entremeada com cerdas pretas.

Forma e proporções. Olhos um pouco divergentes para baixo, DIOS 2,65 e DIOI 2,83 (2,54:2,74). Distância ocelocular 1,62-1,82 vezes o diâmetro do ocelo médio, $0,62: 0,34(0,60: 0,37)$. Distância interocelar 2,46-2,76 vezes o diâmetro do ocelo médio, 0,94:0,34 (0,89:0,35 - 0,91:0,37). Distância entre alvéolos antenais 3,50-3,88 vezes o diâmetro alveolar, 1,01:0,26 (0,98:0,28). Distância alveolocular 2,50-2,85 vezes o diâmetro alveolar, 0,74:0,26 (0,70:0,28). Comprimento do escapo 0,89-0,95 o do primeiro flagelômero, $0,98: 1,03(0,91: 1,02)$. Primeiro flagelômero $1,43-1,47$ vezes mais longo que os três seguintes juntos, $1,03: 0,72(1,03: 0,70)$. Comprimento da área malar $0,23-0,29$ vezes a largura da mandíbula, 0,25:0,96 (0,22:0,94 - 0,26:0,89). Comprimento da mandíbula 2,29-2,38 vezes a largura de sua base, 2,20:0,96 (2,12:0,89). Mandíbula com a base do dente apical larga (Fig. 51). Palpo maxilar com 4 artículos. Parte da segunda abcissa de $\mathrm{M}$, anterior à $1 \mathrm{a} \mathrm{m}$-cu, $0,46-0,47$ vezes o seu comprimento total, $0,38: 0,82(0,36: 0,77)$. Placa basitibial estreita (Fig. 67).

Tipos. Holótipo macho com as seguintes etiquetas: "CHILE:Region I, Zapahuira-Murmuntani, 3340-3380m., 3 March 1984, M. T. Kalin Arroyo", "Coreopsis suaveolens", "1548" (número manuscrito a lápis) e "HOLOTYPE, Centris toroi sp. n., F. Zanella, 2002" (SEMK). Alótipo fêmea do mesmo local e data de coleta, com a primeira etiqueta igual à do holótipo, mais as seguintes: "Sisyrinchium trinerve", "1543" (número mauscrito a lápis) e "ALOTYPE, Centris toroi sp. n., F. Zanella, 2002" (SEMK). Parátipo, fêmea, com a seguinte etiqueta manuscrita: "Socoroma, 3000m, Arica, Tarapacá, Chile.20-II1979, Coll. N. Hichins O.” (IDEA). Parátipo, macho, com a seguinte etiqueta manuscrita: "Belén Alto, Queñuales, Enero 29, 1982, B.H.V. colls.” (IDEA). 1 parátipo fêmea com as seguintes etiquetas: "CHILE:Region I, Zapahuira, 3250-3300m., 3 March 1984, M. T. Kalin Arroyo", "Senna birostris" " "1508" e 1 parátipo macho com as seguintes etiquetas: "CHILE:Region I, Putre, 3250m., 2 March 1984, M. T. Kalin Arroyo", "Viguiera pazensis" e "1479" (UCVC). Parátipos, todos depositados no SEMK e com etiqueta com número manuscrito a lápis: 2 fêmeas com primeira etiqueta idêntica à do holótipo e com as seguintes etiquetas adicionais: "Bidens andicola", "1514" e "Coreopsis suaveolens" e "1549", respectivamente. 1 fêmea com as seguintes etiquetas: "CHILE:Region I, Zapahuira, 3250-3300m., 3 March 1984, M. T. Kalin Arroyo", "Senna birostris" e "1556". 


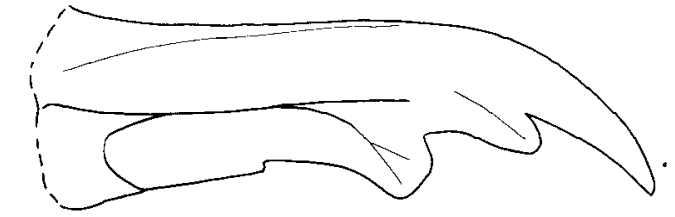

93

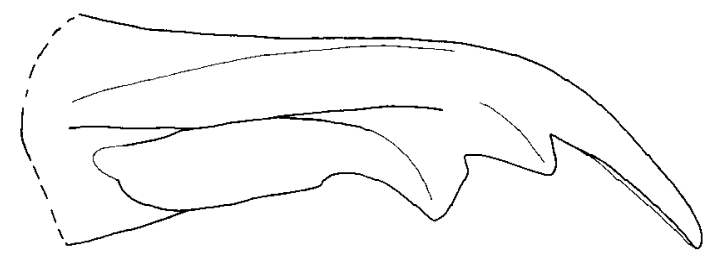

95

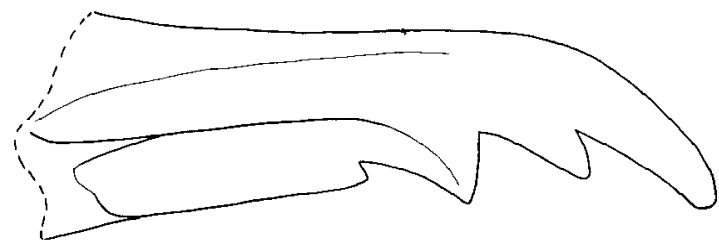

97

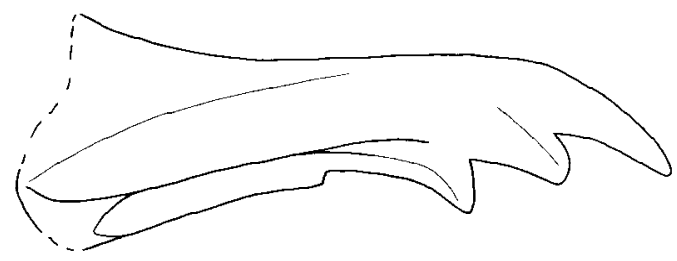

99

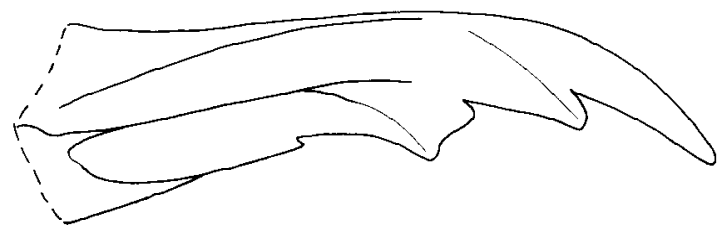

101

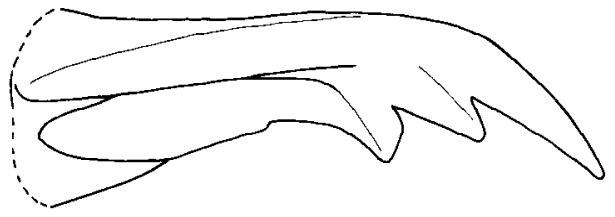

94

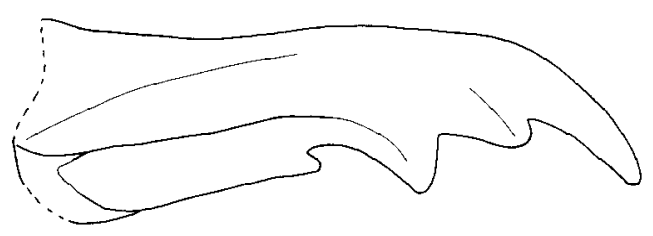

96

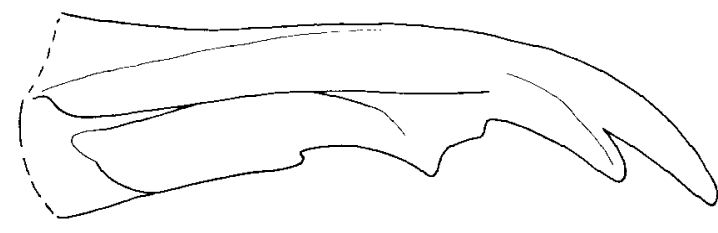

98
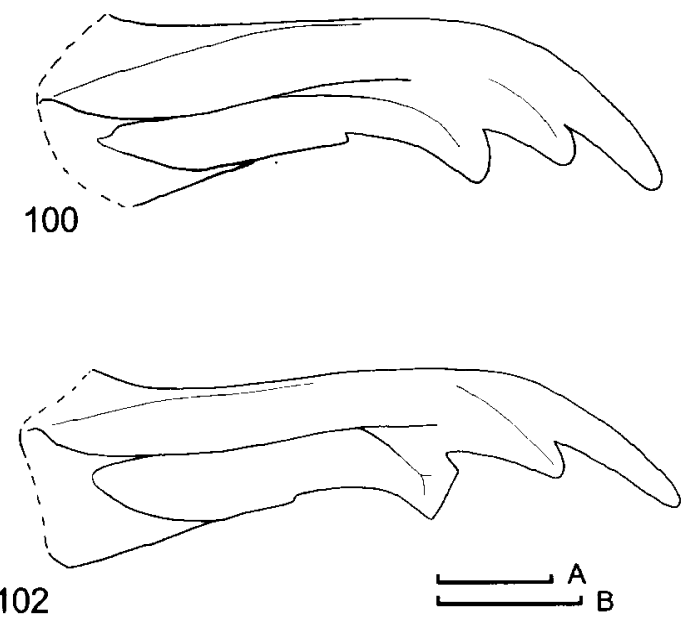

Figs. 93-102. Centris, mandíbula dos machos, vista superior. 93, C. (Paracentris) caelebs; 94, C. (P.) euphenax; 95, C. (P.) flavohirta; 96, C. (P.) vogeli; 97, C. (P.) lyngbyei; 98, C. (P.) neffi; 99, C. (P.) melanotrica sp. nov.; 100, C. (P.) nigerrima; 101, C. (P.) toroi sp. nov.; 102, C. (P.) unifasciata. Escalas $=0,5 \mathrm{~mm}$, A corresponde à figura $94 \mathrm{e} B$ às restantes.

1 fêmea com as seguintes etiquetas: "CHILE:Region I, Zapahuira, 3250m., 5 March 1984, M. T. Kalin Arroyo", "1580” e "Centris (Paracentris) autrani Vach. sp. nr., fêmea (símbolo), det. R. R. Sneling '86" ("autrani Vach. sp. nr., fêmea (símbolo)" e "'86" manuscritos). 1 fêmea sem abdômen, com as seguintes etiquetas: "CHILE:Region I, Zapahuira, 3150-3160m., 28 Feb 1984, M. T. Kalin Arroyo", "Calceolaria pulchella" e "1357”. 1 fêmea com as seguintes etiquetas: "CHILE:Region I, Putre, 3400m., 28-29 Feb 1984, M. T. Kalin Arroyo" e "1361". 1 fềmea com as seguintes etiquetas: "CHILE:Region I, Putre, 3280- 3500m., 4 March 1984, M. T. Kalin Arroyo", "Calceolaria pulchella" e "1568". 1 macho com as seguintes etiquetas: "CHILE:Region I, Putre, 3500m., 26-28 Feb 1984, M. T. Kalin Arroyo", "Adesmia verrucosa" e "1291". 1 macho com as seguintes etiquetas: "CHILE:Region I, Putre, 3400m., 28-29 Feb 1984, M. T. Kalin Arroyo", “Adesmia verrucosa" e "1290”. Todos os parátipos com etiqueta "PARATYPE, Centris toroi sp. n., F. Zanella, 2002".

Distribuição geográfica. Na vertente ocidental dos Andes, 
sendo registrada apenas na província de Tarapacá, Chile, em altitudes entre 3250 e $3500 \mathrm{~m}$ (Fig. 162).

Etimologia. O nome da espécie é uma homenagem ao Prof. Haroldo Toro (in memoriam), da Universidade Católica de Valparaíso, pela sua contribuição ao conhecimento das abelhas do Chile e pelo apoio ao presente trabalho.

\section{Centris (Paracentris) tricolor Friese, 1900} (Figs. 46, 61, 77, 92, 108, 126, 144, 157)

Centris lanipes; Burmeister, 1876: 163 (non Centris lanipes Fabricius, 1775; identificação errônea).

Centris tricolor Friese, 1900: 45; 1901: 309

Hemisia (Penthemisia) tricolor; Michener, 1951: 4.

Centris (Paracentris) tricolor, Roig-Alsina, 2000: 188.

\section{Redescrição}

Lectótipo, fềmea. Dimensões (mm). Comprimento total 14,4 $(13,0-15,3)$; largura da cabeça 5,36 $(4,81)$; comprimento da cabeça 3,47 (3,11-3,53); largura do mesossoma, incluindo tégulas, 5,85 (5,78-6,03); comprimento da asa, do esclerito costal ao ápice, 10,12 $(9,33)$.

Tegumento. Preto a castanho-escuro na cabeça, mesossoma, pernas e parte apical da placa pigidial. Predominantemente vermelho-ferrugíneo no metassoma. Membrana das asas translúcida, com um suave tom méleo. Clípeo com pontuação alveolada, fina-moderada, densadispersa; Tegumento liso e brilhante entre os pontos; Faixa mediana longitudinal lisa (ás vezes um pouco enrugada, provavelmente devido à preservação).

Pilosidade. Amarelo-palha no pronoto, lóbulo pronotal, mesonoto, metanoto, terço superior do mesepisterno, no vértice, tégulas, $\mathrm{T} 1$ e predominantemente no propódeo; no labro entremeada com cerdas castanho-escuras; tufos nas áreas paroculares e na supra-clipeal, abaixo dos alvéolos antenais (em alguns exemplares de Mendoza, Tucumán e Córdoba, a pilosidade do labro e da fronte é totalmente preta). Pilosidade castanho escura a preta na fronte, genas, pernas e, de modo predominante, na região ventral do corpo. Semi-erecta, não ramificada e de coloração ferrugínea no disco do T2. Fímbrias pré-pigidial e pigidial castanho-escuras a pretas (em alguns exemplares de Mendoza, são mais claras, com um tom ferrugíneo).

Forma e proporções. Olhos um pouco convergentes para baixo, DIOS 2,88 e DIOI 2,59 (2,57:2,52). Distância ocelocular 1,71-1,95 vezes o diâmetro do ocelo médio, $0,70: 0,37(0,60: 0,35$ $-0,72: 0,37)$. Distância interocelar 2,30-2,41 vezes o diâmetro do ocelo médio, 0,89:0,37 (0,83:0,35). Distância entre alvéolos antenais 2,76-3,88 vezes o diâmetro alveolar, 1,01:0,26 (0,94:0,29 $-0,94: 0,34)$. Distância alveolocular 1,82-2,31 vezes a o diâmetro alveolar, 0,60:0,26 (0,58:0,29-0,62:0,34). Escapo 1,05-1,12 vezes mais longo que o primeiro flagelômero, 1,10:0,98 (0,98:0,91 1,01:0,96). Primeiro flagelômero $1,08-1,14$ vezes mais longo que os três seguintes juntos, 0,98:0,91 (0,91:0,83 - 0,96:0,86). Comprimento da área malar $0,12-0,14$ vezes a largura da mandíbula, $0,13: 1,06(0,12: 0,96-0,14: 1,01)$. Comprimento da mandíbula 1,83-2,10 vezes a largura de sua base, 1,97:1,06 $(1,87: 1,02-2,02: 0,96)$. Palpo maxilar com cinco artículos (em uma fêmea do Chaco, Argentina, somente quatro). Parte da segunda abcissa de $\mathrm{M}$, anterior à $1 \mathrm{a} \mathrm{m}-\mathrm{cu}, 0,44-0,47$ vezes o seu comprimento total, 0,38:0,81 (0,39:0,89). Placa basitibial secundária com bordo apical formando uma linha arredondada e com declive acentuado no bordo posterior (Fig. 61). Placa pigidial com bordos laterais côncavos (Fig. 77).

Macho. Diagnose. Comprimento total, 11,9-13,8; largura da cabeça, 4,40-4,87. Tegumento castanho-escuro a preto na cabeça, mesossoma e pernas; amarelo no labro e disco do clípeo; vermelho-ferrugíneo no metassoma. Pilosidade predominantemente castanho-escura a preta na cabeça, pernas e região ventral do corpo; amarelo-palha no pronoto, mesonoto, metanoto, chegando até a metade dos mesepisternos (em alguns exemplares de Mendoza cobrindo toda a parte lateral do mesossoma), tégulas, vértice (às vezes se estendendo pela parte posterior das genas) e T1. No labro, pilosidade esbranquiçada entremeada com umas poucas cerdas castanhoclaras; nos bordos, cerdas castanho-escuras a pretas. Ferrugínea, semi-erecta, não ramificada, no disco do T2. Distância interocular superior semelhante à inferior, 2,11:2,04$2,16: 2,18$. Escapo um pouco mais longo que o primeiro flagelômero, 0,91:0,79-0,94:0,84. Primeiro flagelômero menor que os três seguintes juntos, $0,79: 0,89-0,84: 1,01$. Comprimento da área malar $0,11-0,14$ vezes a largura da mandíbula, 0,10:0,94 $-0,12: 0,86$. Comprimento da mandíbula 1,64-1,84 vezes a largura de sua base, 1,54:0,94 - 1,58:0,86. e) S7 com lados da projeção apical quase paralelos e bordo apical formando ângulo (Fig. 108). S8 com ápice truncado (Fig. 126).

Tipos. Lectótipo, aqui designado, fềmea, com as seguintes etiquetas: "1575" (?, etiqueta manuscrita ilegível), "Montevid., Sello" (etiqueta verde), "Centris tricolor, fêmea (símbolo) det Friese 1898" (nome da espécie e símbolo do sexo manuscritos), "Type" (etiqueta alaranjada), "Zool. Mus. Berlin" e "LECTOTYPE, Centris tricolor Friese, F. Zanella, 2002" (etiqueta amarela) (MNHU). Paralectótipos: uma fêmea com as seguintes etiquetas: "Stieglmayr, Rio Gr. do Sul", "Centris tricolor, fêmea (símbolo), det. Friese, 1898, n. sp." (etiqueta manuscrita com "det. Friese" e ano impressos), " " (etiqueta redonda pequena amarela), "Paratype" (etiqueta rosa) e "PARALECTOTYPE, Centris tricolor Friese, F. Zanella, 2002" (etiqueta amarela) (NHMW); duas fêmeas com etiquetas semelhantes, mas faltando a etiqueta pequena amarela e, em uma delas, faltando também a notação "n. sp." (NHMW). FriESE (1900) menciona na descrição original ter estudado seis fêmeas coletadas no Rio Grande do Sul por Stieglmayer e depositadas no Museu de Viena; machos e fêmeas coletadas em Montevidéu por Sello, sem especificar o número, depositadas no Museu de Berlim; e uma fêmea de Mendoza, coletada por Burmeister, mais fêmeas e machos de Blumenau e Córdoba, coletados por Hyeronomus e depositados no Museu de Halle. A presente designação de lectótipo, e a sua descrição, tem por objetivo a definição segura do sentido do nome, tendo em vista a 

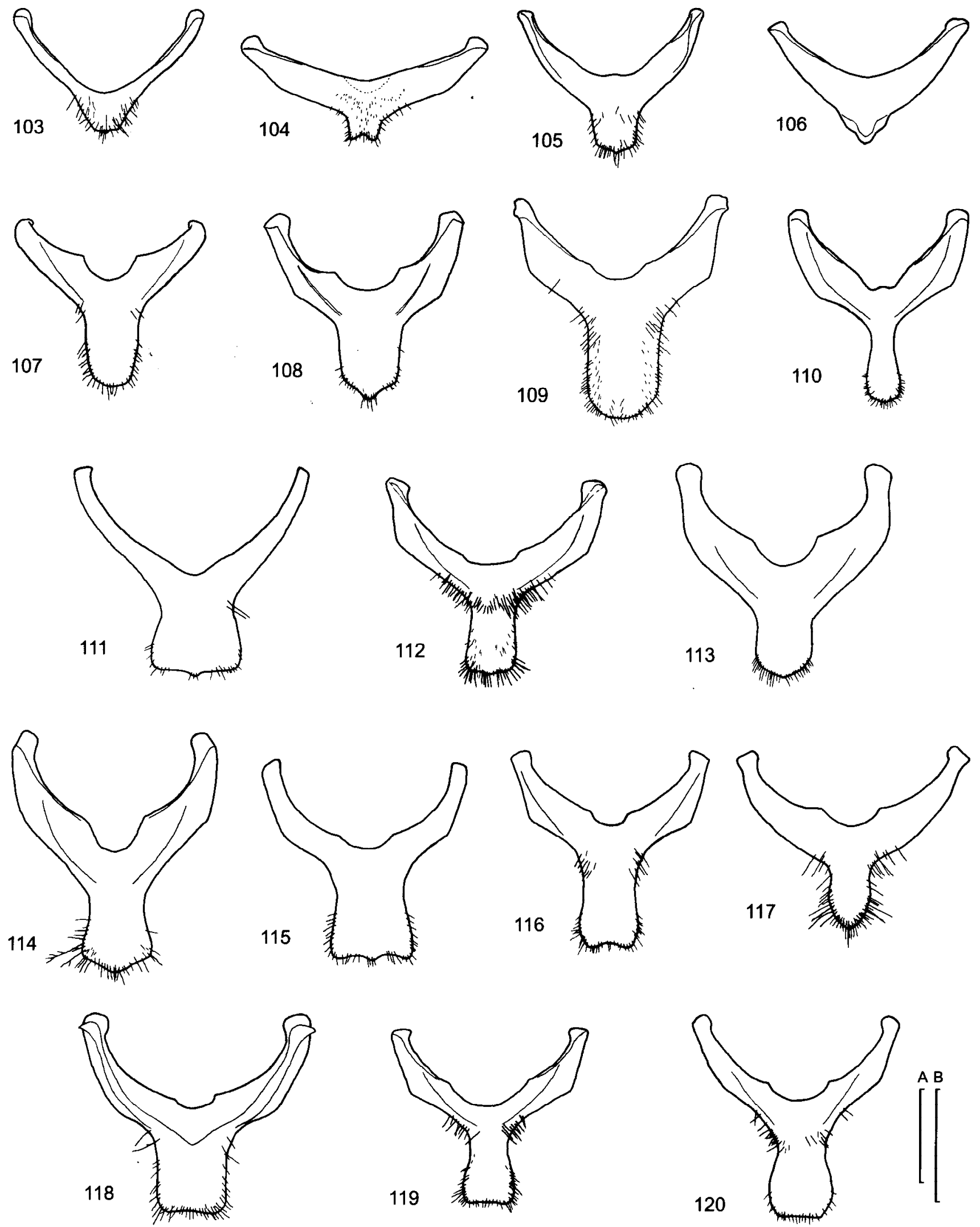

Figs. 103-120. Centris, S7, machos. 103, C. (Penthemisia) brethesi; 104, C. (P.) buchholzi; 105, C. (P.) chilensis; 106, C. (P.) mixta tamarugalis; 107, C. (Paracentris) mourei; 108, C. (P.) tricolor; 109, C. (P.) burgdorfi; 110, C. (P.) klugii; 111, C. (P.) lyngbyei; 112, C. (P.) caelebs; 113, C. (P.) euphenax; 114, C. ( $($.) flavohirta; 115, $C$. ( $(P$.$) vogeli; 116, C. (P$.$) neffi; 117, C. (P.) cordillerana; 118, C .(P$.$) nigerrima; 119, C .(P$.$) toroi sp. nov.;$ 120, $C$. (P.) unifasciata. Escalas $=0,5 \mathrm{~mm}$, A corresponde à figura $109 \mathrm{e} \mathrm{B}$ às restantes. 
semelhança com outras espécies do gênero, o que determinou uma certa confusão (ver comentários e relação de material examinado em C. lyngbyei e C. mourei).

Distribuição geográfica. Em uma larga faixa que inclui o sul do Paraguai e do Brasil, o Uruguai e o norte da Argentina, até a latitude de Buenos Aires, sendo limitada a oeste pelos Andes e a leste, chegando próximo à costa do Atlântico (Fig. 157). Roig-Alsina (2000) menciona, ainda, a sua ocorrência nas provícias de Jujuy e San Luis. Registrada até 3000 m de altitude, em Catamarca, Argentina (ver relação de material examinado). Segundo Moure (comunicação pessoal, em SiLVEIRA \& CURE, 1993), um exemplar de C. tricolor foi coletado em Minas Gerais, na região de Diamantina. Dentre o material analisado no presente estudo o registro mais ao norte corresponde à região central do Paraguai e, no Brasil, ao Estado de Santa Catarina. É possível que o exemplar observado em Diamantina se trate de um $C$. klugi, espécie semelhante a C. tricolor e que já foi confundida em relação a exemplares coletados no Paraná (ver relação de material examinado de C. klugi).

Material adicional examinado. BRASIL. Santa Catarina: $1 \mathrm{M}$, Blumenau, 1897, s. c. (MNHU), etiquetas adicionais: "Centris tricolor Fr, macho (símbolo), 1910 Friese det.", "Type (etiqueta vermelhoescura). 33 F e 1 M, Seara, Nova Teutônia, VI. X. XI. XII/1951, II/1952, L. E. Plaumann leg. (SEMK). Rio Grande do Sul: 3 F, Caçapava do Sul, Guaritas, em 12/XI/1991, 15/XI/1991 e 7/XII/1991, respectivamente, C. Schlindwein leg. (LPB). 1 M, Porto Alegre, 24/I/1987, D. Wittmann leg. (MCNZ). 1 F, Quaraí, 19/XI/1985, M. Hoffman leg. (MCNZ). 2 macho, ibidem, 20 e 22/XI/1985, R. Radtke leg. (MCNZ). 1 F, Rosário do Sul, 30/XI/1985, D. Wittmann leg. (MCNZ). 1 M, São Leopoldo, $s$. d., J. W. Stahl leg. (SMNH). PARAGUAI. 6 M, Chaco, s. d., Fiebrig leg. (NHMW). 20 M, Serro - Pelado, XI/1951, F. H. Selade leg. (SEMK). Guairá: $1 \mathrm{~F}$, Col. Independência, 25/I/1951, J. Foester leg. (SEMK). Itapúa: $1 \mathrm{M}$, Hohenau, IV/1953, Walz leg. (SEMK). ARGENTINA: Salta: 2 F, r. 34 km 21, 14/I/1973, J. Neff leg. (CAS). Formosa: 2 F e 30 M, Gran Guardia, 21/X. 1/XI. 15/XII/1952, J. Foester leg. (SEMK). Chaco: 1 F, Colônia Benitez, 11/XII/1948, R. Gelbach leg. (IMLA). Catamarca: $3 \mathrm{~F}$ e $1 \mathrm{M}$, Andalgalá, s. d., J. Neff leg. (CAS). $1 \mathrm{~F}$ e $3 \mathrm{M}$, Belen, s. d., idem (CAS). 1 M, Buena Vista-Aconquija, 11/XI/1972, idem (CTMI), em Lathyrus pubescens. $4 \mathrm{~F}$ e $1 \mathrm{M}$, Cuesta Minas Capillitas, $3000 \mathrm{~m}$, s. d., idem (CAS). Outros exemplares de mesmo local, coletor e depositados no CTMI: 1 F, 21/XII/1972, em Opuntia sulfurea; 2 F, 28/ I/1973, uma em Solanum sp. e outra em Calceolaria loventziana; 1 M, 18/II/1973, em Oxalis argentina; 1 F, 17/XII/1973, em Nierembergia sp.; e 1 M, 23/XII/1973, em Cercidium praecox. 4 M, El Pucara, puna site, s. d., idem (CAS). $1 \mathrm{M}$, Joyango-Colpes site, s. d., idem (CAS). $2 \mathrm{M}$, El Alto Km 170, 13/I/1960, Willink leg. (IMLA). Tucumán: 1 F, Horco Molle, 16-31/X/1967, C. Porter leg. (AMNH). 1 F, Los Cardones, 16/ XII/1973, J. Neff (CTMI), em Justicia sp. 1 F, Nr-Anpimpa [sic](=Ampimpa), 27/XII/1968, C. Porter leg. (AMNH). 2 M, Trancas, San Pedro de Colaloa $[s i c](=$ S. P. de Colalao), II/1951, s. c. (SEMK). 1 F, San Pedro de Colalao, 30/III/1944, Guanuco leg. (IMLA). 2 F e 5 M, (possivelmente San Miguel de Tucumán), s. d., M. Arnau leg. (SEMK). 1 M, ibidem, San Vincente, 25/I/1986, J. Neff leg. (CTMI). 1 F, Trancas, San Pedro de Calalao, 30/III/1949, Guanuco leg. (IMLA). Misiones: $1 \mathrm{M}$, Loreto, XII/1955, s. c. (SEMK). 1 macho. Pto. Bemberg (Atualmente Pto. Libertad), 13/XII/1933, Hayward expedition (SEMK). 1 F, San Ignacio, IV/1956, s. c. (SEMK). 1 F, s. l., 13-14/I/1927, F. \& M. Edwards leg. (BMNH). Corrientes: $1 \mathrm{~F}$, Stuzaingo, Isla Apipe Grande, XI/1945, A. Martinez leg. (SEMK). Córdoba: $1 \mathrm{~F}$, Capilla d. Monte, s. d., Coll. Prf. Hosseus (ZSMC). 1 M, ibidem, 11/II/1928, idem (ZSMC), em Perezia multiflora. $1 \mathrm{~F}$, Salsacate, $8 \mathrm{Km}$ W Cordoba, 17/IV/1967, L. Pena leg. (AMNH). 1 F, ibidem, 24/II/1966, C. Porter leg. (AMNH). 1 F, s. l., s. d., Hienonym. leg. (SEMK). Santa Fé: 1 F, Estancia La Noria, Rio San Javier, 9/XII/1911, G. Bryant leg. (BMNH). 1 F, Tastagal, 27/II/1946, Hayward \& Willink leg. (IMLA). 2 F, Villa Ana, 4/II/1946, Hayward \& Willink leg. (IMLA), etiqueta adicional "Centris brethesi Schr. Det. J. Moure". La Rioja: 1 F, Anjullon, 3/XI/1972, J. Neff leg. (CTMI), em Solanum sp. Entre Rios: 1 F, rio Martinez, IX/1953, J. Foester leg. (SEMK). 1 M, delta do rio Parana, 16/II/1954, M. M. Senkute leg. (SEMK). $1 \mathrm{~F}$, Villaguay, 15/XI/1951, idem (SEMK). Mendoza: $1 \mathrm{M}$, Cacheuta, 17/II/1966, C. Porter leg. (AMNH). 1 F, Chacras de Coria, 2/ XI/1906, Jensen-Haarup leg. (ZMUC). 1 F, ibidem, 28/XI/1904, P. Jörgensen leg. (ZMUC). 1 F, Est. Pedregal, 14/XII/1906, Jensen-Haarup leg. (ZMUC). $1 \mathrm{~F}$, Mendoza, 2/IV/1967, L. Pena leg. (AMNH). $6 \mathrm{~F}$ e 4 M, possivelmente Mendoza, 12/XII/1904, 3/IV. 4/IV. 26/XI. 30/XI / 1908, P. Jörgensen leg. (ZMUC). Buenos Aires: 1 M, San Isidro, 23/II/ 1951, J. Foester leg. (SEMK). 1 M, Tigre, 8/II/1920, s. c. (CUIC).

Centris (Paracentris) unifasciata (Schrottky, 1913) (Figs. 52, 68, 84, 102, 120, 138, 155, 159)

Hemisia garleppi unifasciata Schrottky, 1913: 708.

Centris (Paracentris) unifasciata; Moure, 2000 [1999]: 155.

Centris (Penthemisia) autrani; Moure, 1950: 392 (sinonímia com Hemisia garleppi unifasciata).

Centris (Paracentris) autrani; Moure, 2000 [1999]: 148 (identificação errônea).

As diferenças de tamanho entre os espécimens do Chile e do Peru sugerem que podem ser espécies distintas; entretanto, não foram observados caracteres estáveis, além dos relacionados ao tamanho, que permitissem a sua separação. A análise de mais exemplares, especialmente de machos do Peru, deve esclarecer esta questão. No presente trabalho são apresentadas diagnoses separadas para as duas populações, para ressaltar as diferenças encontradas. Ver também nota em Centris caelebs, no item variação.

Fêmea. Diagnose (espécimens do Peru). Comprimento total, 16,8-17,2; largura da cabeça, 5,45-5,79. Tegumento predominantemente preto. Vermelho-ferrugíneo nos S5 e 6 e nos T5 e 6. Metade apical da placa pigidial preta. Membrana das asas translúcida, com um tom castanho. Clípeo com microcarenas longitudinais e, às vezes, com carena medianolongitudinal suave. Pilosidade predominantemente preta, inclusive nos escleritos metassomáticos avermelhados; amarelo-palha na cabeça, região dorsal do pronoto, mesoscuto e escutelo; nas genas, entremeada com longas cerdas pretas. Distância interocular superior $0,88-0,93$ vezes a inferior, 2,90:3,29 $-2,94: 3,16$. Distância ocelocular 1,83-2,30 vezes o diâmetro do ocelo médio, $0,66: 0,36-0,77: 0,38$. Distância interocelar cerca de 2,39-2,72 vezes o diâmetro do ocelo médio, 0,91:0,38 0,98:0,36. Distância entre alvéolos antenais 3,94-4,31 vezes o diâmetro alveolar, 1,30:0,33 - 1,25:0,29. Comprimento do escapo 0,83-0,84 vezes o do primeiro flagelômero, $1,06: 1,27-1,18: 1,39$. Primeiro flagelômero 1,51-1,56 vezes mais longo que os três seguintes juntos, 1,27:0,84 - 1,39:0,89. Comprimento da mandíbula 2,26-2,28 vezes a largura de sua base, 2,76:1,22 2,62:1,15. Parte da segunda abcissa de $\mathrm{M}$, anterior à $1 \mathrm{a} \mathrm{m}-\mathrm{cu}, 0$, $37-0,50$ vezes o seu comprimento total, $0,41: 1,10-0,52: 1,04$.

Fêmea. Diagnose (espécimens do Chile). Comprimento total, 

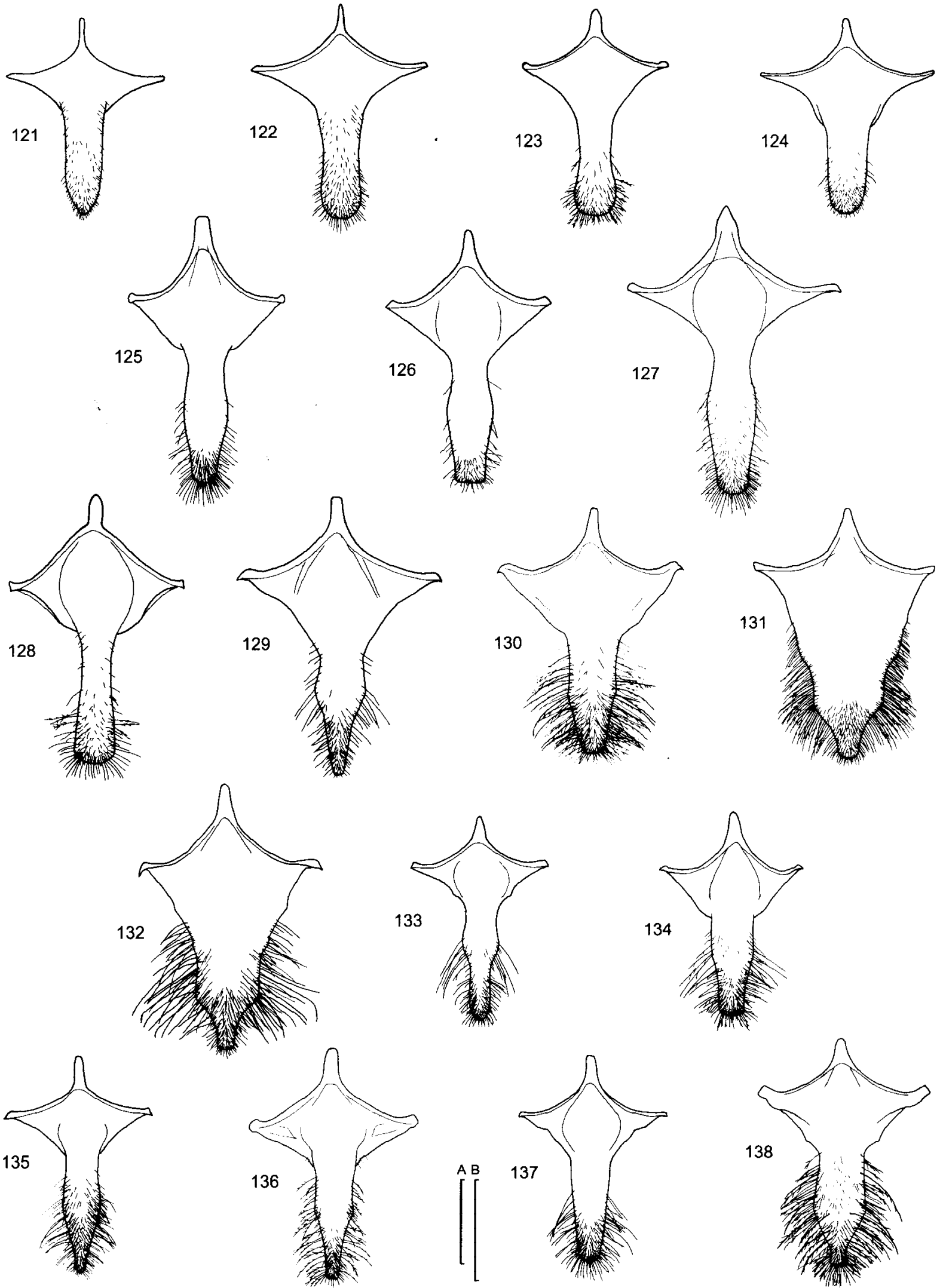

Figs. 121-138. Centris, S8, machos. 121, C. (Penthemisia) brethesi; 122, C. (P.) buchholzi; 123, C. (P.) chilensis; 124, C. (P.) mixta tamarugalis; 125, C. (Paracentris) mourei; 126, C. (P.) tricolor; 127, C. (P.) burgdorfi; 128, C. (P.) klugii; 129, C. (P.) lyngbyei; 130, C. (P.) caelebs; 131, C. $(P$.$) euphenax; 132, C. (P.) flavohirta; 133, C. (P.) vogeli; 134, C. (P.) neffi; 135, C. (P.) cordillerana; 136, C. (P.) nigerrima; 137, C. (P.) toroi sp.$ nov.; 138, $C$. (P.) unifasciata. Escalas $=0,5 \mathrm{~mm}$, A corresponde às figuras 127 e $130-138$ e $\mathrm{B}$ às restantes. 
12,0-13,3; largura da cabeça, 4,78-5,09. Tegumento predominantemente preto. Vermelho-ferrugíneo nos S5 e 6, T5 e $6 \mathrm{e}$, às vezes, também no terço apical do T4. Placa pigidial e membrana das asas como nos espécimens do Peru. Carena mediano-longitudinal do clípeo suave, com ou sem microcarenas longitudinais. Pilosidade semelhante à dos espécimens do Peru; usualmente preta no pronoto; em uma fêmea, amarelo-palha na região dorsal. Nas genas variável, predominantemente preta, com poucos pêlos baixos esbranquiçados, a predominantemente amarelo-palha-esbranquiçada, entremeada com longas cerdas escuras. Distância interocular superior 0,900,93 vezes a inferior, 2,76:3,06 - 2,69:2,90. Distância ocelocular $1,77-1,80$ vezes o diâmetro do ocelo médio, $0,62: 0,35-0,65: 0,36$. Distância interocelar cerca de 2,53-2,60 vezes o diâmetro do ocelo médio, 0,91:0,36 - 0,91:0,35. Distância entre alvéolos antenais 3,79-4,19 vezes o diâmetro alveolar, 1,10:0,29-1,09:0,26. Comprimento do escapo $0,74-0,92$ vezes o do primeiro flagelômero, 0,91:1,22 - 1,06:1,15. Primeiro flagelômero 1,401,58 vezes mais longo que os três seguintes juntos, 1,15:0,821,22:0,77. Comprimento da mandíbula 2,17 a 2,33 vezes a largura de sua base, 2,30:1,06-2,40:1,03. Parte da segunda abcissa de $\mathrm{M}$, anterior à $1 \mathrm{a} \mathrm{m}-\mathrm{cu}, 0,38-0,51$ vezes o seu comprimento total, 0,41:1,08-0,46:0,90. Placa pigidial estreita (Fig. 84).

Macho. Diagnose (espécimens do Chile). Comprimento total, 12,2-15,2; largura da cabeça, 4,48-4,93. Tegumento predominantemente preto. Amarelo-claro no disco do labro e do clípeo. Pilosidade predominantemente preta; amarelo-palhaesbranquiçada no disco do labro, vértice, área supra-clipeal, mesoscuto, quinto superior dos mesepisternos, laterais da base do propódeo e laterais do T1, no clípeo, próximo à área amarela, e, ás vezes, na região dorsal do pronoto e bordos apicais dos T5 e 6. Nas genas variável, de modo semelhante às fêmeas. Distância interocular superior 0,85-0,94 vezes a inferior, 1,93:2,26 $-2,28: 2,42-2,28: 2,69$. Distância ocelocular 0,76-1,15 vezes o diâmetro do ocelo médio, 0,29:0,38 - 0,46:0,40. Distância interocelar cerca de 1,87-2,05 vezes o diâmetro do ocelo médio, 0,71:0,38-0,82:0,40. Distância entre alvéolos antenais 3,00 a 3,63 vezes o diâmetro alveolar, 0,90:0,30-1,09:0,30. Comprimento do escapo 0,84-0,95 vezes o do primeiro flagelômero, 0,91:1,08 $-0,89: 0,94$. Primeiro flagelômero 1,06-1,32 vezes mais longo que os três seguintes juntos, 0,94:0,89-1,08:0,82. Comprimento da mandíbula 1,97 a 2,17 vezes a largura de sua base, 1,99:1,01 $-1,78: 0,82$. Segundo dente subapical subquadrangular (Fig. 102). Parte da segunda abcissa de $\mathrm{M}$, anterior à $1^{\mathrm{a}} \mathrm{m}-\mathrm{cu}, 0,32-$ 0,41 vezes o seu comprimento total, $0,32: 1,00-0,43: 1,03$. S8, ápice estreito, com lados paralelos (Fig. 138).

Tipo. Holótipo, fêmea, de Apurimac, Peru. Segundo Moure (2000), encontra-se em sua coleção e pertençe ao Muzeu de Zoologia da Universidade de São Paulo (não examinado).

Distribuição geográfica. Espécie andina, ocorre no norte do Chile e no Peru, com registros de 2800 a $3400 \mathrm{~m}$ de altitude (Fig. 159). Há ainda um registro duvidoso para Isla Mocha (ver relação de material examinado), que fica na província de Cautín,
Chile, muito afastada da área de ocorrência dos outros exemplares e ao nível do mar.

Material examinado. PERU. Lima: 1 F, Canta, 2800m, V/1951, Weyrauch leg. (IMLA). Junin: 1 F, Tarma, 3050m, 7/V/1949, (provavelmente Weyrauch leg.) (IMLA). Tacna: 2 F, Tarata, 3100m, II/ 1948, Weyrauch leg. (IMLA). CHILE: I Região: 1 F e 1 M, Chapiquiña, 20/VII/1970, G. Diaz leg. (IDEA). 1 M, Chiappa, 2950m, Cord. Iquique, 23-24/IV/1969, L. E. Pena leg. (MELP). 1 F, Putre, 3400m., 18-20/II/ 1984, M. T. Kalin Arroyo leg. (SEMK), em Caiophora sepiaria. 3 M, Putre, 3250m, 2/III/1984, M. T. Kalin Arroyo leg. (SEMK), em Mutisia acuminata, Viguiera pazensis e Caiophora sepiaria. $1 \mathrm{~F}$, idem, 3600m, 7/XI/1970, N. Hichins leg. (IDEA). 1 F, Putre-Zapahuira, 3300-3350m, 13-14/IV/1984, M. T. Kalin Arroyo leg. (SEMK), em Calceolaria pulchella. 2 M, Zapahuira, 3250-3300m, 3/III/1984, idem (SEMK), um em Bidens andicola. $1 \mathrm{~F}$, ibidem, 3250m, 14/IV/1984, idem (SEMK), em Senecio relcheanus. 1 F, Zapahuira-Murmuntani, 3340-3380m, 3/ III/1984, idem (SEMK). Cautín (?): $1 \mathrm{M}$, Mocha (talvez Isla Mocha; apresenta no verso, impresso, "Coll. Wagenknecht, La Serena-Chile), 20/XI/1950 (UCCC), etiquetas adicionais: 'Penthemisia autrani macho (símbolo)" e "Colección Wagenkneght, 1973".

Centris (Paracentris) vogeli Roig-Alsina, 2000

(Figs. 96, 115, 133, 150, 159)

Centris (Paracentris) vogeli Roig-Alsina, 2000: 184.

Macho. Diagnose. Comprimento total, 13,3; largura da cabeça, 4,69. Tegumento preto na cabeça e mesossoma; disco do clípeo e do labro amarelo; metassoma vermelho-ferrugíneo. Pilosidade amarelo-palha-esbranquiçada na cabeça, mesossoma, fêmures anteriores e T1. No disco do T2, preta, ereta, ramificada e mais longa do que em $C$. tricolor, com cerca de $0,45 \mathrm{~mm}$ de comprimento. Comprimento da área malar 0,22 vezes a largura da base da mandíbula, 0,19:0,86. Comprimento da mandíbula 2,12 vezes a largura de sua base, 1,82:0,86.

Fêmea. Descrição. Dimensões (mm). Comprimento total 13,6; largura da cabeça 4,87; comprimento da cabeça 2,68; largura do mesossoma, incluindo tégulas, 5,72; comprimento da asa, do esclerito costal ao ápice, 9,33.

Tegumento. Predominantemente preto. Castanho nas pernas. Vermelho-ferrugíneo no metassoma. Membrana das asas translúcida, com um tom méleo. Disco do clípeo com poucos pontos e um pouco enrugado, provavelmente devido à preservação.

Pilosidade. Predominantemente amarelo-palhaesbranquiçada na cabeça e mesossoma; um pouco mais escura no dorso. Poucos pêlos castanho-escuros na cabeça, labro, laterais do clípeo, paroculares e fronte, abaixo dos ocelos. Predominantemente preta nas pernas e metassoma, mas com pêlos amarelo-palha-esbranquiçados no bordo posterior dos fêmures anteriores e no T1. Quase sem pêlos no disco do T2, devido ao mau estado de conservação, mas, pelos poucos que ainda persistem pode-se perceber, que é preta e semi-erecta.

Forma e proporções. Olhos um pouco divergentes para baixo, DIOS 2,52 e DIOI 2,76. Distância ocelocular 1,72 vezes o 

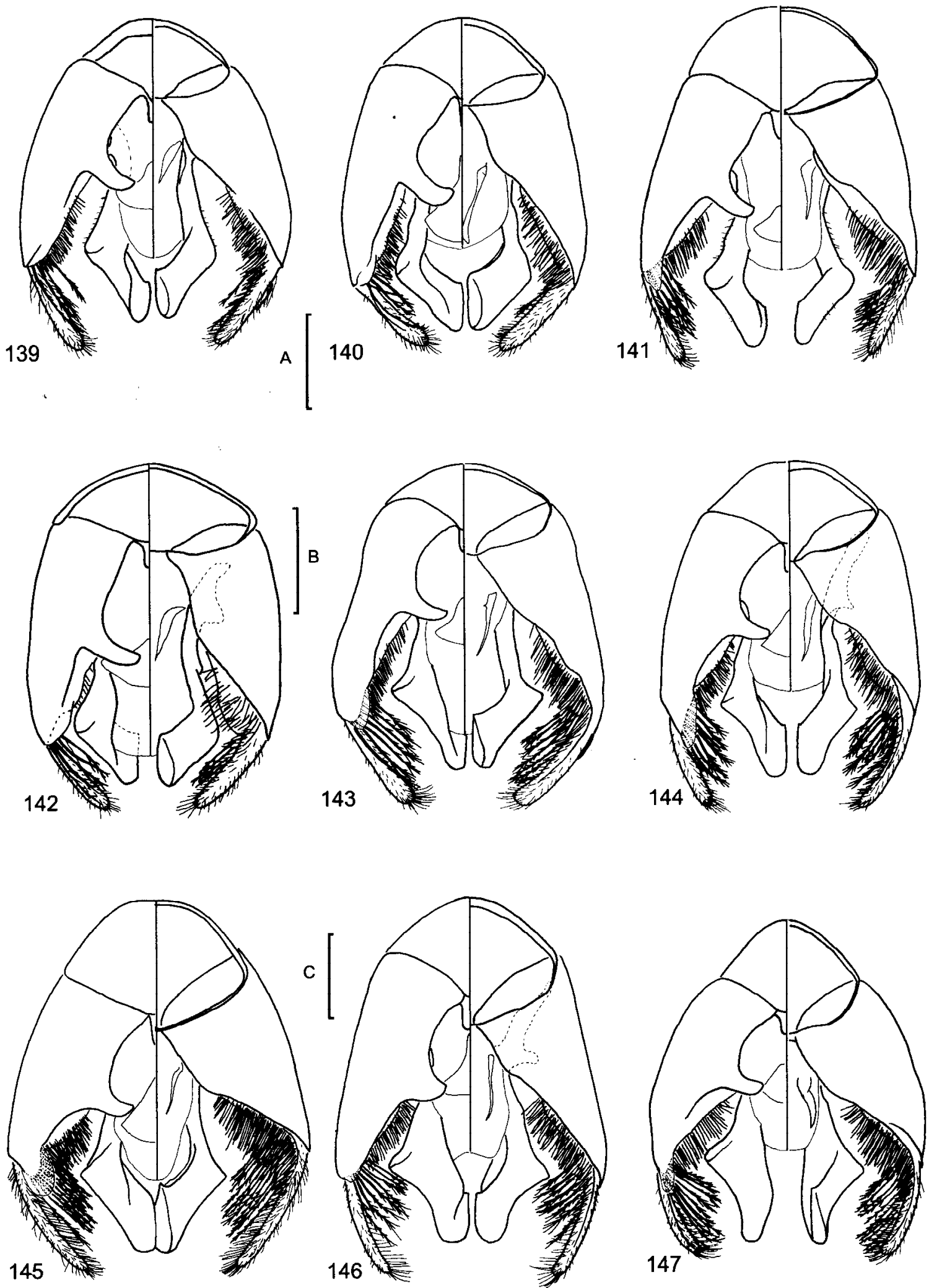

Figs. 139-147. Centris, cápsula genital, machos, vistas dorsal e ventral. 139, C. (Penthemisia) brethesi; 140, C. (Penthemisia) buchholzi; 141, C. (Penthemisia) chilensis; 142, C. (Penthemisia) mixta tamarugalis; 143, C. (Paracentris) mourei; 144, C. (Paracentris) tricolor; $\mathbf{1 4 5 , C .}$ (Paracentris) burgdorfi; 146, C. (Paracentris) klugii; 147, C. (Paracentris) lyngbyei. Escalas $=0,5 \mathrm{~mm}$, A corresponde às figuras $139-141 \mathrm{e} 147, \mathrm{~B}$ à figura 142 e $C$ às restantes. 
diâmetro do ocelo médio, 0,62:0,36. Distância interocelar cerca de 2,11 vezes o diâmetro do ocelo médio, 0,76:0,36. Distância entre alvéolos antenais 3,48 vezes o diâmetro alveolar, 1,01:0,29. Distância alveolocular 1,24 vezes o diâmetro alveolar, 0,65:0,29. Antena sem os flagelômeros, comprimento do escapo 0,96. Comprimento da área malar 0,23 vezes a largura da base da mandíbula, 0,22:0,96. Mandíbula gasta. Parte da segunda abcissa de $\mathrm{M}$, anterior à $1 \mathrm{a} \mathrm{m-cu,} 0,43$ vezes o seu comprimento total, 0,41:0,96.

Tipos. Holótipo, macho, de Termas del Palmar, San Pedro, Jujuy (MACN) (não examinado).

Distribuição geográfica. Conhecida apenas para a província de Jujuy, Argentina (Fig. 159).

Material examinado. ARGENTINA. Jujuy: $1 \mathrm{~F}$ e $1 \mathrm{M}$, Tilcara, 16/I/ 1973, J. Neff leg. (CTMI), em Cercidium sp.

\section{Centris (Penthemisia) Moure, 1950, revalidado}

Centris (Penthemisia) Moure, 1950: 390 (partim). Espécie-tipo: Hemisia chilensis Spinola, 1851, designação original; Toro, 1986: 127 (partim, lista das espécies chilenas).

Hemisia (Penthemisia); Michener, 1951: 3-4 (partim, chave para subgêneros).

Centris (Paracentris); Snelling, 1974: 6 (partim, sinonímia); 1984: 5 (partim); Ayala, 1998: 1-280 (partim).

Abelhas com 9,5-14,5 mm de comprimento. Tegumento castanho-claro a preto na cabeça e mesossoma; manchas amarelas no labro, clípeo, paroculares e base das tíbias anteriores e médias (exceto em $C$. chilensis, que apresenta o tegumento inteiramente preto). Nas fêmeas a mancha do clípeo apresenta dois pequenos emarginados no bordo superior. Metassoma preto ou avermelhado. Membrana das asas hialina. Palpo maxilar com cinco artículos. Fêmeas: mandíbula com quatro dentes (Figs. 39, 40, 42, 44). Bordo apical da placa basitibial secundária com a forma de um " $\mathrm{S}$ " deitado, menos visível em C. mixta (Figs. 54-56, 58, 59), e, em vista lateral, formando uma curta projeção sobre a placa principal (Fig. 12), exceto em C. mixta, onde é arredondado (Fig. 10). Primeiro flagelômero curto, menor do que 0,85 vezes o comprimento do escapo. Basitarso posterior arredondado no ângulo posterior do bordo apical, sem projeção aguda (semelhante às Figs. 15, 16). Machos: mandíbula com três dentes. T7 com área não esclerosada definida no bordo basal (Fig. 17) e com suave emarginado no bordo apical. S7, bordo basal sem emarginado (Figs. 103-106). S8, projeção apical com lados retos e paralelos e o ápice largo, arredondado (Figs. 121-124). Gonocoxito, em vista lateral, com o ápice arredondado, sem projeção próximo ao gonóstilo (Fig. 25); cerdas longas e grossas da região dorsodistal em pequeno número, entre quatro e dez; projeção laminar translúcida curta e estreita (Fig. 25).

A distribuição de $C$. (Penthemisia) é restrita ao sul e oeste da América do Sul, ocorrendo nos desertos da costa do Pacífico, na região central do Chile e nos desertos do oeste da Argentina. Além da espécie-tipo, Centris chilensis (Spinola, 1851), são conhecidas C. brethesi Schrottky (1902), C. buchholzi Herbst (1918), C. mixta mixta Friese (1904) e C. mixta tamarugalis (Toro \& Chiappa, 1989).

Chave para as espécies de Centris (Penthemisia)

1. Tegumento inteiramente preto. $\mathrm{T} 2$ a 6 com pilosidade preta Centris chilensis (Spinola)

Manchas amarelas na cabeça e base das tíbias anteriores e médias. Metassoma vermelho-ferrugíneo ou, quando predominantemente preto, com pilosidade clara, esbranquiçada . 2

2. T3 e 4 com pilosidade esbranquiçada ou amarelo-palhaclara, ramificada ou não. Primeiro flagelômero longo, nas fêmeas o seu comprimento 1,4-1,5 vezes o dos três seguintes juntos e nos machos, 1,1-1,2 vezes. Fêmeas: placa basitibial secundária fracamente definida, sendo evidente somente uma depressão no meio da placa principal (Figs. 58, 59). Elaiospata vestigial nos basitarsos anteriores e médios, com cerdas modificadas afastadas umas das outras ........ C. mixta Friese

T3 e 4 com pilosidade preta, não ramificada. Primeiro flagelômero curto, nas fêmeas o seu comprimento 1,21,3 vezes o dos três seguintes juntos e nos machos, 0,9-1,1 vezes. Fêmeas: placa basitibial secundária com bordo apical bem definido (Figs. 54, 55). Elaiospata bem desenvolvida nos basitarsos anteriores e médios, com cerdas modificadas imbricadas no ápice ........... 3

3. Tegumento amarelo nas áreas malares. Mandíbula longa, seu comprimento, nas fêmeas, 2,4-2,5 vezes a largura da sua base em vista lateral; nos machos, 2,35-2,57 vezes. Fêmeas: pilosidade amarelo-palha nas pernas, inclusive as cerdas da escopa; distância ocelocular 2,0-2,3 vezes o diâmetro do ocelo médio; área malar longa, seu comprimento $0,32-0,35$ vezes a largura da mandíbula em vista lateral. Machos: espaço entre o segundo e o terceiro dentes subapicais da mandíbula largo (Fig. 86); distância ocelocular 1,3-1,4 vezes o diâmetro do ocelo médio; área malar longa, seu comprimento $0,24-0,3$ vezes a largura da mandíbula em vista lateral C. buchholzi Herbst

Tegumento castanho-claro a escuro nas áreas malares. Mandíbula curta, seu comprimento, nas fêmeas, 2,12,3 vezes a sua largura da sua base em vista lateral; nos machos, 1,9-2,0 vezes. Fêmeas: pilosidade castanho-escura nas pernas, inclusive as cerdas da escopa; distância ocelocular 1,5-1,7 vezes o diâmetro do ocelo médio; área malar curta, seu comprimento $0,2-0,3$ vezes a largura da mandíbula, em vista lateral. Machos: espaço entre o segundo e o terceiro dentes subapicais da mandíbula não tão largo (Fig. 85); distância ocelocular 0,8-0,9 vezes o diâmetro do ocelo médio; área malar curta, seu comprimento cerca de 

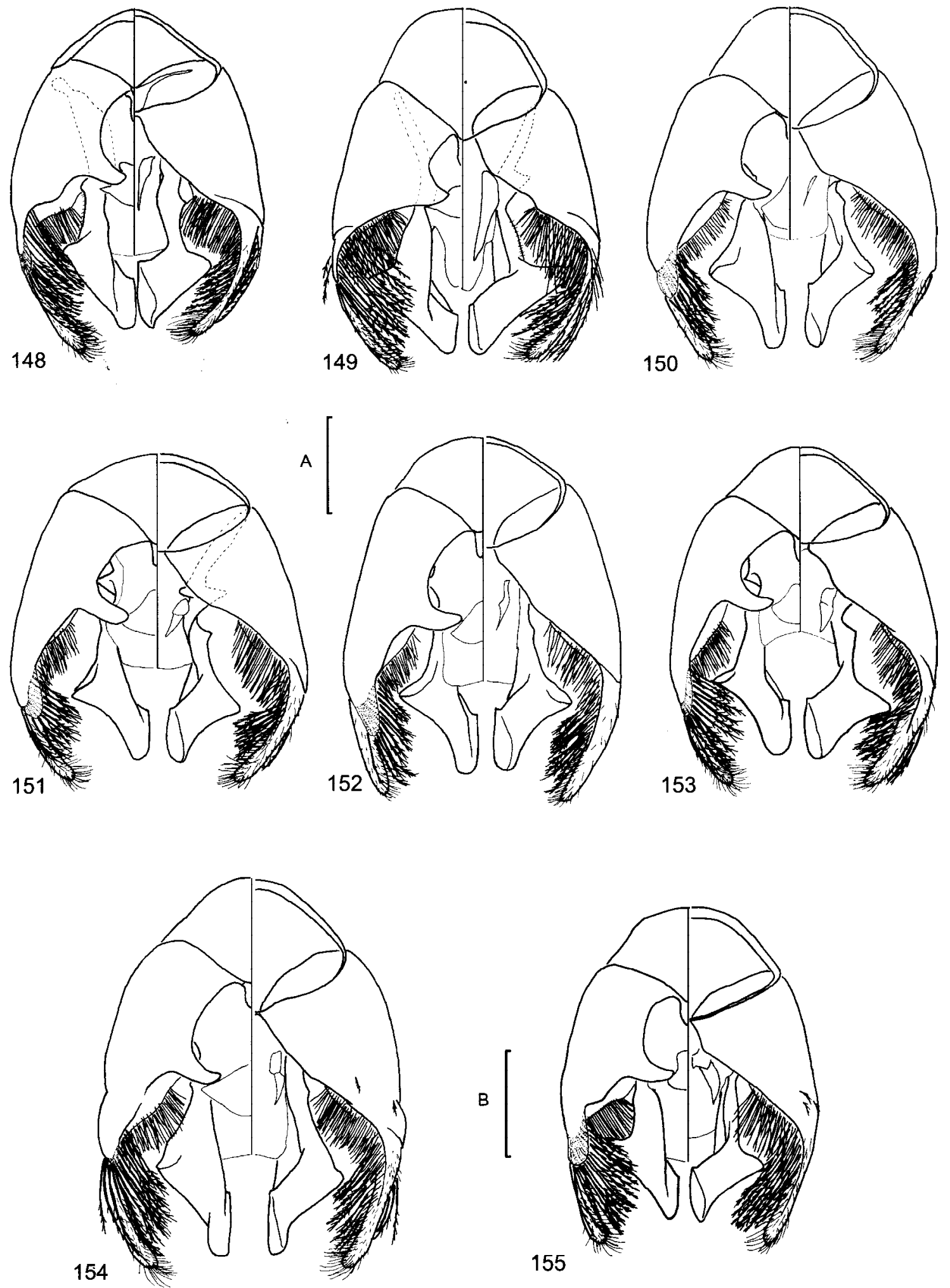

Figs. 148-155. Centris, cápsula genital, machos, vistas dorsal e ventral. 148, C. (Paracentris) caelebs, 149, C. (P.) flavohirta, 150, C. (P.) vogeli, 151, C. (P.) neffi; 152, C. (P.) cordillerana, 153, C. (P.) toroi sp. nov.; 154, C. (P.) nigerrima; 155, C. (P.) unifasciata. Escalas $=0,5 \mathrm{~mm}, \mathrm{~B}$ corresponde à figura $155 \mathrm{e} \mathrm{A}$ às restantes. 
0,2 vezes a largura da mandíbula em vista lateral ....... C. brethesi Schrottky

As espécies do subgênero $C$. (Penthemisia)

Centris (Penthemisia) brethesi Schrottky, 1902

(Figs. 39, 54, 70, 85, 103, 121, 139, 156)

Centris brethesi Schrottky, 1902: 117.

Centris (Paracentris) brethesi; Neff \& Simpson, 1981: 103; Roig-Alsina, 2000: 185.

Fêmea. Diagnose. Comprimento total, 12,3-13,5; largura da cabeça, 5,05-5,42. Tegumento predominantemente preto. Castanho-claro a escuro nas áreas malares. Castanho-escuro nas pernas; mais claro nos fêmures e tíbias posteriores. Placa basitibial com um tom ferrugíneo, aparecendo por transparência a linha de união com a tíbia (Fig. 54). Vermelho-ferrugíneo no metassoma. Amarelo no labro, disco do clípeo; manchas nas paroculares, até a altura do clípeo, pequenas na base das tíbias anteriores e médias. Membrana das asas hialina. Pilosidade predominantemente amarelo-palha-esbranquiçada, inclusive na cabeça, mesossoma e fêmures. Castanho-escura nas tíbias e tarsos, inclusive as cerdas das escopas. Semidecumbente, curta, não ramificada e de coloração castanha no disco do T2. Olhos um pouco convergentes para baixo, DIOS:DIOI, 2,83:2,69 2,70:2,47. Distância ocelocular 1,52-1,72 vezes o diâmetro do ocelo médio, 0,58:0,38 - 0,62:0,36. Distância interocelar 2,342,50 vezes o diâmetro do ocelo médio, 0,89:0,38-0,90:0,36. Comprimento do primeiro flagelômero $1,20-1,28$ vezes o dos três seguintes juntos, 1,01:0,84-1,06:0,83. Comprimento da área malar $0,24-0,30$ vezes a largura da mandíbula, $0,17: 1,03-$ 0,18:0,91. Comprimento da mandíbula 2,08-2,30 vezes a largura de sua base, 2,14:1,03-2,09:0,91.

Macho. Diagnose. Comprimento total, 12,0-13,9; largura da cabeça, 4,57-4,78. Tegumento predominantemente preto. Castanho-escuro nas pernas. Vermelho-ferrugíneo no metassoma. Amarelo no labro e disco do clípeo; pequenas manchas na base das tíbias anteriores e médias, no terço apical do escapo, às vezes também nas paroculares, base das mandíbulas e estreita faixa na área supra-clipeal. Membrana das asas hialina. Pilosidade predominantemente amarelo-palhaesbranquiçada, inclusive na cabeça, mesossoma, e metade basal das pernas; semi-erecta, não ramificada e preta no T2. Olhos um pouco divergentes para baixo, DIOS:DIOI, 1,97:2,14 2,00:2,10. Distância ocelocular 0,84-0,92 vezes o diâmetro do ocelo médio, 0,32:0,38 - 0,35:0,38. Distância interocelar 1,152,05 vezes o diâmetro do ocelo médio, 0,74:0,38 - 0,78:0,38. Comprimento do escapo $0,85-0,95$ vezes o do primeiro flagelômero, 0,82:0,97-0,82:0,86. Primeiro flagelômero um pouco mais longo que os três seguintes juntos, $0,86: 0,84-0,97: 0,89$. Comprimento da área malar 0,17-0,20 vezes a largura da mandíbula, 0,14:0,82-0,16:0,79. Comprimento da mandíbula $1,93-2,03$ vezes a largura de sua base, $1,58: 0,82-1,60: 0,79$.

Tipo. Holótipo, fêmea de San Juan, Argentina, depositado no Museu Argentino de Ciências Naturais, em Buenos Aires, Agentina (não examinado).

Distribuição geográfica. No oeste da Argentina, de Salta a Rio Negro (Fig. 156), acompanhando a área de distribuição da província biogeográfica "del Monte" (CABRera \& WillinK 1973). Segundo Roig-Alsina (2000) ocorre também nas províncias de San Luís, Córdoba, Neuquén e Chubut. Pelos dados de etiqueta, está registrada até $3000 \mathrm{~m}$ de altitude, em Cuesta Minas Capillitas, Catamarca.

Material examinado. ARGENTINA. Salta: 1 F, Angastaco, 23/I/ 1950, Monrós \& Willink leg. (IMLA). Catamarca: $1 \mathrm{~F}$, Andalgalá, 2/I/ 1972, J. L. Neff leg. (CTMI), em Bulnesia retama. Do mesmo local, coletor e depositados no CTMI: 1 M, 29/X/1972, em Atamisquea emarginata; 1 F, 16/II/1973, em Verbesina encelioides; 1 F, 29/II/1973, em Larrea cuneifolia; $1 \mathrm{~F}$ e 1 M, 22/X/1972, em Prosopis chilensis; $1 \mathrm{M}$, 10/X/1973, em Larrea divaricata. 1 F e 2M, ibidem, 5, 6 e 13/X/1973, idem (CUIC), a fêmea em Bulnesia retama. 1 F, ibidem, 18/XII/1973, idem (CUIC), em Cercidium praecox. 4 F, Andalgalá, 24/XI/1971, D. Brothers leg. (SEMK), idem. $1 \mathrm{~F}$, ibidem, 28/I/1960, Willink leg. (IMLA), em Larrea sp. $1 \mathrm{~F}$, Cuesta de Zapata, 25/I/1960, Willink \& Tonsic leg. (IMLA). 2 M, Joyango-Colpes site, 31/X e 8/XI /1972, J. L. Neff leg. (CTMI), em Zuccagnia punctata e Prosopis chilensis. $1 \mathrm{~F}$, Cuesta Minas Capillitas, 3000m, 22/XI/1973, idem (CTMI), em Larrea divaricata. $3 \mathrm{~F}$, Tinogasta, 23/I/1960, Tonsic \& Willink leg. (IMLA), em Larrea sp. Tucumán: 1 M, Amaicha del Valle, 8/XI/1959, Willink leg. (IMLA), em Larrea sp. 1 M, Amaichá (?, Amaichá del Valle), 27/XI/ 1965, L. Stange leg. (IMLA). San Juan: 1 M, Iglesia (Pismanta), 31/X/ 1992, E. Michellete leg. (RPSP). $5 \mathrm{~F}$ e 9 M, Valle de Zonda, 28/XI. 13/ XII/1993, 22/II. 12/X /1994, 13/X. 26/XI. 1/XII/1996, 1. 23/III /1997, idem (RPSP), em Atamisquea emarginata, Capparidaceae, Bulnesia retama e em Larrea sp, um macho com etiqueta adicional "Centris (Paracentris) tricolor Friese, 1899 Det. Moure, 1994”. La Rioja: 1 F, Chilecito, 29/II/1920, R. G. Harris leg. (CUIC). 2 F, ibidem, 20/I/1960, Willink leg. (IMLA), em Larrea. 1 F, Guayapa, 16-24/XI/1963, Hayward leg. (IMLA). 1 M, Las Cañas, 7/X/1954, K. J. Hayward leg. (BMNH). 1 F e 1 M, Mascasim, XI/1961, F. H. Walz leg. (RPSP). 1 F e 4 M, Patquia, X/1932, K. J. Hayward leg. (BMNH). 3 M, Patquia-Guayapa, 4/X/1954, K. J. Hayward leg. (IMLA). 1 F, Estación Amado, X/1934, M. Gomez leg. (SEMK). Mendoza: $23 \mathrm{~F}$ e $47 \mathrm{M}$, Chacras de Coria (atualmente um bairro de Mendoza), 18/II. 1. 2. 7. 9. 10. 12. 14. 18/XII/1904, 17/XII/ 1907, 8/I. 7. 9/XII/1908, Jorgensen leg. (ZMUC). 1 M, Chacras de Coria, 18/I/1906, Jensen-Haarup (ZMUC), com etiqueta adicional "Centris tricolor Fr., macho (símbolo), Friese det.”. 1 M, ibidem, 11/I/1947, Hayward \& Willink leg. (IMLA). 1 F, Est. Pedregal, 12/XI/1906, JensenHaarup leg. (ZMUC). 4 F e 1 M, ibidem, 14. 18. 25/XI. 17/XII/1906, 11/XI/1908, idem (ZMUC). 1 F, La Plata, 16/XI/1906, Jensen-Haarup leg. (BMNH). $1 \mathrm{~F}$, La Plata, 1908, idem (BMNH). $14 \mathrm{~F}$ e $63 \mathrm{M}$, possivelmente Mendoza, 28/XI/1904, 10/I. 5/II. 16. 23. 27/X. 12. 28. 30/XI. 5. 7. 8. 25/XII/1908, P. Jörgensen leg. (ZMUC). 1 M, San Ignácio, 22/XI/1908, Jörgensen leg. (ZMUC). $1 \mathrm{~F}$ e 2 M, s. l., 12/XI. 9. 24/XI/ 1906, Jensen-Haarup leg. (SMNH), tendo um macho etiqueta adicional "Centris tricolor". 2 M, 21/X/1908, Jörgensen leg. (NHMW). Rio Negro: 1 F, RI 3 km 1200, 24/XI/1973, J. L. Neff leg. (CTMI), em Larrea cuneifolia x ameghinoi. 1 F, Villa Regina, 20/I/1956, H. N. Piacentini leg. (MZSP).

Centris (Penthemisia) buchholzi Herbst, 1918

(Figs. 40, 55, 71, 86, 104, 122, 140, 157)

Centris buchholzi Herbst, 1918: 149-150.

Centris (Penthemisia) buchholzi; Moure, 1950: 392.

Hemisia (Penthemisia) buchholzi; Michener, 1951: 4.

Centris (Paracentris) buchholzi; Roig-Alsina, 2000: 185.

Centris (Trachina) wilmattae Cockerell, 1926: 224. Syn. nov. 

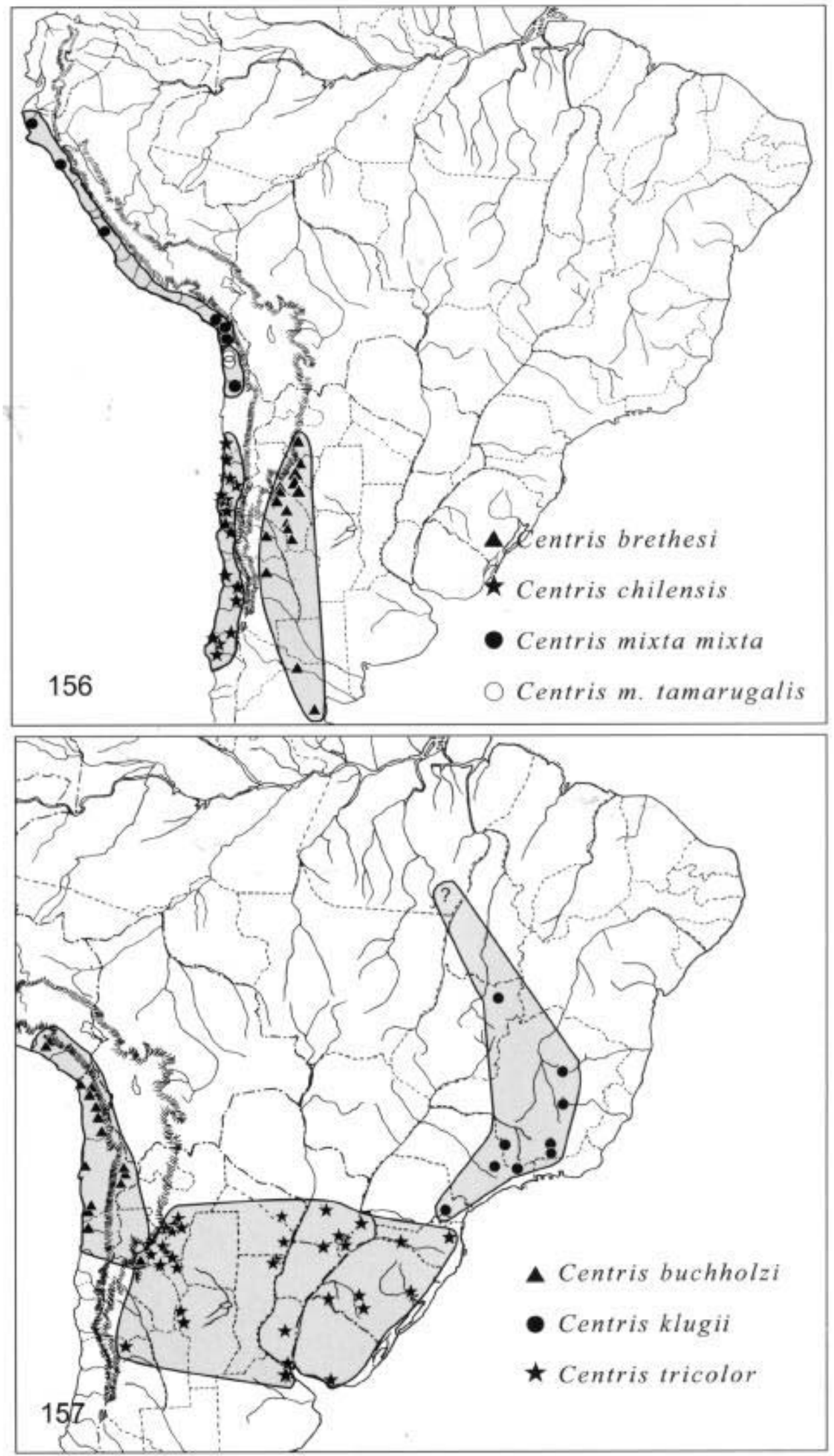

Fig. 156. Distribuição geográfica de Centris (Penthemisia) brethesi; $C$. (P.) chilensis; $C$. (P.) mixta mixta e C. (P.) m. tamarugalis. Fig. 157. Distribuição geográfica de Centris (Penthemisia) buchholzi; C. (Paracentris) klugii e C. (Paracentris) tricolor. 
Fêmea. Diagnose. Comprimento total, 12,7-14,2; largura da cabeça, 5,05-5,42. Tegumento amarelo no labro, disco do clípeo, dois terços basais das mandíbulas e área malar; manchas nas paroculares, se estendendo até a altura dos alvéolos antenais, e uma linha fina em volta dos olhos, interrompida apenas na parte superior; pequenas manchas também na base das tíbias anteriores e médias. Preto a castanho-escuro nas antenas. Membrana das asas hialina. Vermelho-ferrugíneo no metassoma. Pilosidade predominantemente amarelo-palha-clara, inclusive a das pernas e cerdas das escopas. Preta, semidecumbente, e não ramificada no disco do T2. Distância ocelocular 2,03-2,26 vezes o diâmetro do ocelo médio, 0,77:0,38-0,79:0,35. Distância entre alvéolos antenais 3,71-3,74 vezes o seu diâmetro, 1,15:0,31 $-1,16: 0,31$. Primeiro flagelômero 1,29-1,30 vezes mais longo do que os três seguintes juntos, 1,15:0,89-1,12:0,86. Comprimento da área malar 0,32-0,34 vezes a largura da base da mandíbula, 0,31:0,96-0,31:0,90. Mandíbula longa, comprimento 2,40-2,48 vezes a largura da base, 2,16:0,90-2,33:0,94. Célula marginal $3,15-3,18$ vezes mais longa que larga, 1,70:0,54-1,75:0,55.

Macho. Diagnose. Comprimento total, 12,2-13,1; largura da cabeça, 4,63-4,99. Tegumento amarelo no clípeo, exceto estreitas faixas laterais, no labro, área malar, cinco sextos basais das mandíbulas; manchas nas paroculares se estendendo até a altura dos alvéolos antenais. Pequenas manchas na base das tíbias anteriores e médias. Antenas pretas a castanho-escuras. Membrana das asas hialina. Vermelho-ferrugíneo no metassoma. Pilosidade predominantemente amarelo-palha-esbranquiçada. Preta, semi-erecta e não ramificada no disco do T2. Distância ocelocular 1,32-1,37 vezes o diâmetro do ocelo médio, 0,50:0,38 - 0,48:0,35. Distância entre alvéolos antenais 3,40-3,69 vezes o seu diâmetro, 1,02:0,30 - 0,96:0,26. Distância alveolocular 1,271,58 vezes o diâmetro dos alvéolos antenais, 0,38:0,30-0,41:0,26. Comprimento do primeiro flagelômero $0,95-0,96$ vezes o dos três seguintes juntos, 0,96:1,01-0,88:0,92. Comprimento da área malar 0,24-0,30 vezes a largura da mandíbula, 0,22:0,91 0,24:0,79. Mandíbula longa, comprimento 2,35-2,57 vezes a largura da base, 2,14:0,91 -2,16:0,84 (Fig. 86). Célula marginal $3,23-3,46$ vezes mais longa que larga, 1,97:0,61 - 1,80:0,52.

Tipos. Síntipos de Centris bucholzi Herbst (1918), fêmeas e machos da província de Tarapacá, Chile (instituição depósitária não mencionada) (não examinados).

Holótipo de Centris wilmattae Cockerell (1926), fêmea, com as seguintes etiquetas manuscritas: "Tingo. Peru. Aug. 22, (W.P. Cockerell)", "Centris wilmattae Ckll. TYPE" e "ac33337” (AMNH). Essa fêmea foi considerada como holótipo da espécie porque a descrição original foi baseada em somente nesse espécimen.

Distribuição geográfica. Desertos costeiros do sul do Peru e norte do Chile, até a província de Atacama, mas também com registros em regiões altas dos Andes, até 3400-3600 m de altitude, em Putre, na província de Tarapacá e em Tumbre, Pocos e Talabre, na província de Antofagasta. Há ainda dois registros para a vertente oriental dos Andes, na província de Catamarca,
Argentina (ver material examinado e Fig. 157). RoIG-AlsinA (2000) também registrou a presença dessa espécie na Argentina, na província de Salta, a $3200 \mathrm{~m}$ de altitude.

Material examinado. PERU. 1 F, Atiquipa, 200m, 11/XII/1951, Weyrauch leg. (IMLA). Arequipa: $2 \mathrm{M}$, Aplao (?, ilegível), 2,8 km NO, 17/I/1977, J. L. Neff leg. (CTMI), em Larrea divaricata. 1 F, Yura, 15/ I/1977, idem (CTMI), em Solanum. CHILE, I Região: 1 M, Chiapa, cord. Iquique, 23-24/IV/1969, L. Peña leg. (MELP). 1 M, Codpa, 8/IX/ 1989, A. Gallardo leg. (IDEA). 1 M, Cuesta Cardones, 2810m, 28/II/ 1984, M. T. Kalin Arroyo leg. (SEMK), em Tarasa operculata. 1 F, Guatacondo, IX/1971, Montenegro leg. (CFZ), em Medicago sativa. 1 F, Lupica, 26/X/1984, G. Diaz leg. (IDEA). 48 F e 5 M, Iquique, Mamima (provavelmente Mamiña), IX/1951, Pena leg. (SEMK). 2 F, ibidem, Parca, idem, idem (SEMK). 1 M, Poroma, cord. Iquique, 20-21/IV/ 1969, L. Peña leg. (MELP). 3 F, Putre, 3400-3600m, 11-16/IV/1984, M. T. Kalin Arroyo leg. (SEMK), em Senna birostris e Solanum lycopersicum. $1 \mathrm{~F}$, rio Lluta, 500m, 11-13/XI/1955, L. Peña leg. (SEMK). $2 \mathrm{~F}$, Sobraya, 700m, 10/XI/1955, idem (SEMK). $1 \mathrm{~F}$, Socoroma, 4/V/ 1982, H. Vargas leg. (IDEA). 1 M, idem, 3/VII/1987, D. Bobadilla leg. (IDEA). 1 F, Valle del Lluta, 500m, 11-13/XI/1955, L. E. Peña leg. (SEMK). 1 F e 1 M, Zapahuira-Pucará, 2950m, 19/II/1984, M. T. Kalin Arroyo leg. (SEMK), em Baccharis petiolata. II Região: $1 \mathrm{M}$, Aeropuerto (provavelmente em Antofagasta), 23/XI/1943, s. c. (SEMK). $16 \mathrm{~F}$ e 1 M, Pocos, X/1953, III. 1-5/IV. 5/X/1954, L. E. Pena leg. (SEMK). 1 F e 2 M, Peini, 5-8/XII/1975, L. Peña leg. (AMNH). 1 M, Q. Paposo, 26/X/ 1993, E. Chiappa leg. (CFZ) em Loasa chilensis. 1 F, Talabre, basin NW Lascar Vol., XI/1965, L. Peña leg. (AMNH). 1 F, Q. Taltal, 31/X/1993, E. Chiappa leg. (CFZ) em Nolana crasufolia. 2 M, ibidem, 20/X/1993, H. Toro (CFZ) em Calandrinia salsoloides. $2 \mathrm{~F}$, Taltal, 600m, 14-15/X/ 1983, J. L. Neff leg. (CTMI), em Dinemandra ericoides. 1 M, ibidem, Cuesta de Paposa, 1100m, idem (CTMI). 2 F e $1 \mathrm{M}$, Tocopilla, 7/XI/ 1916, P. Herbst leg. (CAS). 1 F, Tumbre, NW Laskar Vol., 3500m, XI/ 1965, L. Peña leg. (AMNH). III Região: 1 M, Chañaral, 28/XII/1947, D. S. Bullock leg. (CAS). ARGENTINA. Catamarca: $1 \mathrm{M}$, Tinogasta, Fiambalá, camino internacional, $2400 \mathrm{~m}, 1 / \mathrm{I} / 1956$, s. c. (SEMK). $1 \mathrm{M}$, Fiambalá, Cam. Internacional., 2400m, 10/I/1956, s. c. (SEMK).

\section{Centris (Penthemisia) chilensis (Spinola, 1851)}

(Figs. 42, 56, 73, 88, 105, 123, 141, 156)

Hemisia chilensis Spinola, 1851: 166-167.

Centris chilensis; Friese, 1901: 323.

Centris (Penthemisia) chilensis; Moure, 1950: 392.

Hemisia (Penthemisia) chilensis; Michener, 1951: 4.

Centris smithii Friese, 1900: 43; 1901: 290.

Centris bicolorella Cockerell, 1904: 236 (nom. nov.); Moure, 1950: 392 (sinonímia).

Fêmea. Diagnose. Comprimento total, 12,2-13,9; largura da cabeça, 4,75-5,02. Tegumento predominantemente preto. Castanho-escuro nas pernas e, em alguns exemplares, também no clípeo, labro e laterais do mesossoma. Membrana das asas hialina, com um suave tom méleo. Pilosidade amarelo-palha no vértice, região dorsal do pronoto, incluindo o lóbulo pronotal, mesoscuto, escutelo, área pré-episternal, laterais do metanoto e do propódeo; tufos de pêlos claros nas laterais do T1. Preta a castanho-escura no restante do corpo. Olhos um pouco convergentes para baixo, DIOS:DIOI, 2,66:2,58 - 2,81:2,29. Distância interocelar 2,32-2,39 vezes o diâmetro do ocelo médio, 0,86:0,37-0,82:0,36. Distância alveolocular 2,07-2,23 vezes o diâmetro alveolar, 0,60:0,29-0,58:0,26. Comprimento do escapo 0,89-0,93 vezes o do primeiro flagelômero, 0,94:1,06-0,91:0,98. Comprimento da mandíbula 2,29-2,34 vezes a largura de sua 


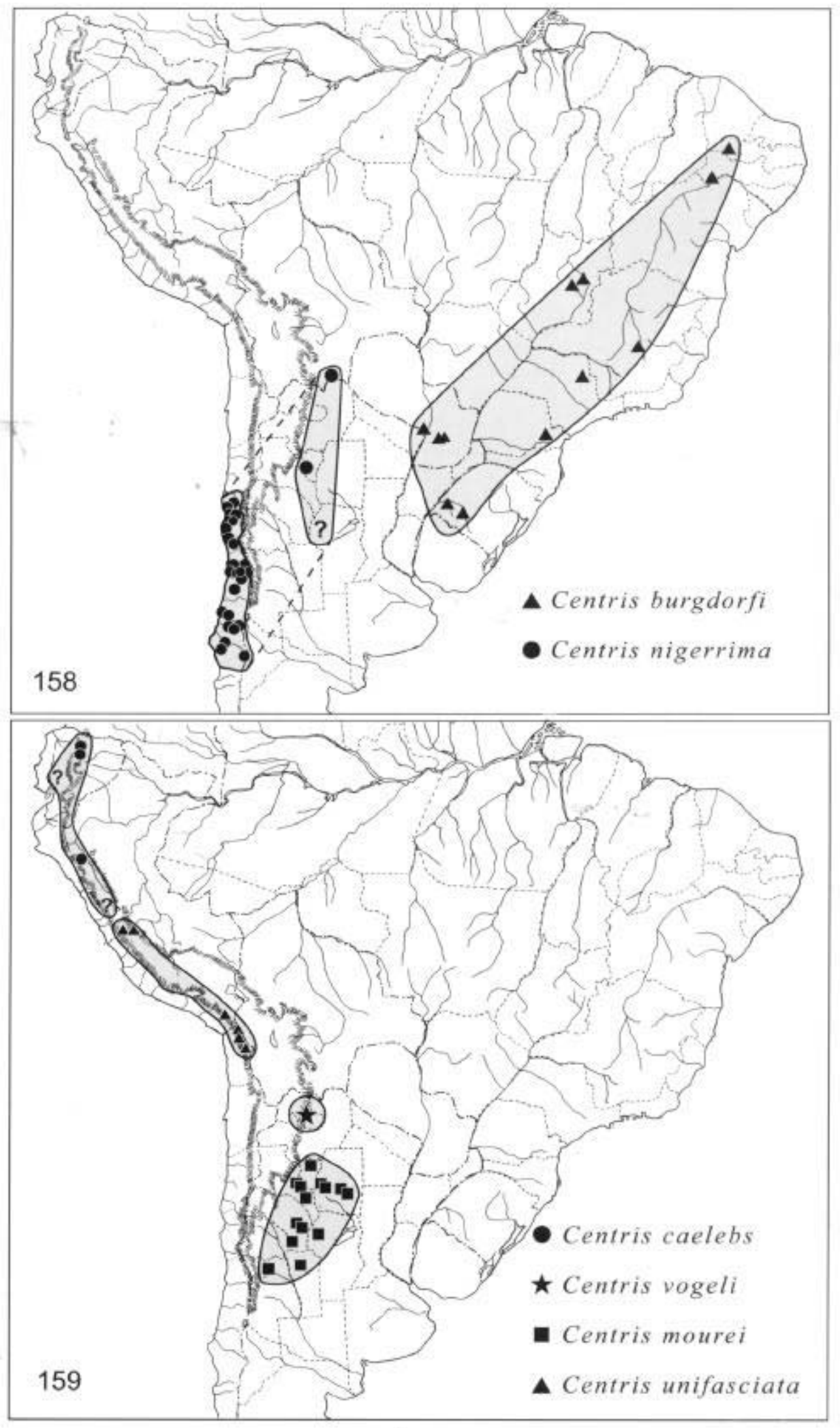

Fig. 158. Distribuição geográfica de Centris (Paracentris) burgdorfi e C. (P.) nigerrima. Fig. 159. Distribuição geográfica de Centris (Paracentris) caelebs, C. (P.) vogeli., C. (P.) mourei e C. (P.) unifasciata. 
base, 2,08:0,91 - 2,02:0,88. Célula marginal 2,68-2,78 vezes mais longa que larga, 1,42:0,53-1,50:0,54.

Macho. Diagnose. Comprimento total, 10,7-13,0; largura da cabeça, 3,90-4,69. Tegumento semelhante ao das fêmeas. Membrana das asas hialina. Pilosidade semelhante à das fềmeas, mas amarelo-esbranquiçada também no T1. Olhos divergentes para baixo, DIOS:DIOI, 1,87:2,26-1,76:1,97. Distância interocelar 1,94-2,08 vezes o diâmetro do ocelo médio, 0,72:0,37-0,77:0,37. Distância alveolocular 0,93-1,16 vezes o diâmetro alveolar, 0,26:0,28-0,29:0,25. Comprimento do escapo 0,87-0,94 vezes o do primeiro flagelômero, 0,79:0,91 - 0,73:0,78. Comprimento da mandíbula 2,01-2,18 vezes a largura de sua base, 1,73:0,91 1,44:0,66. Célula marginal 3,00-3,05 vezes mais longa que larga, $1,44: 0,48-1,68: 0,55$.

Tipos de Hemisia chilensis Spinola, 1851: síntipo(s) fêmea(s) da Cordilhera de Coquimbo, Chile (não examinados, instituição depositária desconhecida, possivelmente no "Museo Regionale Scienze Naturali" em Turim, Itália). Tipos de Centris smithii Friese, 1900: lectótipo, macho, pela presente designação, com as seguintes etiquetas: "1898" (etiqueta manuscrita) "Centris smithii n. sp., macho (símbolo), det. Friese 1898” (nome da espécie e símbolo do sexo manuscritos", "Type" (etiqueta vermelho-escura) e "Zool. Mus. Berlin" (MNHU). Paralectótipo, macho, com as seguintes etiquetas: "Chile" (etiqueta manuscrita) e "Centris smithii n. sp. macho (símbolo), det. Friese 1898" (nome da espécie e símbolo do sexo manuscritos) (MLUH). FrIESE (1900) cita ainda a existência de mais duas fêmeas e um macho, coletados no Chile, por Phillipi (Museu de Berlin) e 1 fềmea da Bolívia (não examinados). É provável que a fêmea da Bolívia seja de outra espécie, uma vez que $C$. chilensis é restrita ao Chile, assim a designação do macho acima referido como lectótipo, garantirá a estabilidade do nome.

Distribuição geográfica. Região central do Chile, do sul de Antofagasta a Malleco, com registro até $1000 \mathrm{~m}$ de altitude, em Pajonales, Coquimbo (Fig. 156). ScHROTTKY (1913: 260) menciona a sua ocorrência do outro lado dos Andes, na Patagônia argentina, mas isto não foi confirmado através do material examinado.

Material adicional examinado. CHILE. II Região: 2 F, Q. Cifuncho, 24/X/1993, E. Chiappa (CFZ), em Cristaria intonsa e Dinemandra ericoides. $1 \mathrm{~F}$, Q. Taltal, 28/X/1993, H. Toro leg. (CFZ), em Dinemandra ericoides. III Região: 2 M, Caldera 20 km SE, 16/X/1957, L. Peña leg. (SEMK). 2 M, Canto del Agua, 21/X/1969, Rozen \& Peña leg. (AMNH). $1 \mathrm{~F}$, Carrizal Bajo, Coast N Huasco, 8/XI/1965, L. Pena leg. (AMNH). 2 F, ibidem, $20 \mathrm{~km} \mathrm{E}, 28 / \mathrm{IX} / 1957$, idem (SEMK). $1 \mathrm{M}$, Chacritas, 14/X/ 1969, Rozen \& Peña leg. (AMNH). 1 M, Chañaral, Pan de Azúcar, 30/ XII/1993, C. Schlindwein leg. (CFZ)". 1 M, 66 Km s Copiapó, 19/X/ 1971, Rozen \& Peña leg. (AMNH). 1 F, Copiavo [sic](=Copiapó), 20/X/ 1983, J. L. Neff leg. (CTMI). 2 M, ibidem, $50 \mathrm{~km} \mathrm{NE,} \mathrm{21/X/1983,} \mathrm{idem}$ (CTMI). $5 \mathrm{~F}$ e $4 \mathrm{M}$, Cuesta Pajonales (em duas fêmeas consta também "a Vallenar"), 15/X/1957, L. Peña leg. (SEMK). 1 M, Dolmeyco, 15/X/ 1957, idem (SEMK). $10 \mathrm{M}$, Freirinha $20 \mathrm{~km} \mathrm{~N}, 20 / \mathrm{X} / 1957$, idem (SEMK). $4 \mathrm{~F}$, Huasco, 20-22/X/1957, s. c. (SEMK). $1 \mathrm{~F}$, Huasco, Vallenal, $60 \mathrm{Km}$ N, 22/X/1983, J. L. Neff leg. (CTMI), em Peganum sp. 1 M, Las Juntas, 5/X/1982, Magunacelay leg. (CFZ). 1 F, Paipote, 12/X/1971, Rozen \&
Peña leg. (AMNH). 1 F e 3 M, 10 ENE Puquios, 10/X/1971, idem (AMNH), em Prosopis sp. 2 M, NE de Puquios, 16/X/1969, idem (AMNH). 5 F e 1 M, Quebrada de Chanaral, 300m, 23/X/1957, L. Peña leg. (SEMK). $1 \mathrm{~F}$, Vallenar $20 \mathrm{~km} \mathrm{E.,} \mathrm{29/IX/1957,} \mathrm{idem} \mathrm{(SEMK).} \mathrm{IV} \mathrm{Região:} 2 \mathrm{~F}$, Carrizalillo, 25/X/1957, L. Peña leg. (SEMK). $1 \mathrm{~F}$, Elqui, Vicunha $3 \mathrm{~km}$ S, 7/X/1983, J. L. Neff leg. (CTMI), em Dinemogonum gayanum. 2 F, Incahuasi, 14/X/1988, V. Cabezas (CFZ). 1 F, La Serena, Qda. Honda, 29/ XI/1917, Wagenknetch leg. (UCCC). 1 F, Llano de la Higuera, N de El Tofo, 14/X/1971, Rozen \& Peña leg. (AMNH). 16 F e 1 M, ibidem, 14/ X/1957, L. Peña leg. (SEMK). 17 F e 18 M, Lomas de Peñuelas, 13. 20. 26. 27/XI. 18/XII/1955, Wagenknecht leg. (SEMK). $1 \mathrm{M}$, Los Chorros, 6/XI/1954, idem (SEMK). 3 F e 1 M, Pajonales, 1000m, 16/X. 30/XI/ 1956, Wagenknecht leg. (SEMK). 23 F e 35 M, Peñuelas, 20. 26. 27. 30/ XI. 18/XII/1955, idem (SEMK). 1 M, Vicuna, 18/X/1971, L. Pena (AMNH). 1 M, 10 Km, 17/XII/1963, Cekalovick leg. (UCCC). V Região: 6 M, Guardia Vieja, XI/1953, L. E. Pena leg. (SEMK). 1 M, Valparaíso, s. d., C. Porter leg. (CUIC). Santiago: 1 F e 3 M, El Radal, I/1951, Pena leg. (SEMK). 1 M, Huelquén, 28/XII/1947, idem (SEMK). 1 M, 14/I/ 1963, F. Werner leg. (AMNH), em Baccharis sp. VI Região: 1 F e 2 M, Rancagua, XII/1903, P. Herbst leg. (MZSP). VIII Região: $2 \mathrm{M}$, Concepción, 4/XII/1908, P. Herbst leg. (ZSMC). 1 M, ibidem, 28/XI/ 1905, idem (CUIC). 1 F, Laja, 29/XII/1973, L. Peña leg. (AMNH). 2 M, Las Trancas, I/1966, 6/XI/1975, idem (AMNH). $1 \mathrm{~F}$, Yumbel, 26/XI/ 1956, Cid leg. (UCCC). IX Região: $1 \mathrm{M}$, Angol, 21(?)/X/1940, H. Rebolledo leg. (SEMK).

\section{Centris (Penthemisia) mixta mixta Friese, 1904}

(Figs. 44, 58, 59, 75, 90, 106, 124, 142, 156)

Centris mixta Friese, 1904: 91-92.

Centris (Penthemisia) mixta; Moure, 1950: 392.

Centris (Xerocentris) mixta; Snelling, 1974: 4; Ayala, 1998: 115.

Centris (Paracentris) mixta; Neff \& Simpson, 1981: 108.

Centris mixta mixta; Toro \& Chiappa, 1989: 243.

Hemisia (Penthemisia) mixta; Michener, 1951: 4

Fêmea. Diagnose. Comprimento total, 11,1-14,2; largura da cabeça, 4,32-4,75. Tegumento amarelo no clípeo (exceto nas laterais superiores), labro, área malar, três quartos basais das mandíbulas; manchas nas paroculares, pequenas na base das tíbias anteriores e médias. Membrana das asas hialina. Pilosidade esbranquiçada, semidecumbente e não ramificada no disco do T2. Distância ocelocular 1,53-1,73 vezes o diâmetro do ocelo médio, 0,52:0,34-0,52:0,30. Distância entre alvéolos antenais 3,50-3,65 vezes o diâmetro do alvéolo, 0,98:0,28 0,95:0,26. Primeiro flagelômero $1,36-1,51$ vezes mais longo que os três seguintes juntos, $1,01: 0,74-1,01: 0,67$. Comprimento da área malar $0,20-0,22$ vezes a largura da mandíbula, $0,16: 0,82-$ 0,17:0,77. Dentículo da expansão trimal vestigial (Figs. 3 e 59). Célula marginal 2,77-2,92 vezes mais longa que larga, 1,55:0,56 $-1,43: 0,49$. Elaiospata vestigial, representada, nos basitarsos anteriores e médios, por apenas uma fileira de cerdas mais resistentes e não imbricadas. Placa basitibial secundária pouco evidente, seu bordo apical indicado por uma depressão no meio da placa principal (Figs. 58, 59).

Macho. Diagnose. Comprimento total, 9,5-12,0; largura da cabeça, 3,65-4,51. Tegumento amarelo no clípeo, labro, área malar e dois terços basais das mandíbulas; manchas nas paroculares e base das tíbias anteriores e médias. Membrana das asas hialina. Pilosidade do disco do T2 amarelo-palha, esbranquiçada ou não, erecta e ramificada. Distância ocelocular 

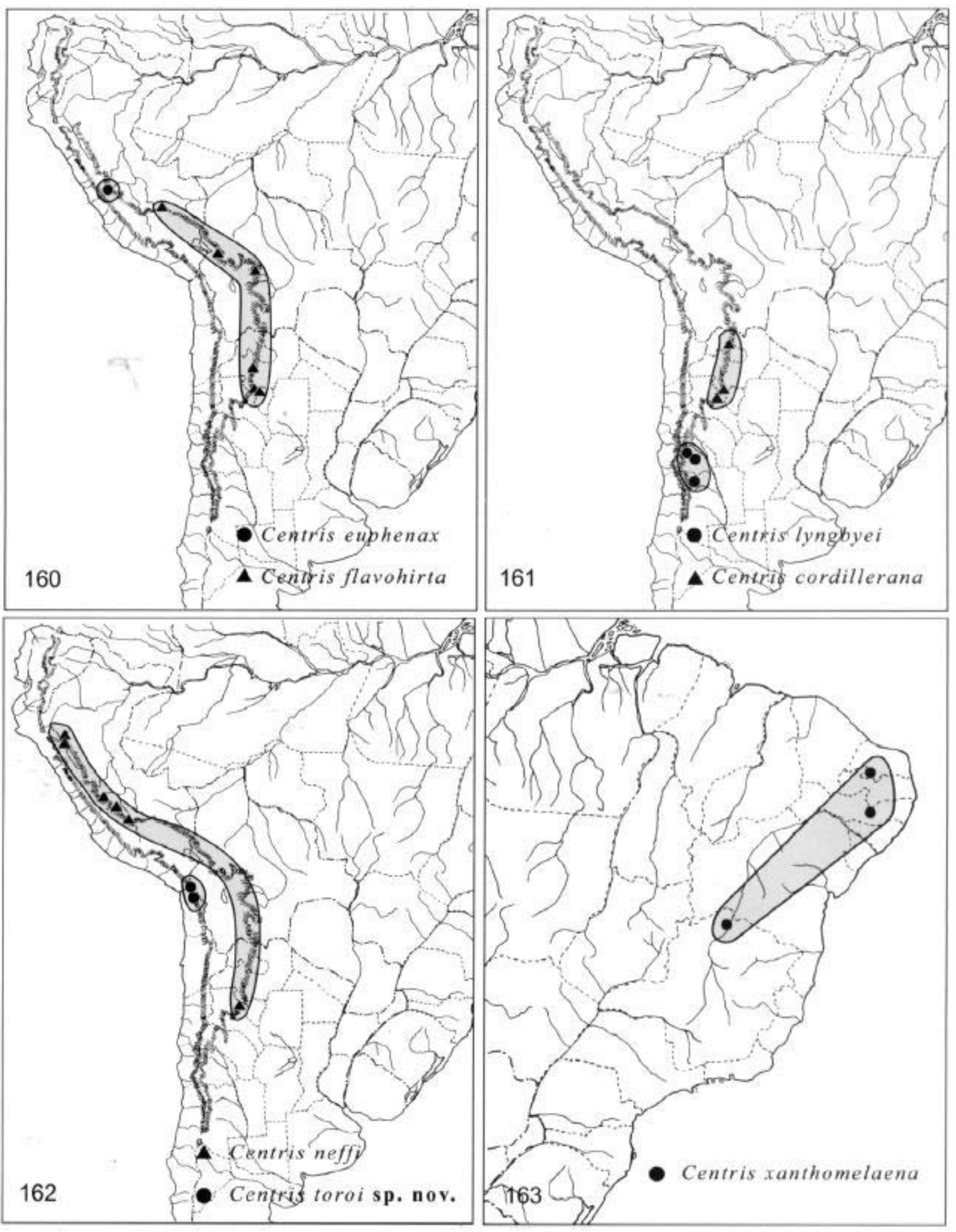

Fig. 160. Distribuição geográfica de Centris (Paracentris) euphenax e C. (P.) flavohirta. Fig. 161. Distribuição geográfica de Centris (Paracentris) lyngbyei e $C$. (P.) cordillerana. Fig. 162. Distribuição geográfica de Centris (Paracentris) neffi, C. (P.) toroi sp. nov. Fig. 163. Distribuição geográfica de Centris xanthomelaena. 
0,59-0,82 vezes o diâmetro do ocelo médio, $0,22: 0,37-0,28: 0,34$. Distância entre alvéolos antenais $3,04-3,19$ vezes o seu diâmetro, 0,79:0,26-0,83:0,26. Distância alveolocular 0,88-0,96 vezes o diâmetro alveolar, 0,23:0,26 - 0,24:0,25. Primeiro flagelômero 1,15-1,29 vezes mais longo que os três seguintes juntos, 0,91:0,79-1,03:0,80. Comprimento da área malar 0,210,22 vezes a largura da mandíbula, 0,17:0,80-0,16:0,72. Comprimento da mandíbula 1,99-2,03 vezes a largura de sua base, 1,43:0,72-1,54:0,76. Dentículo da expansão trimal vestigial (Fig. 90). Célula marginal 3,04-3,19 vezes, 1,52:0,50-1,72: 0,54.

Comentários. Centris (Penthemisia) mixta mixta Friese, 1904 difere de Centris (Penthemisia) mixta tamarugalis Toro \& Chiappa, 1989 pelas seguintes características:

- Fêmea: tegumento do T5 predominantemente vermelhoferrugíneo. Escapo de coloração ferrugínea, com mancha amarela atingindo mais do que a sua metade apical. Placa basitibial mais amplamente e profundamente escavada (Fig. 58).

- Macho: metassoma com pilosidade mais rala, de cor palha clara, não tão esbranquiçada como em C. m. tamarugalis. Pernas com pilosidade palha clara, não tão esbranquiçada. T5 predominantemente vermelho-ferrugíneo (exceto nos exemplares de Negritos, Peru, onde é predominantemente preto). Proporção entre a distância interocular superior e a inferior em geral entre 0,79 e 0,82 (apenas um exemplar muito pequeno apresentou um valor maior, 0,88$)$.

Tipos. Síntipo(s), macho(s), de Arica, Chile, Staudinger leg. Pela descrição não é possível saber se Friese descreveu a espécie com base em um ou mais exemplares. Intituição depositária desconhecida (não examinados).

Distribuição geográfica. Nos desertos da costa do Pacífico no Peru e no norte do Chile (Fig. 156). Registrada de Piúra, no norte do Peru, à I Região, Chile.

Material examinado. PERU. Piura: 4 M, Negritos, 27/I/1952, A. Fischer leg. (SEMK). Libertad: 1 F, 15 mi. E. Trujillo, 500m, 16/I/1955, Schilinger \& Ross leg. (CAS). Lima: $1 \mathrm{~F}$ e $2 \mathrm{M}$, Lima, s. d., s. c. (ZMUC), um dos machos em Galatia. 4 F e 1 M, ibidem, 5/I/1977, J. Neff leg. (CTMI), em Parkinsonia aculeata. Tacna: 11 F e 5 M, Tacna, 500m,1315/XI/1955, L. E. Peña leg. (SEMK). CHILE. I Região: $1 \mathrm{~F}$, Arica, Lluta, 27/XI/1946, s. c. (SEMK). 1 F e 1 M, Camarones, 4/II/1971, N. Hichins leg. (IDEA), em Brea taltape. 19 M, Chaca, Arica, 5-8/XI/ 1955, L. E. Peña leg. (SEMK). 1 F e 16 M, Sobraya, 700m, 10/XI/1955, idem (SEMK). 2 F, Tiliviche, 13/III/1956, Wagenknecht leg. (SEMK).

Centris (Penthemisia) mixta tamarugalis Toro \& Chiappa, 1989 Centris mixta tamarugalis Toro \& Chiappa, 1989: 243-246.

Semelhante à Centris (Penthemisia) mixta mixta Friese, 1904, diferenciando-se dessa pelas seguintes características:

- Fêmea: tegumento do T5 predominantemente preto. Escapo predominantemente preto; mancha amarela restrita à metade apical. Placa basitibial com área escavada reduzida (Fig. 59).
- Macho: pilosidade esbranquiçada densa no metassoma e nas pernas. T5 predominantemente preto e sempre pelo menos a sua faixa basal. Proporção entre a distância interocular superior e a inferior entre 0,87 e 0,95 .

A identificação dos machos desta subespécie é fácil, mesmo a olho nú, devido ao característico aspecto conferido pela pilosidade mais densa e esbranquiçada. Cabe ressaltar, entretanto, que entre os exemplares da subespécie típica foi observada uma variação no grau de dispersão dos pêlos dos tergos metassomáticos; de modo que, nos exemplares de localidades mais ao sul, portanto mais próximo da área de ocorrência da outra subespécie, a pilosidade é mais densa.

Algo semelhante foi observado em relação à proporção entre a distância interocular superior e a inferior. $\mathrm{O}$ único exemplar que apresentou valores que se sobrepõe aos observados em C. m. tamarugalis (ver dados acima), foi coletado na localidade de Chaca (Chile), a localidade mais ao sul em que foram coletados machos da subespécie típica.

A identificação das fêmeas é, em geral, fácil. Mas, quando se comparam fêmeas de C. m. mixta de Tiliviche e de C. $m$. tamarugalis de Tamarugal, só uma combinação de caracteres indica a que subespécie pertencem. Além disso, o caráter coloração do escapo pode ser apenas um artefato da preservação, pois, entre as fêmeas coletadas em Lima (Peru), há uma que apresenta o tegumento do escapo preto, com uma mancha amarela restrita à metade apical. Estas observações sugerem que pode se tratar realmente de uma espécie politípica, entretanto os dados obtidos são insuficientes para se fazer um melhor julgamento, além de fugir ao escopo do presente trabalho.

Tipos. Holótipo, macho, e alótipo, fêmea, de La Tirana, Prov. de Tarapacá, I Região, Chile (Coleção Toro, UCVC, não examinados). Parátipos, vários indivíduos de ambos os sexos, de La Tirana e Pica, Prov. de Tarapacá, depositados nas seguintes instituições: UCVC, SEMK, AMNH, "Museo Nacional de Historia Natural" em Santiago e "Universidad Metropolitana de Ciencias de la Educación" em Santiago (não examinados).

Distribuição geográfica. No desertos do norte do Chile, na I e II Região (Fig. 156). Foram examinadas duas fêmeas com etiqueta indicando terem sido coletadas em Huerta, no Peru, a $3800 \mathrm{~m}$ de altitude. Como não há nenhum outro registro para regiões de altitude tão elevada, mesmo considerando também a subespécie típica, é possível que se trate de um caso de troca de etiquetas, sendo necessário novas coletas para confirmar este registro.

Material examinado. PERU. 2 F, Huerta, 3800m, 24-28/XI/1955, L. E. Peña leg. (SEMK). CHILE: I Região: 1 F, Pampa del Tamarugal, 20/IX/1966, G. Loyza leg. (MELP). 2 F e 1 M, Pampa del Tamarugal, X/ 1991, H. Toro leg. (CFZ). 17 F e 4 M, Pintados, 20 km S., 4/XI/1955, L. E. Peña leg. (SEMK). 2 M, Tamarugal, 29/X/1993, Chiappa leg. (CFZ) em Caesalpinea aphylla. II Região: $1 \mathrm{~F}$, Quillagua, 26/IX/1967, R. Charlin leg. (MELP). 1 F e 1 M, ibidem, 3/XI/1955, L. E. Peña leg. (SEMK). 

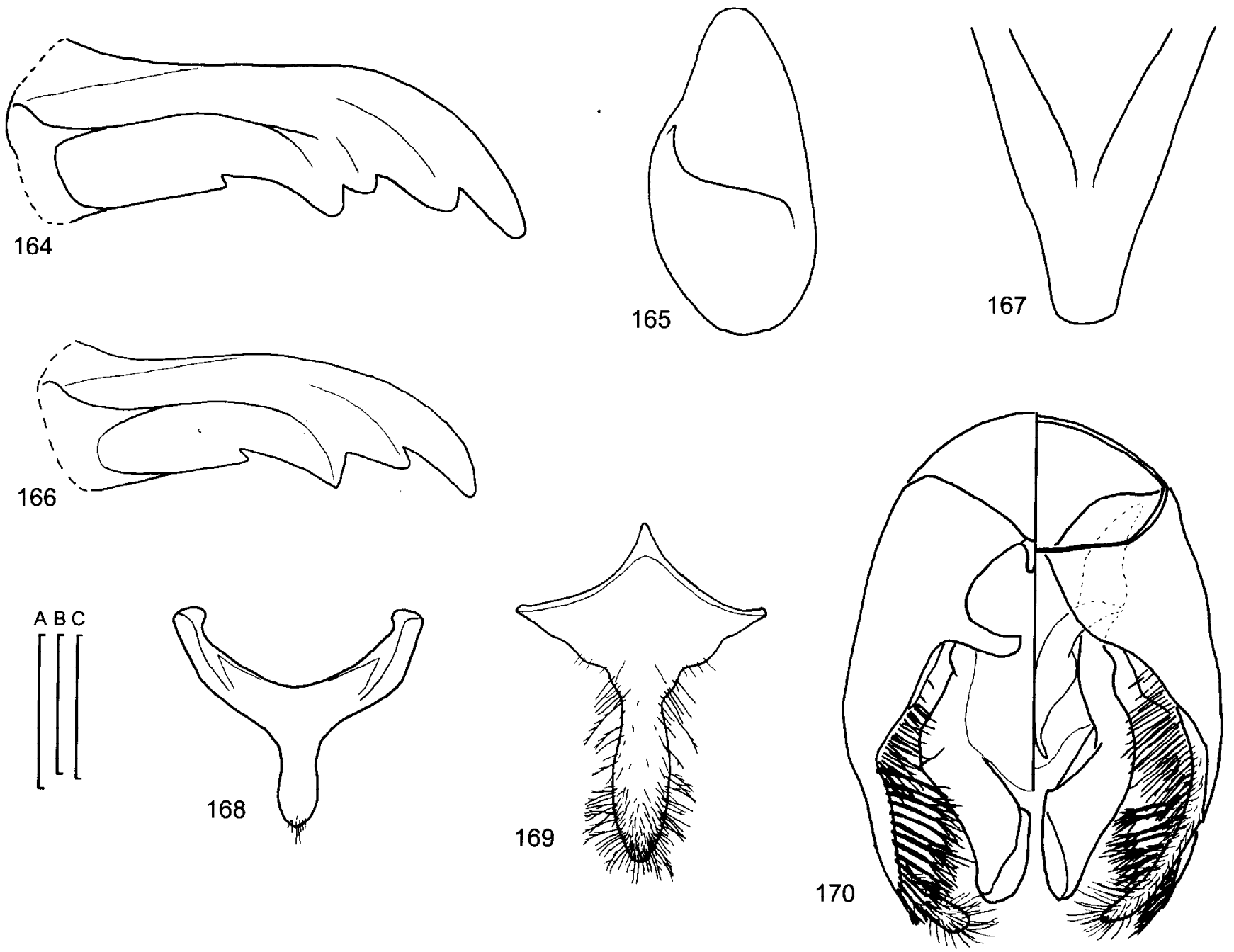

Figs. 164-170. Centris xanthomelaena. 164, Mandíbula, fêmea; 165, Placa basitibial, fêmea; 166, Mandíbula, macho; 167, Placa pigidial, fêmea; 168, Sétimo esterno metassomático, macho; 169, Oitavo esterno metassomático, macho; 170, Cápsula genital, macho, vista dorsal e ventral. Escalas $=0,5 \mathrm{~mm}$, A corresponde às figuras 164 e 166, B às figuras 165 e 167 e C às restantes.

\section{ESPÉCIE ADICIONAL EXAMINADA}

Centris xanthomelaena Moure \& Castro, 2001

(Figs. 163-170)

Centris (Paracentris) "xanthomelaena", Vogel \& Machado, 1991: 163. nomen nudum.

Centris xanthomelaena Moure \& Castro, 2001: 329-333.

A análise filogenética indicou que essa espécie, antes considerada um $C$. (Paracentris), está mais próxima do subgênero $C$. (Centris), possivelmente constituindo um grupo a parte. Apresenta algumas sinapomorfias com as espécies do subgênero $C$. (Centris), como a presença de uma projeção laminar translúcida do gonocoxito curta e larga, acompanhando a projeção dorsodistal do gonocoxito, e de um forte emarginado no bordo apical do T7, mas não deve pertencer a C. (Centris) s. str., porque esse subgênero é muito uniforme, com várias autapomorfias seguras, ausentes em C. xanthomelaena (ver análise filogenética no item resultados e discussão). Uma análise mais detalhada de C. (Centris) s. str. deve fornecer elementos mais seguros para decidir se deve ser colocada em um novo subgênero.

Fêmea. Diagnose. Comprimento total, 13,1-13,3; largura da cabeça, 4,48-5,05. Tegumento preto. Microrreticulado no clípeo, com pontuação alveolada fina-moderada, cerrada-densa e estreita faixa mediano-longitudinal sem pontos. Pilosidade amarela, com um suave tom esverdeado típico, na cabeça, laterais e dorso do mesossoma e laterais e área basal do T1. Preta, semidecumbente, curta e não ramificada no disco do T2. Escapo 1,13-1,19 vezes mais longo que o primeiro flagelômero, $1,01: 0,89-1,06: 0,89$. Primeiro flagelômero $1,09-1,16$ vezes mais 
longo que os três seguintes juntos, 0,89:0,82 - 0,89:0,77. Comprimento da área malar 0,12 vezes a largura da mandíbula, $0,12: 1,01-0,12: 0,97$. Comprimento da mandíbula $1,65-1,73$ vezes a largura de sua base, 1,67:1,01 - 1,68:0,97.

Macho. Descrição. Dimensões (mm). Comprimento total 11,9; largura da cabeça 4,63; comprimento da cabeça 2,80; largura do mesossoma, incluindo tégulas, 5,54; comprimento da asa, do esclerito costal ao ápice, 9,33.

Tegumento. Amarelo em quase todo o clípeo e labro, com estreitas faixas escuras nos bordos laterais e no bordo apical do labro. Manchas na área supra-clipeal e nas paroculares, atingindo a altura do bordo superior do clípeo. Pequenas manchas na base das tíbias anteriores e médias. Castanhoclaro na face anterior do flagelo, exceto a metade apical do flagelômero apical, que é preta. Preto no restante. Membrana das asas hialina com um suave tom méleo. Tegumento do clípeo com microcarenas, sem brilho.

Pilosidade. Semelhante à das fêmeas, mas com longos pêlos amarelos no lado posterior dos fêmures anteriores.

Forma e proporções. Distância interocular superior 1,06 vezes a inferior, 2,08: 1,96. Distância ocelocular 1,03 vezes o diâmetro do ocelo médio, $0,38: 0,37$. Distância interocelar 2,11 vezes o diâmetro do ocelo médio, 0,78: 0,37. Distância entre alvéolos antenais 2,67 vezes o diâmetro alveolar, 0,80: 0,30. Distância alveolocular igual ao diâmetro alveolar, 0,30: 0,30. Escapo 1,23 vezes mais longo que o primeiro flagelômero, 0,91: 0,74. Primeiro flagelômero 0,88 vezes os três seguintes juntos, $0,74: 0,84$. Comprimento da área malar 0,09 vezes a largura da mandíbula, $0,08: 0,84$. Comprimento da mandíbula 1,58 vezes a largura de sua base, 1,33: 0,84. Palpo maxilar com quatro artículos. Parte da segunda abcissa de $\mathrm{M}$, anterior à $1 \mathrm{a} \mathrm{m}$-cu, 0 , 35 vezes o seu comprimento total, 0,27: 0,77.

Esternos pré-genitais e genitália. S7 e S8 (Figs. 168, 169). Projeção dorsodistal do gonocoxito longa, $2 / 3$ do comprimento do gonóstilo (Figs. 26, 159).

Tipos. Holótipo, fêmea, de Milagres, Bahia, na Coleção Entomológica Regional do Laboratório de Abelhas da Empresa Bahiana de Desenvolvimento Agrícola (EBDA), Salvador, Bahia. Dois parátipos, fêmeas, um na mesma coleção e outro na Coleção de Entomologia Pe. J. S. Moure, Departamento de Zoologia, Universidade Federal do Paraná (não examinados).

Distribuição geográfica. Considerada endêmica da região semi-árida do nordeste do Brasil (Fig. 163), entretanto, segundo o Dr. Gabriel Melo (comunicação pessoal), há na coleção do Pe. Moure em Curitiba, um exemplar fêmea da Serra do Roncador, no Mato Grosso.

Material examinado. BRASIL. Rio Grande do Norte: $1 \mathrm{M}$, Serra Negra do Norte, Estação Ecológica do Seridó, 12/VIII/1995, F. C. V. Zanella leg. (CFZ). Pernambuco: 1 F, Alagoinha, 18/VI/1987, I. C. S. Machado leg. (RPSP). Bahia: 1 F, Monte Santo, 3/XI/2000, C. Aguiar leg. (CFZ). Minas Gerais: 1 F e 1 M, Cônego Marinho, 44o25'W 15o18', 1/IV/1988, Nereu leg. (RPSP).
Comentários. Pelas dimensões e padrão de coloração assemelha-se a Centris hyptidis Ducke (1908), espécie simpátrica que pertence ao grupo Melacentris sensu Ayala (1998), mas é facilmente distinguível pelo tom esverdeado da pilosidade amarela da cabeça, mesossoma e $\mathrm{T} 1$.

\section{NOTAS SOBRE BIOGEOGRAFIA}

O mapeamento detalhado dos registros de coleta das espécies e as hipóteses de relacionamento histórico entre as espécies e entre os subgêneros pertencentes ao "grupo Centris" (sensu Ayala, 1998) fornecem subsídios ao conhecimento da biogeografia das abelhas do Novo Mundo. Apesar de ainda haver lacunas nos registros de coletas, em regiões pouco ou nunca coletadas, os comentários a seguir buscam apresentar as questões biogeográficas mais importantes sucitadas pelos resultados obtidos no presenta trabalho.

As espécies do subgênero C. (Penthemisia) estão basicamente distribuídas em terras relativamente baixas, que ocorrem próximo aos Andes (Figs. 156 e 157). Aparentemente têm sua distribuição limitada pelos Andes; a única exceção é Centris buchholzi. Essa espécie ocorre desde a costa do Pacífico até cerca de $3600 \mathrm{~m}$ de altitude, entretanto há dois registros para a encosta oriental dos Andes, em Catamarca, Argentina (Fig. 157). Schrotтky (1913) cita C. chilensis na Argentina, na Patagônia, mas essa ocorrência não foi confirmada na presente revisão e precisa ser verificada. De modo semelhante, $C$. (Paracentris) nigerrima tem sua área principal de distribuição na região central do Chile, tendo sido coletada apenas até $1500 \mathrm{~m}$ de altitude, mas há registros isolados na Argentina, do outro lado dos Andes (Fig. 158).

Esse padrão de distribuição, com possíveis populações disjuntas nos dois lados dos Andes e sem diferenciação evidente, sugere que tenha havido pelo menos um momento, no passado relativamente recente, em que ocorreram trocas faunísticas através da Cordilheira.

Dentre as outras espécies de C. (Paracentris), Centris lyngbyei, C. mourei e C. tricolor aparentemente apresentam distribuição limitada a oeste pelos Andes (Figs. 157, 159 e 161).

Outro conjunto de espécies ocorre apenas em terras altas, nas encostas dos Andes e/ou no altiplano, tendo sido registradas, em geral, próximo ou acima dos $3000 \mathrm{~m}$ de altitude. Dentre essas espécies, algumas constituem clados, indicando a ocorrência de processos especiativos no espaço geográfico dos Andes, como, por exemplo, o clado ((C. caelebs $-C$. unifasciata)(C. euphenax - C. flavohirta)) (Figs. 159 e 160). Outro clado é representado por C. neffi e C. toroi. Nesse caso, uma das espécies parece estar restrita às encostas ocidentais dos Andes e a outra, às encostas orientais (Fig. 162).

Essas duas espécies, por sua vez, resultaram, na análise filogenética, como um grupo monofilético incluindo também $C$. klugii e C. burgdorfi (Fig. 36), espécies que ocorrem na parte leste do continente, afastado, portanto, da influência dos Andes. Merece ser destacado aqui, que C. klugi ocorre nas serras e planaltos do Sul, Sudeste e Centro-Oeste do Brasil 
(Fig. 157), e que a sua relação histórica com C. neffi e C. toroi pode ser um indicativo da existência no passado de uma biota comum entre os Andes e as serras do Brasil. Centris burgdorfi apresenta uma distribuição mais ampla, do nordeste do Brasil ao Rio Grande do Sul, incluindo as Chapadas do Brasil Central e o Paraguai (Fig. 158).

Uma outra contribuição do presente trabalho refere-se à questão dos grupos com distribuição anfitropical, i.e., grupos que ocorrem nas regiões temperadas da América do Norte e da América do Sul, especialmente em regiões secas, com vegetação aberta, mas que estão ausentes nas áreas intermediárias de florestas tropicais úmidas (Michener 1979; SiMPSON \& NefF 1985). Dentre o grande número de táxons com esse padrão biogeográfico, são também citados os $C$. (Paracentris) e os $C$. (Xerocentris), que segundo SNelling (1974) incluiria sete espécies na América do Norte, mais Centris mixta, na América do Sul.

Os resultados obtidos na análise cladística indicam que $C$. (Xerocentris), conforme definido por Snelling, é um grupo não monofilético, corroborando a posição de NEFF \& Simpson (1981), de que C. mixta, está relacionada a espécies da América do Sul, e não a espécies da América do Norte. Desse modo, não há suporte para uma distribuição anfitropical.

Em relação aos $C$. (Paracentris), como definido no presente trabalho, é confirmada a ocorrência de um padrão anfitropical. Grupos de espécies exclusivos da América do Norte e previamente reconhecidos como subgêneros distintos, como C. (Acritocentris), C. (Exallocentris) e C. (Xerocentris) (Michener 2000; SNelling 1984), resultaram como ramos internos de C. (Paracentris), formando um clado junto com os Paracentris da América do Norte (Fig. 34: clado J e Fig. 36). Esta hipótese de filogenia é especialmente interessante porque indica uma possível origem única para todos os $C$. (Paracentris) da América do Norte.

A posição desse clado na filogenia não ficou bem resolvida, mas, pelo menos em algumas das árvores mais parcimoniosas obtidas, resulta como grupo-irmão de um clado formado por cinco espécies que ocorrem nos Andes ou próximo: Centris caelebs, C. euphenax, C. flavohirta, C. nigerrima e $C$. unifasciata (ver Fig. 18). Dentre essas espécies, Centris caelebs é a que apresenta a distribuição mais ao norte conhecida para um Paracentris da América do Sul (Fig. 159). Já havia sido ressaltado por Michener (1979: 317) que a presença de $C$. (Paracentris) nos Andes colombianos resulta em uma menor distância de isolamento entre as espécies da América do Norte e as da América do Sul, em relação a outros grupos de distribuição anfitropical.

A possível posição derivada do clado formado pelas espécies da América do Norte estaria ainda de acordo com uma origem dos C. (Paracentris) na América do Sul. É possível que tenha ocorrido uma migração para o norte após a formação da conexão entre América do Sul e do Norte, pela elevação final dos Andes e aparecimento do Istmo do Panamá, no Plioceno superior; entretanto o número de espécies na América do Norte (ca. de 26) é maior do que o número de espécies registrado para a América do Sul, sendo relativamente elevado para ter se originado nos últimos 3-3,5 milhões de anos (Marshal et. al., citado por SimpSON \& NEFF, 1985).

Uma migração anterior à formação do Istmo, por meio de ilhas que existiriam entre os dois continentes, é uma hipótese que já foi considerada para alguns grupos de abelhas por MiCHENER (1979: 315), entretanto até o momento não há outros elementos, como por exemplo o registro de espécies remanecentes de Centris (Paracentris) no Caribe, para corroborá-la.

Agradecimentos. Expresso meus sinceros agradecimentos ao Prof. Dr. João M. F. de Camargo pela orientação, apoio e interesse no desenvolvimento desse trabalho; aos professores, funcionários e colegas da Pós-Graduação em Entomologia e do Departamento de Biologia, em especial à Maria Cristina Gaglianone, Márcio L. Oliveira (UFAC) e Gabriel A. R. Melo (UFPR), pelo companheirismo e apoio constante; ao Departamento de Engenharia Florestal da Universidade Federal da Paraíba, pela liberação de minhas atividades docentes e ao Dr. Haroldo Toro (UCV, in memoriam), Dr. John Neff (CTMI), Dr. Abraham Willink (IMLA, in memoriam) e Pe. Moure (UFPR), pelas informações prestadas. Maria Cristina Gaglianone também reviu pacientemente vários manuscritos prévios e o Dr. Gabriel Melo colaborou sobremaneira com os programas gráficos e de análise filogenética. Agradeço também aos curadores das coleções entomológicas que me enviaram espécimens ou permitiram o acesso às coleções sob suas responsabilidades (ver relação no item Material \& Métodos), sem o qual este trabalho certamente não seria possível; em especial agradeço ao Dr. Jerome Rozen Jr. (AMNH), Dr. David Notton e Christine Taylor (BMNH), Dr. Valter Raineri (MCSN), Dra. Janine Casevits-Weullerse (MNHN), Dr. Frank Koch (MNHU), Dr. Johannes Schubert (ZSMC), Dr. Stefan Schoedl (NHMW), Dr. Lars Wilhelmsen e Dr. Rudolf Meier (ZMUC), pelo empréstimo de tipos. Pe. Moure permitiu a análise do tipo de Centris neffi. Agradeço ao Dr. Haroldo Toro, Dr. Jerome Rozen Jr., Dr. John Neff, Dr. Gustavo Scrocchi (IMLA), Dr. Carlos R. Brandão (MZSP), Dr. Robert Brooks (SEMK), Dr. Clemens Schlindwein (UFPE) e Prof ${ }^{a}$ Cândida Aguiar (UEFS), pela doação de espécimens para minha coleção de referência. Por fim, agradeço ao Dr. John Neff, Dr. Gabriel Melo, Dr. Albino Sakakibara e Dra. Dilma S. Napp pelos comentários e correções à versão final do manuscrito e à CAPES pela concessão de bolsa de estudos.

\section{REFERÊNCIAS}

Ayala, R. B. 1998. Sistematica de los taxa supraespecificos de las abejas de la tribu Centridini (Hymenoptera, Anthophoridae). Tesis, Doctorado. Universidad Nacional Autonoma de Mexico, D.F., Mexico, iv $+280 \mathrm{pp}$.

Brooks, R. W. 1988. Systematics and Phylogeny of the Anthophorine Bees (Hymenoptera: Anthohoridae; Anthophorini). University of Kansas Science Bulletin 53 (9): 436-575.

Burmeister, H. 1876. Hymenopterologische Mittheilungen. Sttetiner Entomologische Zeitung 37: 151-183.

Cabrera, A. L. \& A. Willink. 1973. Biogeografia de América Latina. Monografia 13, série de biología. Washington, DC, Organización de los Estados Americanos (OEA), 120 p.

CAmeron, P. 1903. Descriptions of new species of Hymenoptera taken by Mr. Edward Whymper on the Higher Andes of Equator. Transactions of the American Entomological Society 29: 225-238.

Cockerell, T. D. A. 1904. New records of bees. The Entomologist 37: 231-236

Cockerell, T. D. A. 1913. Descriptions and records of bees. - LIII. Annals and Magazine of Natural History 12: 103-110.

Cockerell, T. D. A. 1926. Descriptions and records of bees. - CVIII. Annals and Magazine of Natural History 17: 214-226. 
FARRIS, J. S. 1972. Estimating phylogenetic trees from distance matrices. American Naturalist 106: 645-668.

FriesE, H. 1900. Neue arten der Bienengattungen Epicharis Klug und Centris Fabr. Természetrajzi Füzetek 23: 39-48.

Friese, H. 1901. Monographie der Biennengattung Centris (s. lat.). Annalen des K. K. Naturhistorischen Hofmuseums, 15: 237 350 .

Friese, H. 1904. Nachtrag zur monographie der bienengattung Centris. Annales Musei Nationalis Hungarici 2: 90-92.

Friese, H. 1909. Zur synonymie der Apiden. Deutsche Entomologische Zeitschrift 1909: 124-128.

Goloboff, P. A. 1996. NONA. Version 1.5. Programa de computador distribuído pelo autor. New York

Goloboff, P. A. 1997. Pee-Wee. Version 2.6. Programa de computador distribuído pelo autor. New York.

Hauser, D. L. \& W. Presch. 1991. The effect of ordered characters on phylogenetic reconstruction. Cladistics 7: 243-265.

Herbst, P. 1918. Nuevas avispas antófilas de Chile. Revista chilena de Historia Natural 22: 149-152.

Jensen-HaArup, A. C. 1908. Two new argentine species of Apidae. Flora og Fauna 1908: 95-107.

MadDison, W. P. 1993. Missing data versus missing characters in phylogenetic analysis. Systematic Biology 42 (4): 576-581.

Maddison, W. P. \& D. R. Maddison. 1992. MacClade. Analysis of Phylogeny and Character Evolution. Version 3. Sunderland, Massachusetts, Sinauer Associates, Inc. xi +398 pp.

Michelette, E. R. F. \& Camargo, J. M. F. 2000. Bee-plant community in a xeric ecosystem in Argentina. Revista brasileira de Zoologia 17 (3): 651-665.

Michener, C. D. 1951. Subgeneric groups of Hemisia (Hymenoptera, Apoidea). Journal of Kansas Entomological Society 24 (1): 111.

Michener, C. D. 1979. Biogeography of bees. Annals of the Missouri Botanical Garden 66: 277-347.

Michener, C. D. 2000. The Bees of the World. Baltimore, Maryland, The John Hopkins University Press, xvi +913 pp.

Michener, C. D. \& A. Fraser. 1978. A comparative anatomical study of mandibular structure in bees (Hymenoptera: Apoidea). University of Kansas Science Bulletin 51 (14): 463-482.

Moure, J. S. 1950. Alguns agrupamentos novos de abelhas neotropicais (Hymenopt.-Apoidea). Dusenia 1 (6): 385-394.

Moure, J. S. 2000 [1999]. Algumas espécies de Centris (Paracentris) (Hymenoptera, Anthophoridae). Acta Biológica Paranaense 28: 147-158.

Moure, J. S. \& M. Castro. 2001.Uma nova espécie de Centris Fabricius (Hymenoptera, Apoidea, Anthophoridae) do Nordeste do Brasil. Revista Brasileira de Zoologia 18 (supl. 1): 329-333.

Neff, J. L. \& B. B. Simpson. 1981. Oil-collecting structures in the Anthophoridae (Hymenoptera): morphology, function, and use in Systematics. Journal of Kansas Entomological Society 54 (1): 95-123.

Nixon, K. C. \& J. M. Carpenter. 1993. On outgroups. Cladistics 9: 413426.

Nixon, K. C. \& J. M. Carpenter. 1996. On consensus, collapsability, and clade concordance. Cladistics 12: 505-521.

Quicke, D. L. J. 1993. Principles and Techniques of Contemporary Taxonomy. London, Blackie Academic \& Professional, xii +311 p.

Roig-Alsina, A. 2000. Claves para las espécies argentinas de Centris (Hymenoptera, Apidae), con descripción de nuevas especies y notas sobre distribución. Revista del Museo Argentino de Ciencias Naturales, n. s., 2 (2): 171-193.

Roig-Alsina, A. \& C. D. Michener. 1993. Studies on the phylogeny and classification of long-tonged bees (Hymenoptera: Apoidea). University of Kansas Science Bulletin 55: 123-173.

Sснrotткy, C. 1902. Neue argentinische Hymenopteren. Anales del
Museo Nacional de Historia Natural de Buenos Aires 5: 91117.

Schrotткy, C. 1908. Die bisher aus Paraguay bekannten arten der bienengattungen Epicharis und Hemisia (Hym.). Zeitschrift für systematische Hymenopterologie und Dipterologie 8: 138143

Schrottky, C. 1913. La distribuicion geográfica de los himenópteros argentinos. Annales de la Sociedad Cientifica Argentina 75: $115-286$

Silveira, F. A. \& CuRE, J. R. 1993. High-altitude bee fauna of Southeastern Brazil: implications for biogeographic patterns (Hymenoptera: Apoidea). Studies on Neotropical Fauna and Environment 28(1): 47-55.

Simpson, B. B. \& J. L. Neff. 1985. Plants, their pollinating bees, and the Great American Interchange, p. 428-452. In: F. G. Stehli \& S. D. WebB (eds.). The Great American Biotic Interchange. New York, Plenum, $532 \mathrm{p}$.

SNelling, R. R. 1956. Bees of the genus Centris in California. Pan-Pacific Entomologist 32: 1-8.

SNELLING, R. R. 1966. The taxonomy and nomenclature of some North American bees of the genus Centris with descriptions of new species. Los Angeles County Museum Contributions in Science 112: $1-33$

SNeLLING, R. R. 1974. Notes on the distribution and taxonomy of some North American Centris (Hymenoptera: Anthophoridae). Contributions in Science, Los Angeles County Museum 258: 1-41.

SNelling, R. R. 1984. Studies on the taxonomy and distribution of American Centridine bees (Hymenoptera: Anthophoridae). Contributions in Science, Los Angeles County Museum 347: 1-69.

Spinola, M. 1851. Himenópteros, p. 153-569. In: C. GAY. Historia física y política de Chile. VI.

Swofford, D. L. 1993. PAUP: Phylogenetic Analysis Using Parsimony. Version 3.1. Programa de computador distribuído pelo "Illinois Natural History Survey", Champaign, Illinois.

Toro, H. 1986. Lista preliminar de los apidos chilenos (Hymenoptera: Apoidea). Acta Entomologica Chilena 13: 121-132.

Toro, H. \& E. Chiappa. 1986. Nueva especie y subespecie de Centris (Hymenoptera: Apoidea) asociados a Prosopis tamarugo. Acta Entomologica Chilena 15: 243-248.

Urban, D. 1967. As espécies do gênero Thygater Holmberg, 1884 (Hymenoptera, Apoidea). Boletim da Universidade Federal do Paraná, Zoologia, 2 (12): 177-309.

VACHAL, J. 1904. Voyage de M. G. A. Bare au Tucuman (Argentine). Hymenoptera mellifera. Revue d'Entomologie 23: 9-26.

Vogel, S. \& I. C. Machado. 1991. Pollination of four sympatric species of Angelonia (Scrophulariaceae) by oil-collecting bees in NE. Brazil. Plant Systematics and Evolution 178: 153-178.

Wittmann, D. \& M. Hoffmann. 1990. Bees of Rio Grande do Sul, southern Brazil (Insecta, Hymenoptera, Apoidea). Iheringia, Sér. Zool., 70: $17-43$.

Zanella, F. C. V. 2000a. Padrões de distribuição geográfica das espécies de abelhas que ocorrem na Caatinga (NE do Brasil), p. 197-203. In: M. M. G. Bitondi \& K. Hartfelder (eds.) Anais do IV Encontro sobre Abelhas. Ribeirão Preto, USP.

Zanella, F. C. V. 2000b. The bees of Caatinga: a list of species and comparative notes regarding their distribution. Apidologie 31: 57992.

Zanella, F. C. V. 2000c. Taxonomic notes on Microthurge (Hymenoptera; Apoidea; Megachilidae). Jahrbuch des Naturhistorischen Museums 13: 57-60.

Zanella, F. C. V.; M. L. Oliveira \& M. C. Gaglianone. 2000. Standardizing lists of locality data for examined specimens in systematics and biogeography studies of New World taxa. Biogeographica 76 (4): 145-160. 